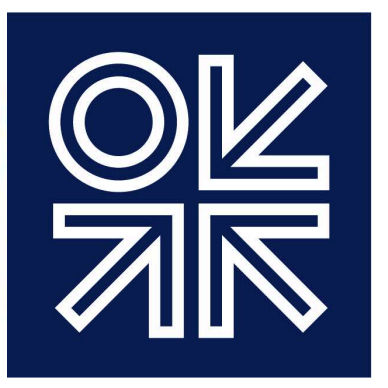

THE OXFORD

INSTITUTE

FOR ENERGY

STUDIES

November 2015

\title{
A holistic framework for the study of interdependence between electricity and gas sectors
}

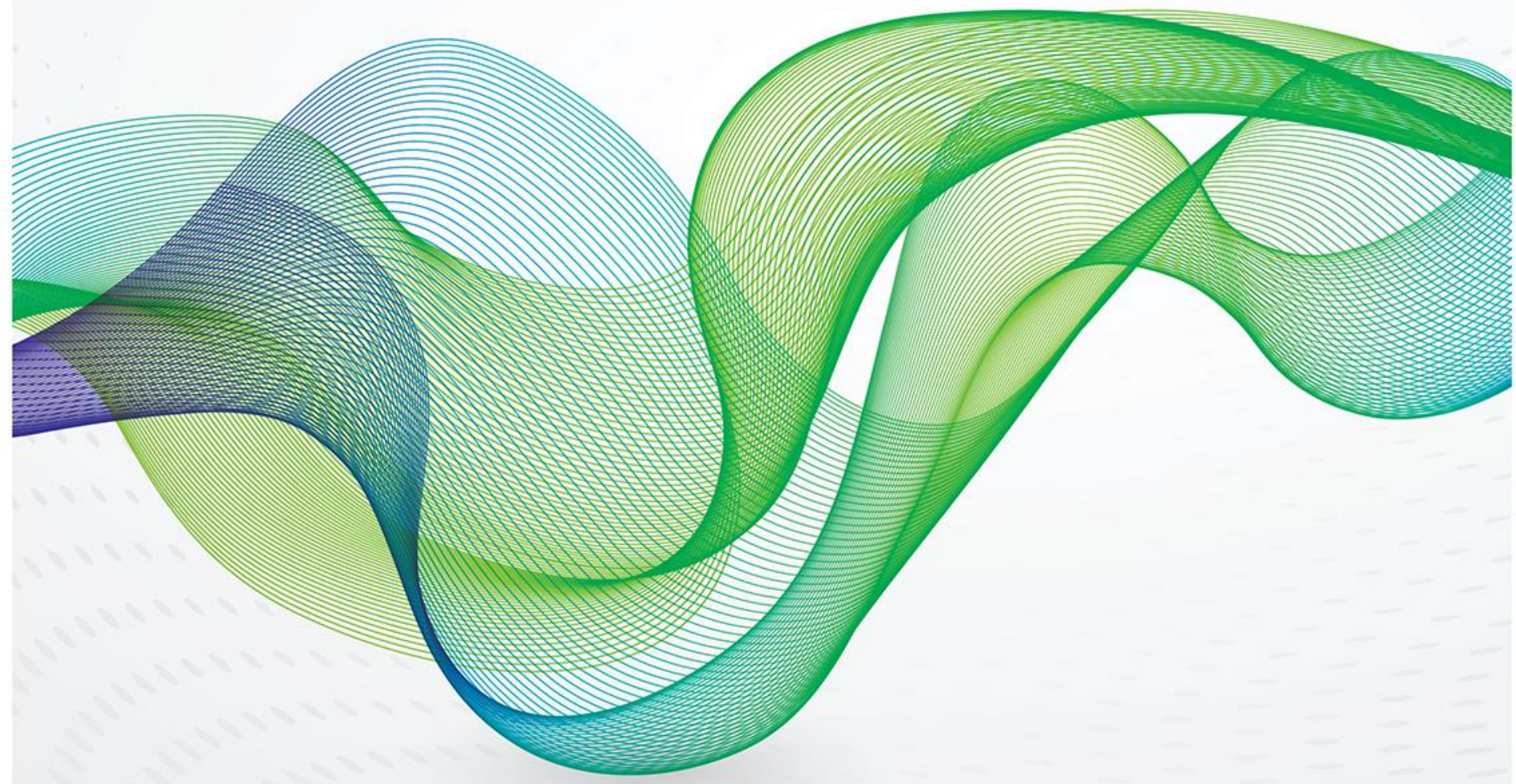



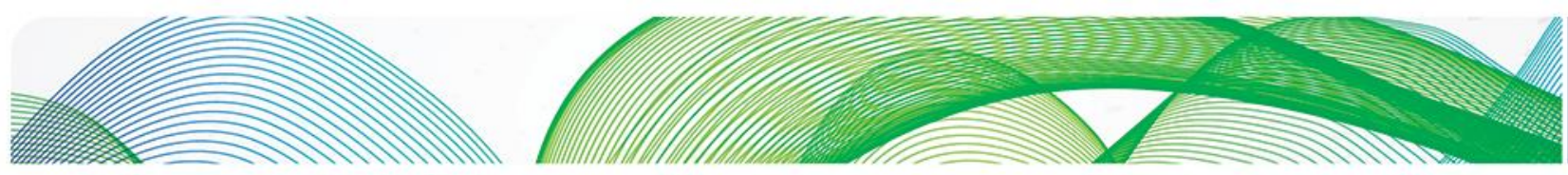

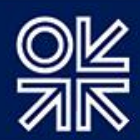

The contents of this paper are the authors' sole responsibility. They do not necessarily represent the views of the Oxford Institute for Energy Studies or any of its members.

Copyright $\odot 2015$

\section{Oxford Institute for Energy Studies}

(Registered Charity, No. 286084)

This publication may be reproduced in part for educational or non-profit purposes without special permission from the copyright holder, provided acknowledgment of the source is made. No use of this publication may be made for resale or for any other commercial purpose whatsoever without prior permission in writing from the Oxford Institute for Energy Studies.

ISBN 978-1-78467-042-9 

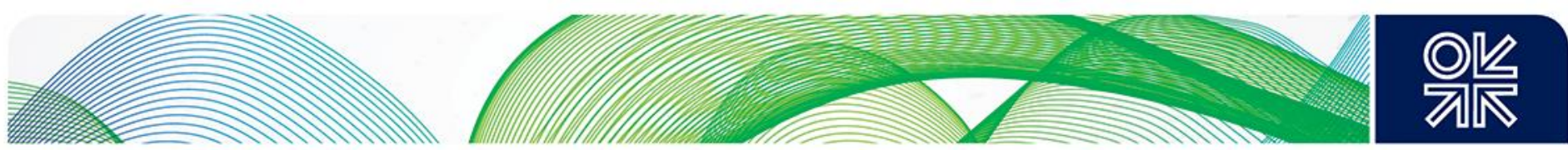

\section{Acknowledgements}

The authors are thankful to Malcolm Keay, Howard Rogers and Pablo Dueñas for their invaluable comments on the earlier version of this paper. The authors would also like to extend their sincere gratitude to Bassam Fattouh, director of OIES, for his support during this project. 

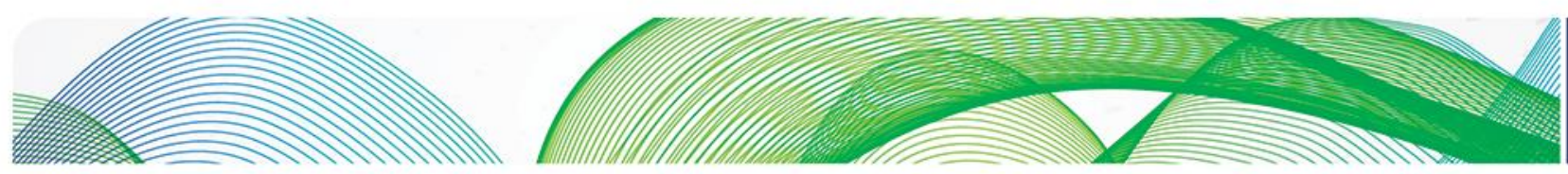

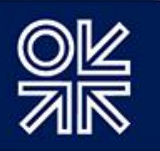

\section{Contents}

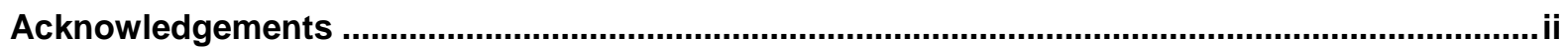

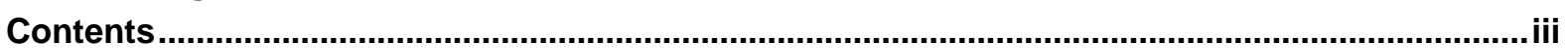

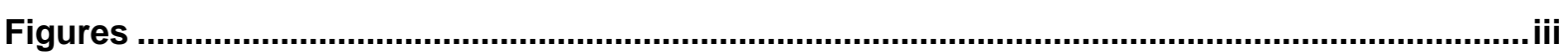

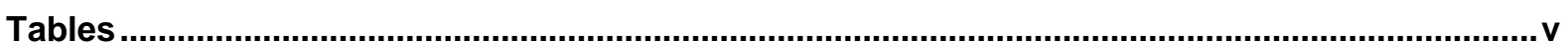

Abstract

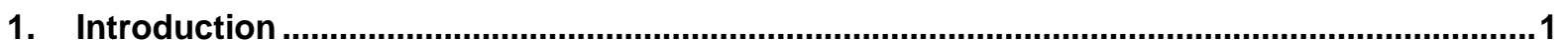

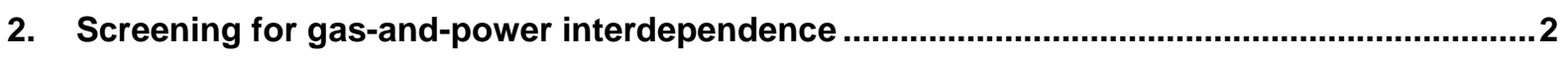

3. Analytical framework for gas-to-power interdependence ...................................................

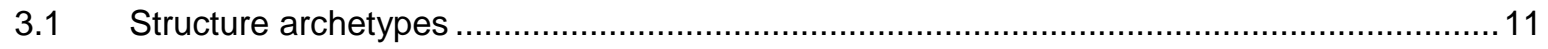

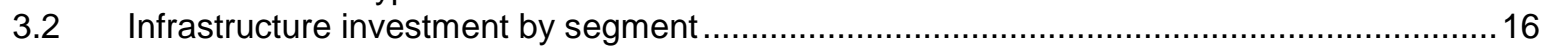

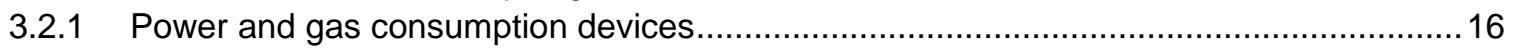

3.2.2 Power and gas transmission \& distribution networks................................................. 19

3.2.3 Gas storage facilities, power storage facilities .......................................................... 21

3.2.4 Power interconnectors, gas import and export infrastructure ........................................22

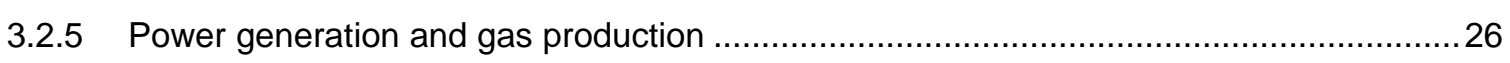

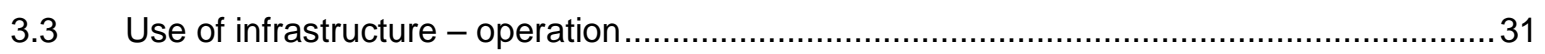

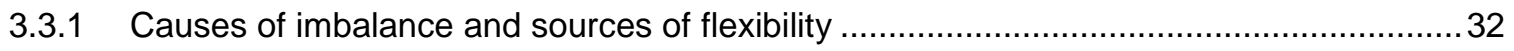

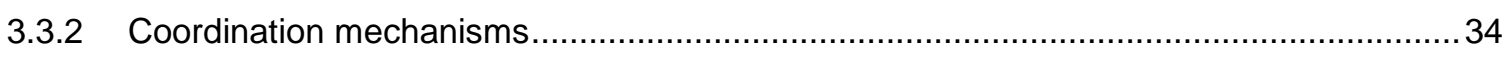

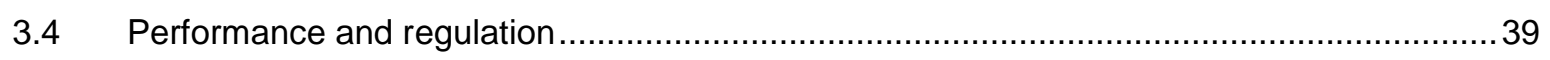

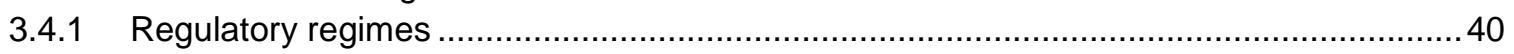

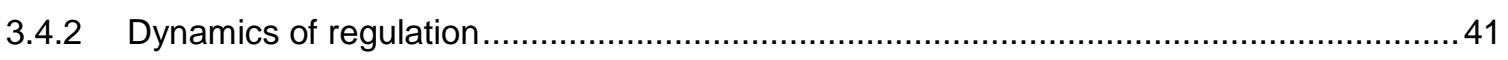

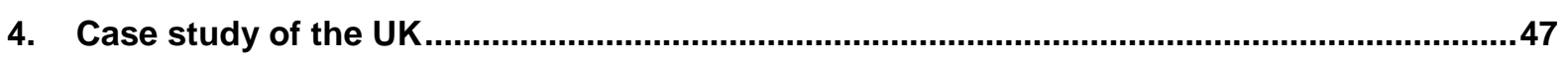

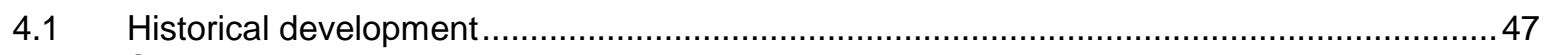

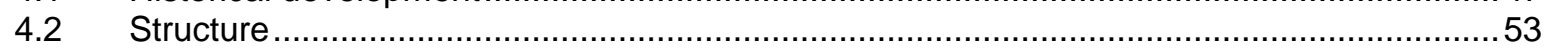

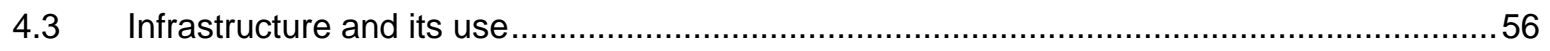

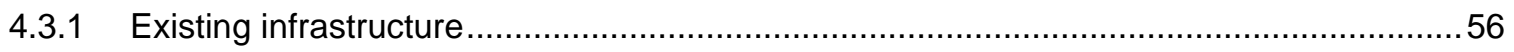

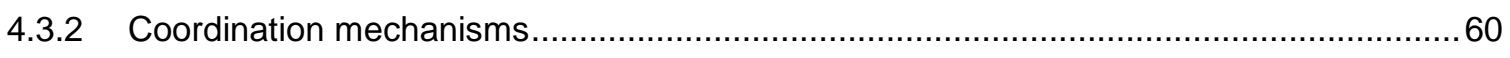

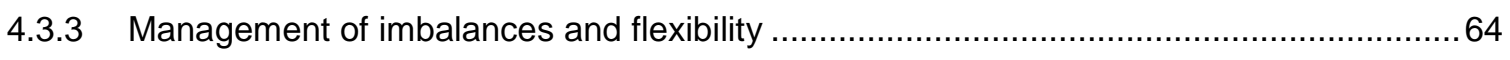

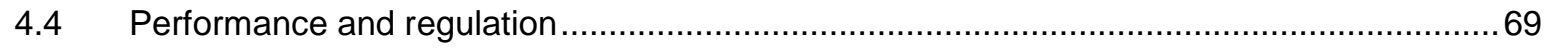

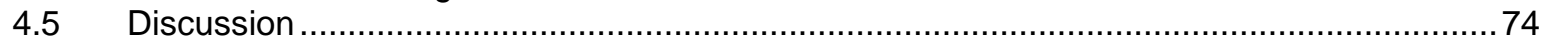

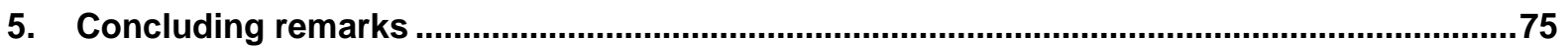

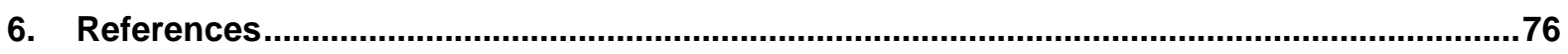

\section{Figures}

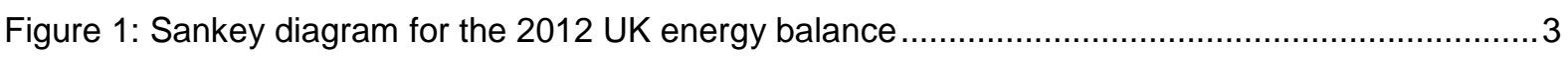

Figure 2: Inverse natural gas self-sufficiency factor for world countries .......................................... 6

Figure 3: Inverse electricity self-sufficiency factor for world countries ............................................

Figure 4: Traditional Structure-Conduct-Performance paradigm ................................................ 8 

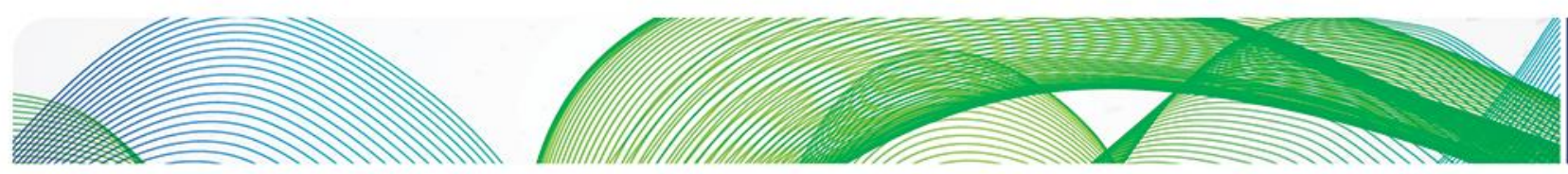

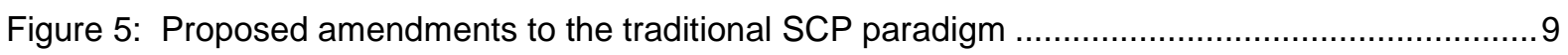

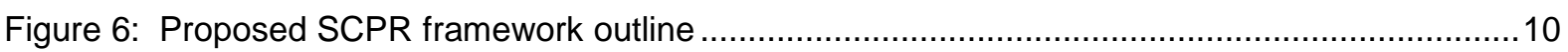

Figure 7: An energy balance-based view of the gas-to-power supply chain ......................................12

Figure 8: Centralized archetype for the gas-to-power supply chain ..............................................13

Figure 9: Decentralized archetype for the gas-to-power supply chain .............................................14

Figure 10: Power supply industry hybrid structures (Adapted from Besant-Jones, 2006) .................15

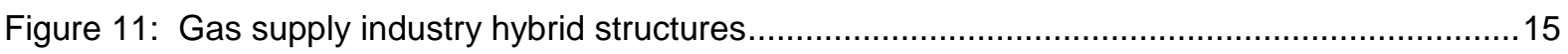

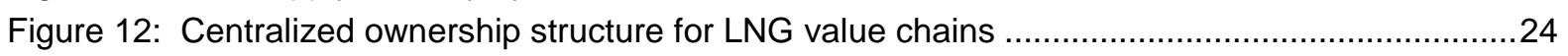

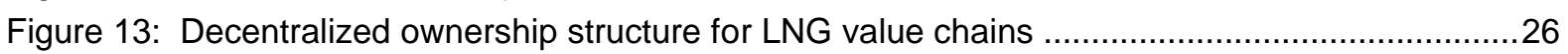

Figure 14: Correlation between world country gas production and oil production $\left(R^{2}=0.66\right) \ldots \ldots \ldots . .29$

Figure 15: Correlation between world country gas production and gas reserve $\left(R^{2}=0.53,0.78\right.$ after

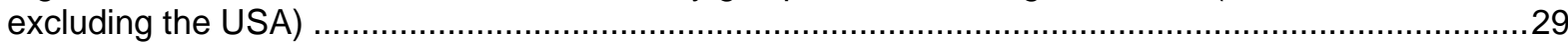

Figure 16: Correlation between world country gas reserve and oil reserve $\left(R^{2}=0.18\right) \ldots \ldots \ldots \ldots \ldots \ldots \ldots . . . . . .30$

Figure 17: Long-term planning based coordination mechanism for centralized power and gas sectors

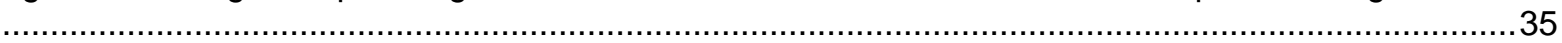

Figure 18: Market-based coordination mechanism for decentralized power and gas sectors .............37

Figure 19: Regulation dynamics for the centralized archetype ...................................................... 41

Figure 20: Example of regulation dynamics for decentralized power sector ........................................4

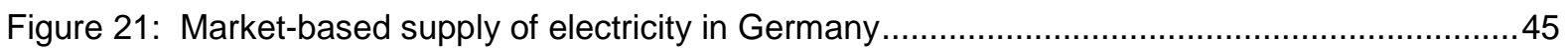

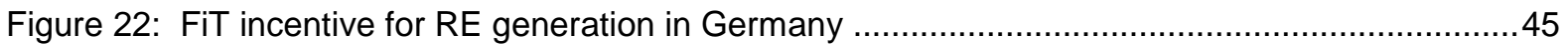

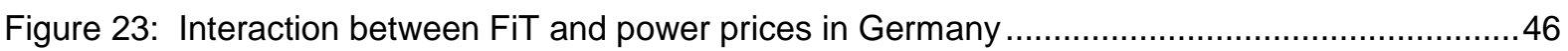

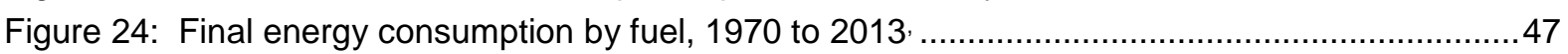

Figure 25: Primary natural gas consumption in the UK and changes in sectoral use ..........................48

Figure 26: Net electricity consumption in the UK and changes in sectoral use ...............................49

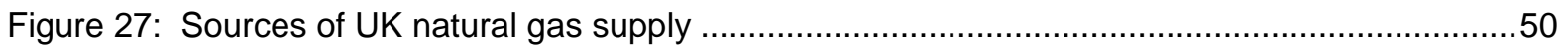

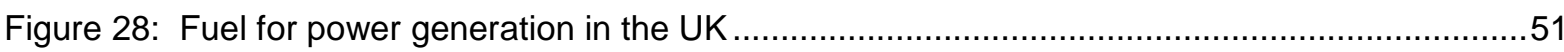

Figure 29: Measures of natural gas and electricity dependence ....................................................52

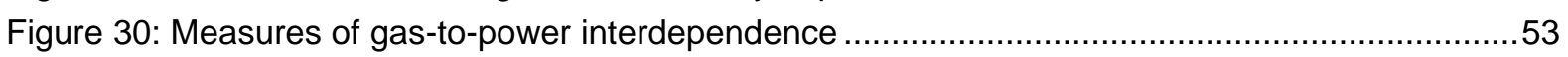

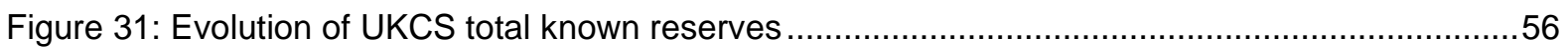

Figure 32: Non major power producer installed capacity of power generator, by fuel type in the UK.57

Figure 33: .Major power producer Installed capacity of power generator by fuel type in the UK .........57

Figure 34: CCGT plants locations and the National Transmission System ........................................58

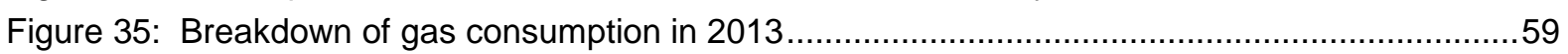

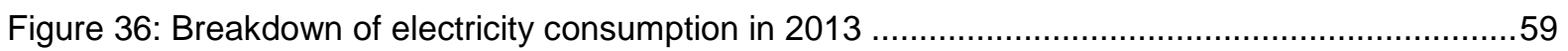

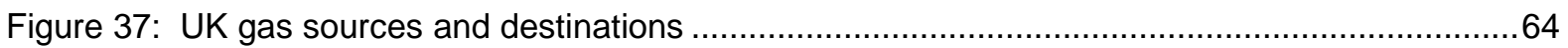

Figure 38: Average UK electricity demand for various temporal resolutions ......................................65

Figure 39: Average UK renewable electricity supply for various temporal resolutions .........................66

Figure 40: Average UK thermal electricity supply for various temporal resolutions) ..........................67

Figure 41: Average UK pumped hydro and interconnector supply for various temporal resolutions ..68 

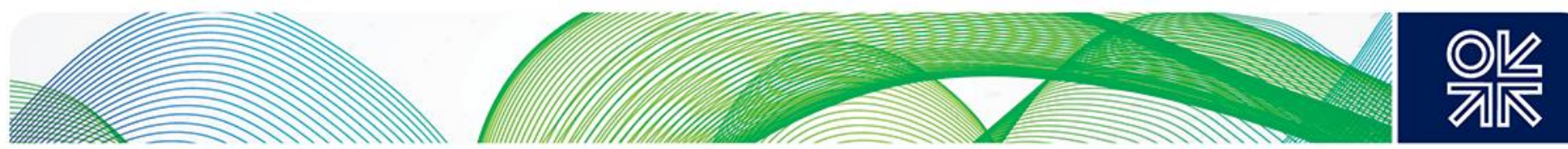

\section{Tables}

Table 1: Energy balance flows and calculated ratio for selected countries 4

Table 2: Ownership and investment for power and gas consumption devices....................................17

Table 3: Energy services fulfilled by power and gas consuming devices ............................................ 18

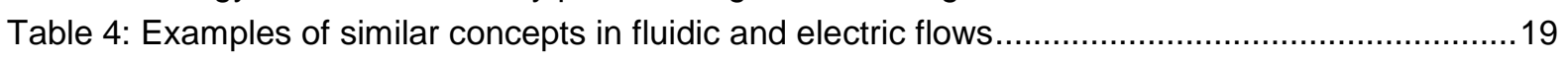

Table 5: Ownership structures for power and gas network infrastructure .......................................20

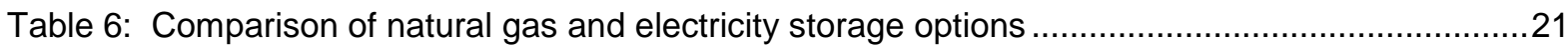

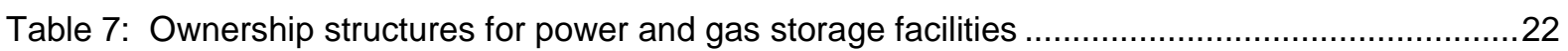

Table 8: Ownership structures for power interconnectors, gas pipelines and LNG terminals ............25

Table 9: Characteristics of groups of power generation technologies .............................................27

Table 10: Characteristics of groups of gas extraction/production technologies ................................28

Table 11: Ownership structures for power generation and gas production facilities ..........................31

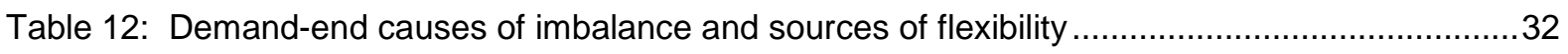

Table 13: Supply-end causes of imbalance and sources of flexibility ................................................33

Table 14: Responsiveness, availability and delivery/uptake rate for various sources of flexibility ......39

Table 15: Ownership structure of the UK gas-to-power supply chain .............................................54

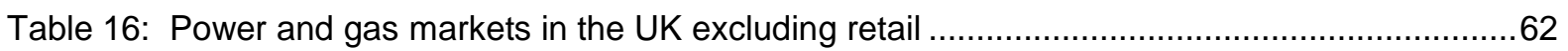

Table 17: Long-term contracts between the UK and natural gas producers ......................................63

Table 18: A non-exhaustive UK energy policy inventory directly relevant to the gas-to-power supply chain 


\title{
A holistic framework for the study of interdependence between electricity and gas sectors
}

\author{
Donna Peng \\ Saudi Aramco Fellow, Oxford Institute for Energy Studies, Oxford \\ Rahmatallah Poudineh \\ Lead Research Fellow, Oxford Institute for Energy Studies, Oxford
}

\begin{abstract}
The increasing global use of natural gas for power generation has resulted in a period of interdependence between two important energy industries. Understanding of the extended gas-topower supply chain is important for industry agents, power and gas system operators or integrated utilities, regulators, and government bodies responsible for overall energy policy. This paper seeks to align the study of gas and power industries by providing a holistic framework for the thorough identification and discussion of power and gas sector structure, infrastructure, market, and regulatory drivers. It acts as a lens through which the combined gas and power supply chains of any given country can be observed and understood. The gas-to-power supply chain of the United Kingdom is profiled to illustrate how the framework proposed can be applied to integrate the various dimensions of power and gas industries.
\end{abstract}

Keywords: gas-to-power supply chain, interdependency between gas and electricity sectors, SCP framework, system dynamics 

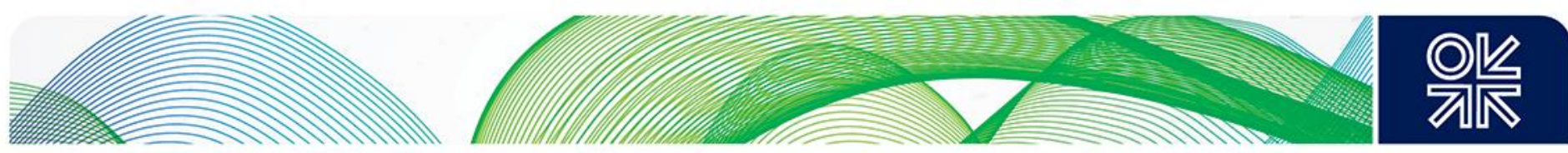

\section{Introduction}

In the last two decades, there has been important convergence between the previously parallel electricity and natural gas industries in a number of countries - the key connector between the industries being the use of gas-fired generators for power generation. The amount of natural gas used for power generation globally has increased steadily since 1973, from 212 to 1167 Mtoe in 2012 (IEA, 2012). This represents 21.8 per cent and 41.5 per cent of world gas production, respectively. As the cleanestburning fossil fuel, natural gas is often portrayed as the transition fuel that will bridge the present (where fossil fuels still dominate world energy supply) to a future powered by renewable forms of energy. Also, natural gas-fired generators have favourable modular investment costs and are flexible to operate. Therefore, the global volume of natural gas used is expected to increase in the mid-term, and its role in power generation is expected to persist (IEA, 2015a). As this convergence continues, the power industry effectively becomes the downstream industry of the natural gas sector, and coordination across this extended supply chain becomes important. The operational flexibility for which natural gas generators are prized is conditional upon the availability and flexibility of their input fuel. As the IEEE (Institute of Electrical and Electronics Engineers) Power and Energy magazine highlighted in its issue dedicated to interdependence between the power and gas sectors, it becomes important to understand both the new risks to which the power sector is exposed via natural gas, and the challenges that the gas sector needs to overcome in supplying the extremely dynamic power sector (Henderson \& Shahidehpour, 2014).

The interdependence of power and gas in regional energy systems is of interest to industry agents, power and gas system operators or integrated utilities, regulators, and government bodies responsible for overall energy policy. A better understanding of such interdependencies will allow these agents to evaluate the reliability of the joint power and gas systems, to facilitate both short-term and long-term coordination between the two industries, and to evaluate the effect of regulatory mechanisms, or of energy policies, on both sectors. Power and gas sector interdependence can be understood and classified at three levels:

1) Diagnostic: At this level, the existing interdependence in an energy system is identified and explained, and the corresponding coordination difficulties, if any, are recognized for further actions;

2) Predictive: At this level, the driving forces behind the natural gas and power sectors are mapped and extrapolated, based on best knowledge, to anticipate future interdependence and potential bottlenecks;

3) Prescriptive: At this level, measures that amend problematic interdependence, existing or anticipated, are designed and evaluated to strengthen the extended gas-to-power supply chain.

This paper seeks to align the study of gas and power industries by providing a holistic framework for the thorough identification and discussion of power and gas sector structure, infrastructure, markets, and regulatory drivers. For any given country, this framework allows the rapid building of a comprehensive joint profile of the power and gas industries in the country/region of interest, acting as a lens through which the complex system of the gas-to-power supply chain can be observed and understood, providing diagnostic-level intelligence. The analytical framework proposed extends the Structure-Conduct-Performance (SCP) paradigm commonly used in industrial organization studies by integrating the fundamental principles of System Dynamics - a new structural theory for operations management that is grounded in system thinking and intensifies the perception of feedback, accumulation, and delays. More specifically, the role of governmental and industrial (self) regulation (feedback) and the difference between investment decisions and operational decisions (delays and accumulation), are both introduced. 

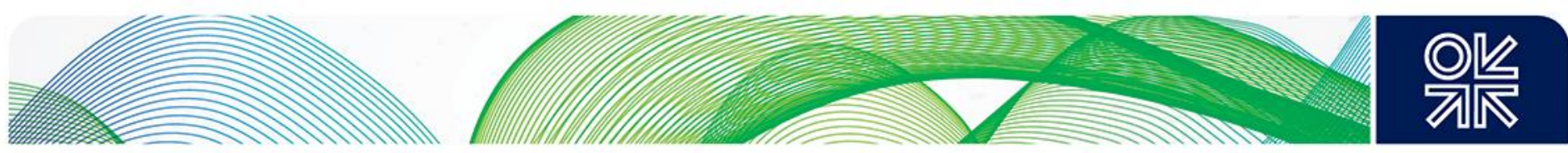

The outline of the paper is as follows. In section two, a suggested method using energy balance information to screen for countries with high gas and power sector interdependence is introduced. In the third section, the SCPR (Structure-Conduct-Performance-Regulation) analytical framework is presented in four parts. The fourth section applies the proposed framework to the United Kingdom, a country whose gas and power industries are both very mature and converging. Finally, the fifth section provides concluding remarks.

\section{Screening for gas-and-power interdependence}

In this section, energy balance data is used to comprehend the overall patterns of energy supply and use in a country, with a focus on the role of electricity and natural gas within its energy system, and on their importance with respect to each other. This is a prerequisite step for a more thorough study of the power and gas sectors, necessitating the use of information that goes beyond the energy balance. At this stage, it is possible to flag up countries that already exhibit important natural gas and power interdependence. For those countries in which the gas-to-power conversion is important, the proposed analytical framework is useful in providing an understanding of the complex coordination mechanism in place. For countries which do not yet exhibit significant interdependence, the proposed framework helps to evaluate the potential for the development and integration of the local power and gas industries.

The energy balance for a national system shares a fundamental principle with energy balances at smaller scales: the conservation of energy. Energy cannot be created or destroyed but it can be converted from one form (such as: kinetic, potential, or internal) to another and be transferred from one point to another; also, unless storage (positive or negative) exists within a system, the inflow of energy into a system must be equivalent to the outflow from it. Therefore, a complete statistical energy balance contains rich information about the sources (either domestic or imported) of a country's energy supply, the energy consumption of its various sectors, and the magnitude of the energy carrier flows that connect them. The efficiency of conversion from one energy carrier to another - coal to electricity, crude oil to refined oil products, for example - can also be monitored through energy balances.

Compared with data in tabular form, the Sankey diagram (in which the magnitude of different flows is represented by bands of different width) is particularly suitable for visualizing the energy balance. The path of flows of energy between points of supply - fossil fuel reservoir, wind energy, imported oil, etc. - is traced to points of consumption - industry, commerce, non-energy use, etc. The screening exercise builds upon the visual insights that can be gleaned from such representations of a nation's energy balance. The Sankey diagram for the UK is enclosed within this paper (Figure 1). References are also made to the energy balance of other countries where this is necessary.

At a first glance, an evaluation of the key structure and diversity of a national energy system can be based on the complexity of the visualized energy balance. Then, the magnitude of the contributions of power and natural gas, and the sectors in which they are used, are noted. Countries that exhibit power and gas sector interdependence are those in which the volume of natural gas used for power generation is significant relative to the size of that country's energy system. Natural gas and power interdependence in the UK and the five largest natural gas producing and consuming countries are screened through their energy balances. 


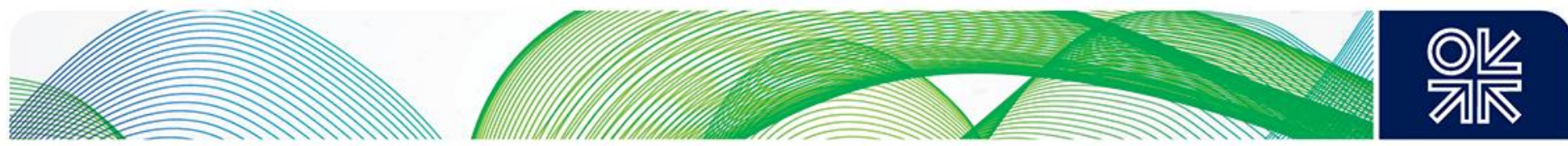

Figure 1: Sankey diagram for the 2012 UK energy balance

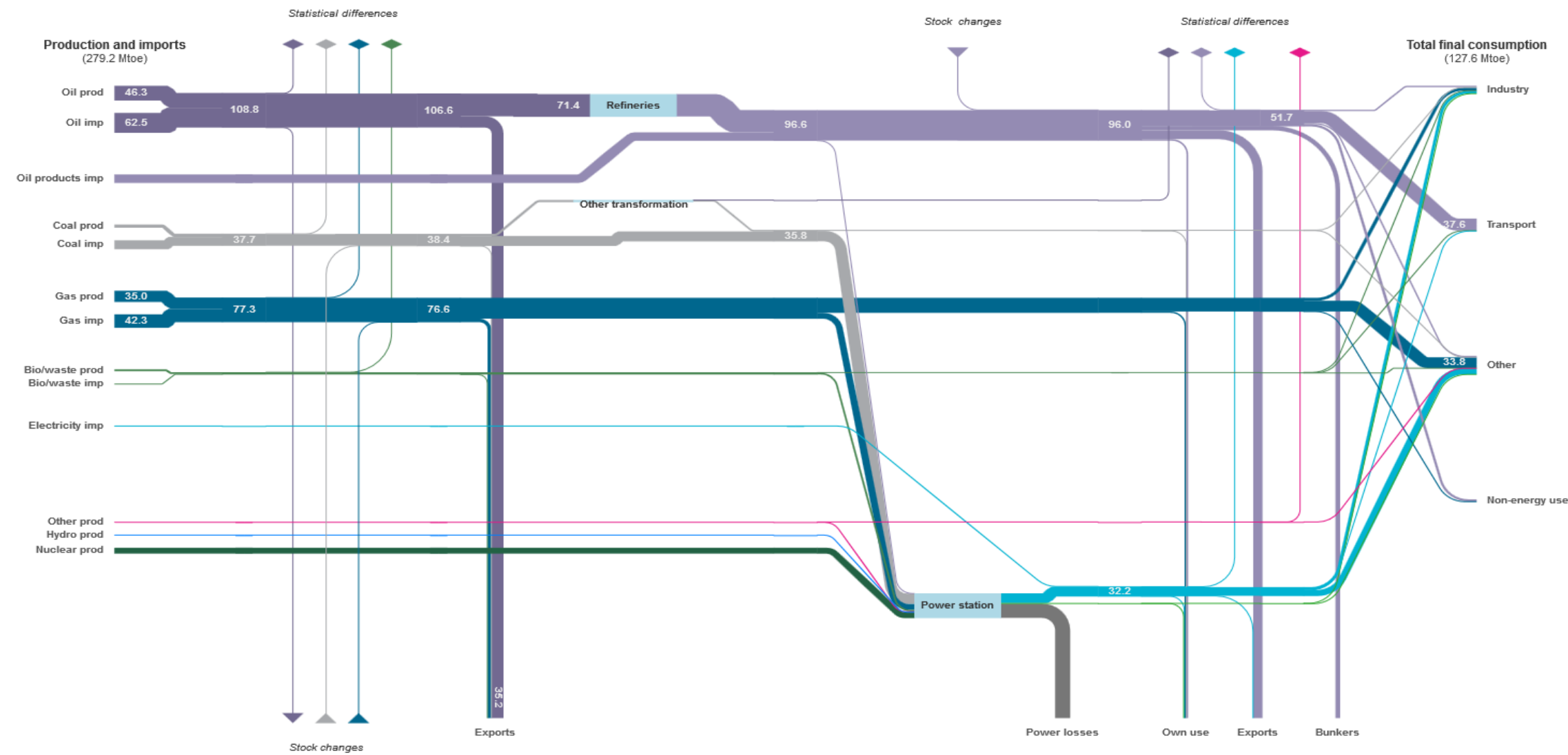

Source: IEA, 2013b 

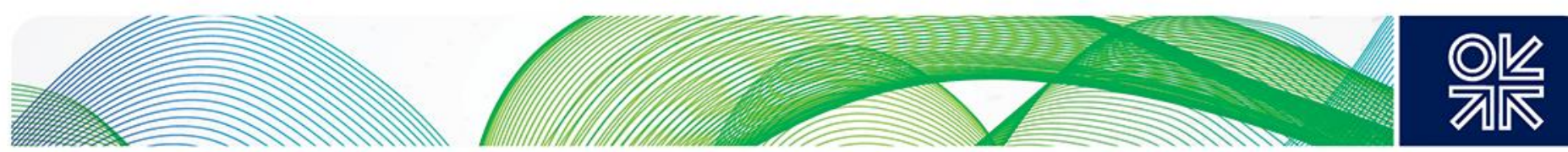

There are eight energy balance flows that are of interest to this study:

1) The aggregate energy production and imports available to a country, including all fossil fuels and renewable energy resources;

2) The aggregate energy exports, including all fossil fuels and their refined products;

3) he total primary energy supply (TPES), which is the difference between the two first terms;

4) The production of natural gas within a country;

5) The consumption of natural gas within a country (including for power generation);

6) The total amount of energy used to generate electricity;

7) The flow of electricity resulting from power generation;

8) The amount of natural gas that is used to generate electricity.

Table 1: Energy balance flows and calculated ratio for selected countries

Countryt+ Japan Russia UK Iran USA Canada Qatar China

\begin{tabular}{lrrrrrrrr}
\hline (1) Production and imports & 478 & 1359 & 279 & 310 & 2442 & 502 & 220 & 3037 \\
(2) Exports & 14 & 591 & 75 & 90 & 261 & 252 & 181 & 43 \\
(3) TPES & 464 & 768 & 204 & 220 & 2181 & 251 & 40 & 2994 \\
(4) NG production & 3 & 541 & 35 & 132 & 559 & 130 & 141 & 90 \\
(5) NG consumption & 110 & 381 & 66 & 128 & 593 & 84 & 26 & 119 \\
(6) Power gen. fuel cons. & 192 & 397 & 77 & 56 & 892 & 91 & 7 & 1173 \\
(7) Power gen. & 88 & 92 & 31 & 22 & 377 & 55 & 3 & 430 \\
(8) NG for power gen. & 72 & 241 & 18 & 34 & 227 & 14 & 7 & 22 \\
\hline
\end{tabular}

\begin{tabular}{ll|llllllll}
\hline (a) \% NG sourced locally (4)/(5) & $3 \%$ & $142 \%$ & $53 \%$ & $103 \%$ & $94 \%$ & $154 \%$ & $535 \%$ & $76 \%$ \\
\hline
\end{tabular}

(b) NG dependence (5)/(3)

(c) Power gen. fuel efficiency (7)/(6)

(d) Power dependence (7)/(3)

(e) \% NG used for power gen (8)/(5)

$\begin{array}{llllllll}24 \% & 50 \% & 32 \% & 58 \% & 27 \% & 34 \% & 67 \% & 4 \%\end{array}$

(f) $\%$ NG in power gen fuel (8)/(6)

$\begin{array}{llllll}46 \% & 23 \% & 40 \% & 39 \% & 42 \%\end{array}$

$60 \% \quad 41 \% \quad 37 \%$

$19 \% \quad 12 \% \quad 15 \% \quad 10 \% \quad 17 \%$

$22 \% \quad 8 \% \quad 14 \%$

$65 \% \quad 63 \% \quad 28 \% \quad 27 \% \quad 38 \%$

$17 \% \quad 28 \% \quad 18 \%$

(g) Relative NG for power gen (8)/(3)

$37 \% \quad 61 \% \quad 24 \% \quad 61 \% \quad 25 \%$

$16 \% \quad 100 \% \quad 2 \%$

NG production

离

NG consumption

$15 \% \quad 31 \% \quad 9 \% \quad 16 \% \quad 10 \%$

\begin{tabular}{l|ll}
$6 \%$ & $19 \%$ & $1 \%$ \\
\hline
\end{tabular}

(n)

Interdependence index

$\begin{array}{llllllll}53 & 2 & 19 & 4 & 1 & 5 & 3 & 7\end{array}$

" numbers in brackets refer to those given in the list above.

† letters in brackets refer to those given in the list below.

Source: own analysis based on IEA 2012 data

Based on these energy balance flows, seven ratios can be calculated. The values used for their calculation are indicated in the table above:

a) The quantity of domestically produced natural gas with respect to domestic gas consumption: a ratio of higher than 100 per cent indicates that the given country exports surplus production of natural gas, while a low ratio is indicative of a country's dependency on imported natural gas;

A holistic framework for the study of interdependence between electricity and gas sectors 

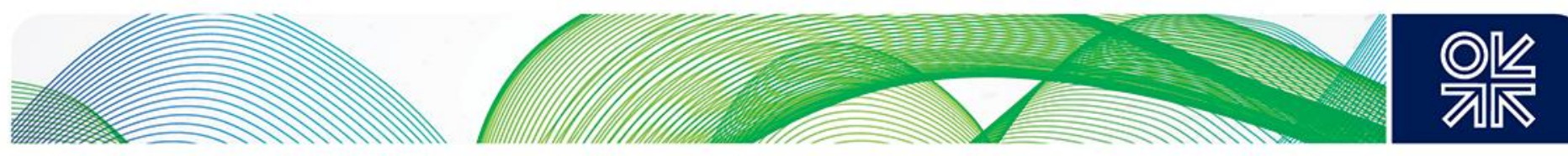

b) The relative importance of natural gas to the energy system studied: a high ratio indicates that natural gas is a dominant fuel while a low ratio indicates that the use of natural gas is not prevalent;

c) The fuel efficiency of the power system: a high ratio indicates that more of the energy contained in generation fuel has been converted to electricity;

d) The relative importance of electricity to the energy system studied: a high ratio indicates more extensive use of electricity;

e) The proportion of natural gas consumed used for power generation: a high ratio indicates that natural gas has relative few applications outside of power generation, so the gas sector is reliant upon the power sector as a major source of demand;

f) The proportion of power generation fuel that is natural gas: a high ratio indicates that there are relatively few alternative fuels used for power generation, so the power sector is reliant upon the gas sector as a major source of fuel supply;

g) The relative importance of natural gas-fired generation to the energy system studied.

In order to quantify the relative degrees of interdependency between the power and gas sectors in a country, the following index is calculated:

$$
I=\left(\frac{F_{N G 2 P}}{F_{s}}\right)\left(\frac{F_{N G, c}}{F_{N G, P}}\right)
$$

I: Index for gas-to-power interdependence

$\mathrm{F}_{\mathrm{NG} 2 \mathrm{P}}$ : Natural gas used for power generation in Mtoe

$\mathrm{F}_{\mathrm{s}}$ : Total primary energy supply in Mtoe

$\mathrm{F}_{\mathrm{NG}, \mathrm{c}}$ : Natural gas consumption in Mtoe

$\mathrm{F}_{\mathrm{NG}, \mathrm{P}}:$ Natural gas production in Mtoe

The first factor is the last ratio term computed in Table $1(\mathrm{~g})$ and measures the relative importance of natural gas-fired generation to the energy system studied. It is the base value of the gas-to-power interdependence index.

The second factor, which accounts for the degree of natural gas self-sufficiency in the country, is the inverse of the first ratio in Table $1(1 / a)$ : when a country is not self-sufficient in natural gas production, it needs to secure its supply of natural gas via imports, thereby extending the gas-to-power supply chain. In other words, import dependency is expected to heighten interdependence issues in the gasto-power supply chain, and surplus domestic production is expected to alleviate it.

The self-sufficiency factor has a value of 1 when domestic natural gas consumption is equal to domestic natural gas production; when local consumption is greater than production, this factor is larger than 1 and increases the gas-to-power interdependence index. Conversely, it decreases the interdependence index when local production exceeds consumption. A map of the second factor for most countries is shown in Figure 2. It can be seen that the EU, Eastern Asia, South Africa, Brazil, and Chile are the least self-sufficient regions in terms of natural gas. 

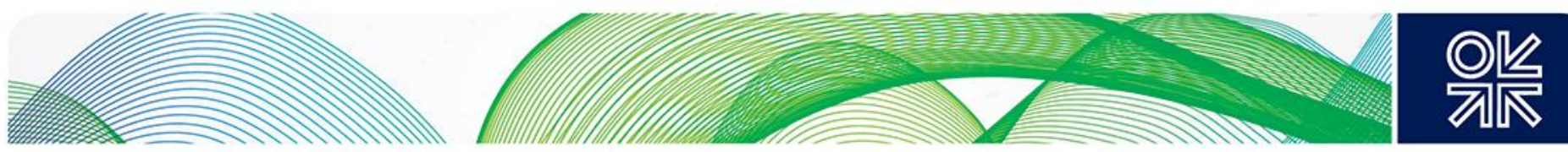

Figure 2: Inverse natural gas self-sufficiency factor for world countries

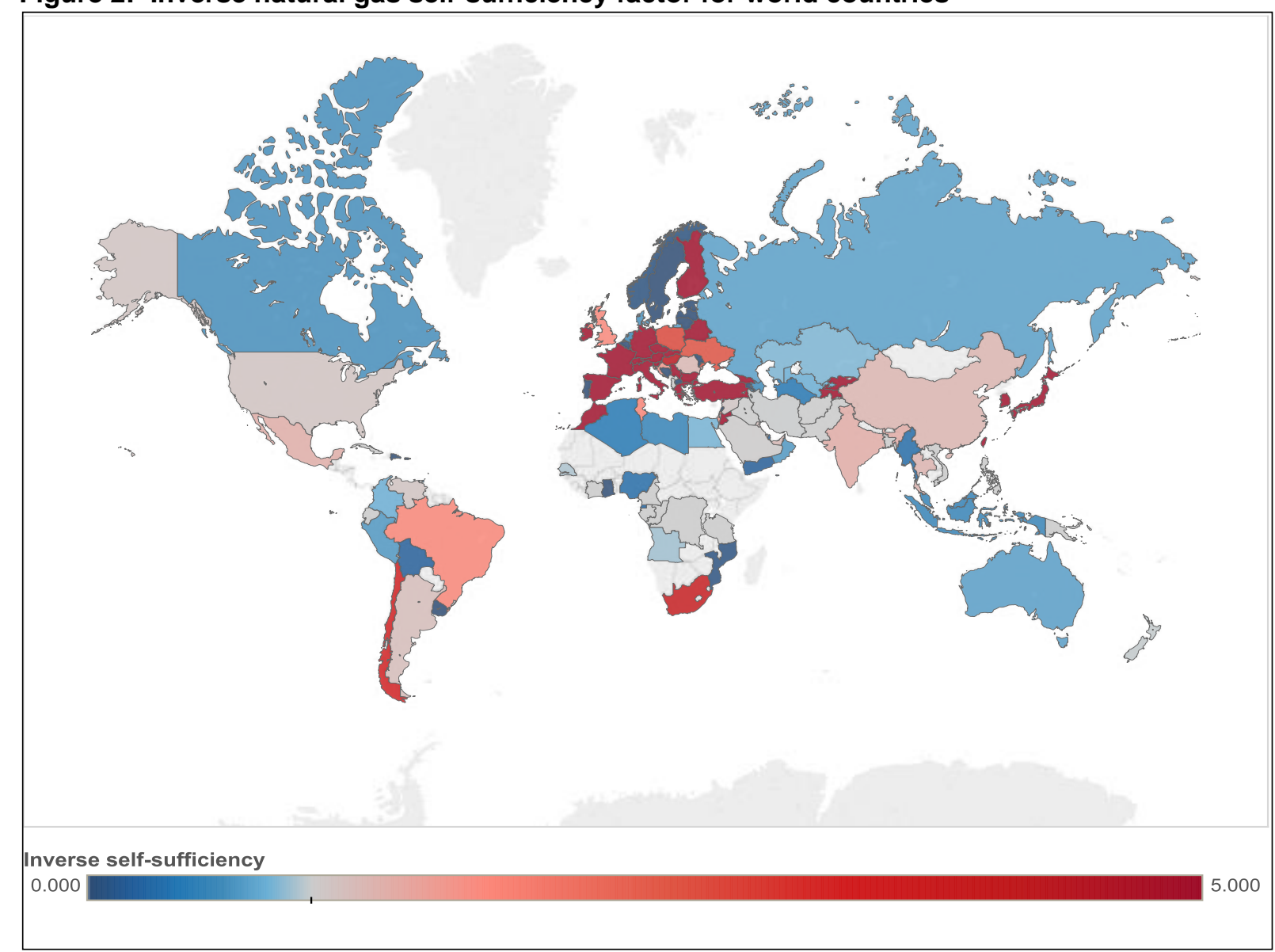

Source: own analysis based on $\mathrm{EIA}^{1}$ data for year 2012

For comparison, the self-sufficiency map for electricity is also included. From Figure 3, it can be seen that most countries have balanced consumption with respect to their domestic power generation. Among large power consumers, those whose consumption significantly exceeds local generation are Finland, Croatia, Lithuania, Luxembourg, and the Palestinian territories. On the opposite end of the spectrum, those that generate significantly more electricity than they consume are Paraguay, Bhutan, Laos, Kyrgyzstan, and Yemen.

\footnotetext{
${ }^{1}$ Blank countries are those without significant natural gas consumption.
}

A holistic framework for the study of interdependence between electricity and gas sectors 

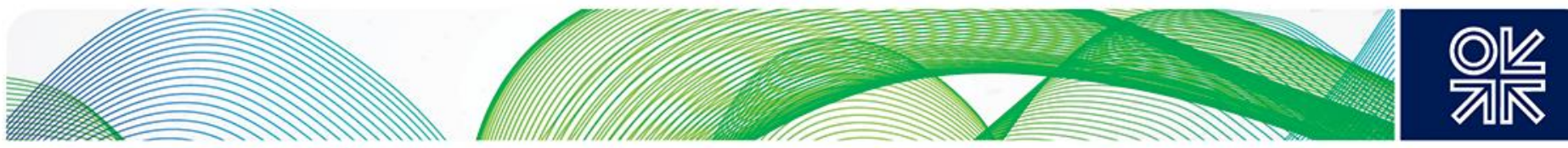

Figure 3: Inverse electricity self-sufficiency factor for world countries

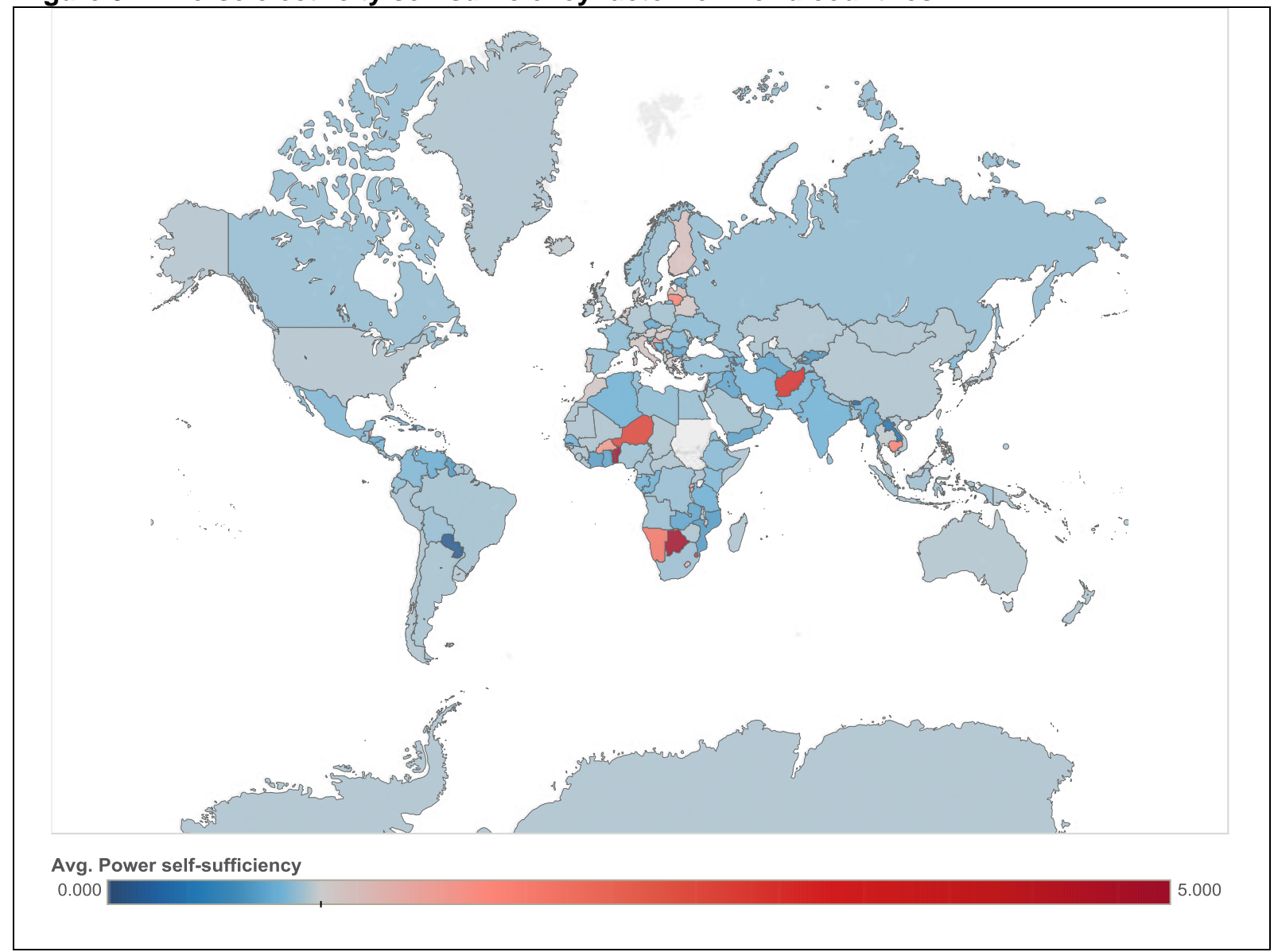

Source: Own analysis based on EIA 2012 data

Values for the gas-to-power interdependence index calculated for the countries surveyed are shown in the last row of Table 1. Japan leads the group, with a significantly higher interdependence index than the runner-up, Russia, due to its extreme dependence upon gas imports. The UK, whose relative use of natural gas for power generation is similar to that of the USA (9 per cent vs. 10 per cent), has a higher interdependence index due to its higher share of imports. Qatar, whose relative gas-to-power use is 19 per cent, has a lower interdependence index because of its important surplus gas production capacity. China, despite being the fourth largest natural gas consumer, with the world's largest energy system, is rated to have the lowest gas-to-power interdependence among the countries surveyed, as its energy system has relatively little penetration by the use of gas. All data pertains to the year 2012 .

The other ratios, although not used directly in the determination of the gas-to-power interdependence index, are useful in signalling the relative strength of the power and gas industries in a country: Qatar and Iran are highly dependent on gas, while Japan and Canada are highly dependent on electricity. Also, the nature of the gas-to-power interdependence differentiates those that are driven by the need for power (countries such as Japan, whose gas consumption is largely due to power generation) from countries such as Russia, Iran, and Qatar which are driven by the availability of natural gas. 

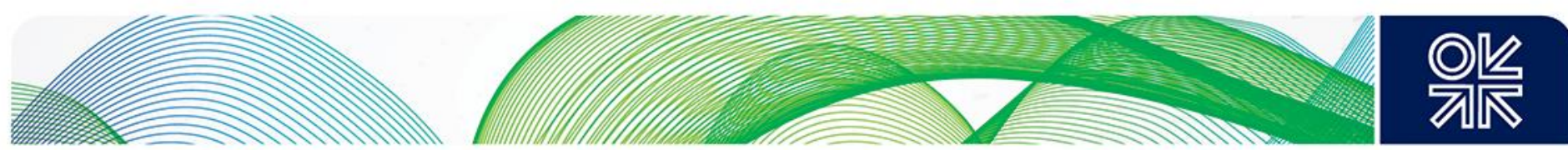

\section{Analytical framework for gas-to-power interdependence}

Following the preliminary screening using energy balance data in the previous section, in order to further the understanding of gas-to-power interdependence in a given country and its likely development, an analytical framework can be used to systematically identify the key driving forces relevant to the gas and power sectors. The inspiration for the proposed framework is based on:

- the Structure-Conduct-Performance (SCP) paradigm (developed by Joe Bain in the 1960s) a foundation of industrial organization theory, and

- System Dynamics, an interdisciplinary perspective that seeks to enhance the understanding of complex dynamic systems. System Dynamics is grounded in the theory of nonlinear dynamics and feedback control that was developed in mathematics, physics, and engineering, and was founded by Jay Forrester, an American computer engineer and systems scientist.

The SCP paradigm postulates that causal relationships exist between the structure of a market, the conduct of firms in that market, and economic performance; it has been used to provide the theoretical justification for competition policy (Ferguson \& Ferguson, 1994).

- 'Structure' in SCP describes the relatively permanent strategic elements of the environment of a firm.

- 'Conduct' refers to the behaviour of the firms in the market: how and what decisions are taken.

- 'Performance' is usually defined as the extent to which firms' operations are allocatively and productively efficient.

The SCP approach argues that industry performance is determined by the conduct of firms, which is in turn determined by the structural characteristics of the market. Traditional competition theory argues that, since concentration (structure) facilitates collusion (conduct), leading to loss of economic welfare for consumers, it is possible to improve industry performance by regulating the structure of the industry via competition law. Revisions to the theory suggest that industry structure is not purely exogenously determined (Ferguson \& Ferguson, 1994). Firms' conduct can also affect industry structure through mergers or innovation (changing product and technology characteristics), among other actions. Moreover, firms may adapt their behaviour to alter their performance.

\section{Figure 4: Traditional Structure-Conduct-Performance paradigm}

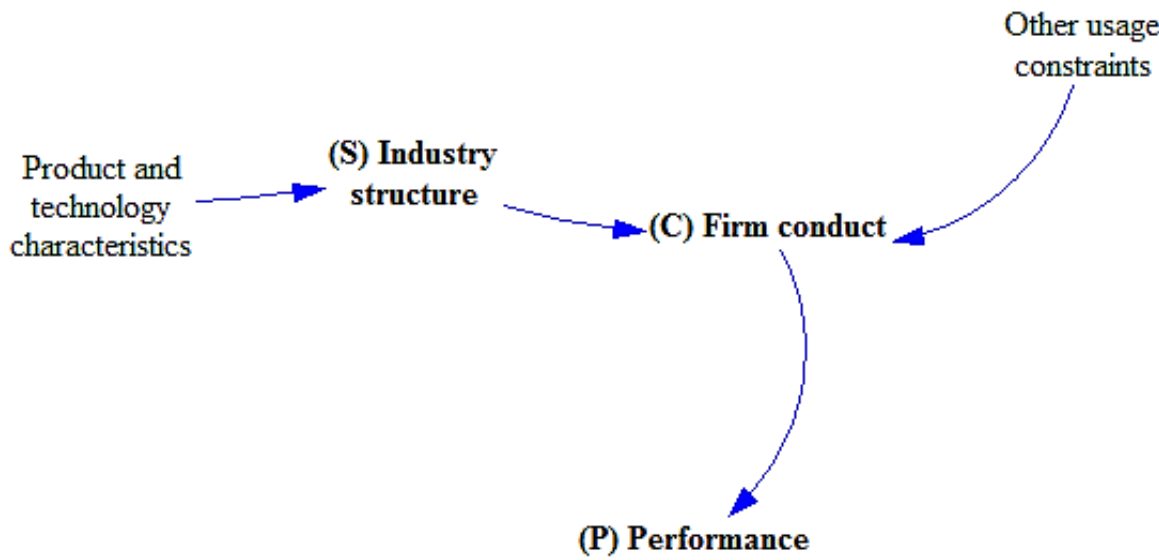

A holistic framework for the study of interdependence between electricity and gas sectors 

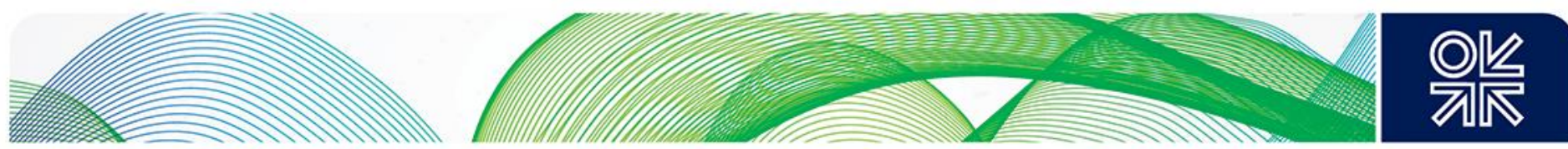

On the other hand, the central principle of System Dynamics theory is the identification of feedback loops, postulating that real systems are rarely sequential and open-loop (Sterman, 2001). It focuses on how action in a given situation defines future situations (feedback), on the delay between taking a decision and its effect, and on the accumulation and dispersal of resources (stocks and flows). It replaces an event-oriented view of the world with a closed-loop view that includes the possibility of an altered environment, side effects, delayed reactions, changing goals, and intervention by other agents. In such a view, the outcome of a decision may be affected by unanticipated results, resulting in ineffective policies.

Combining the two views, the System Dynamics-inspired framework proposed in this paper for the evaluation of gas and power sector interdependence amends the traditional SCP paradigm in the following ways:

1) Differentiating industry agent conduct into two types: long-term investment/retirement decisions related to the accumulation of infrastructure (stock-based) and short-term decisions related to the use of installed infrastructure (flow-based),

2) Recognizing that long-term decisions influence short-term decisions: use of infrastructure cannot exceed the constraint of the infrastructure capacity in place. In other words, energy flowing through the infrastructure is limited by the infrastructure capacity available - a stock variable which changes, with a delay, after investment decisions have been made;

3) Recognizing the dynamic nature of all elements in the original SCP paradigm: the effects of industry and government regulation (feedback) are taken into account.

a) Industry agents regulate their own conduct and structure, making decisions (among others) to invest or to merge, in order to fulfil their organizational objectives;

b) The government constantly interacts with the conduct and, at times, the structure of industry, based on its evaluation of industry performance, in order to fulfil its own evolving energy agenda.

Figure 5: Proposed amendments to the traditional SCP paradigm

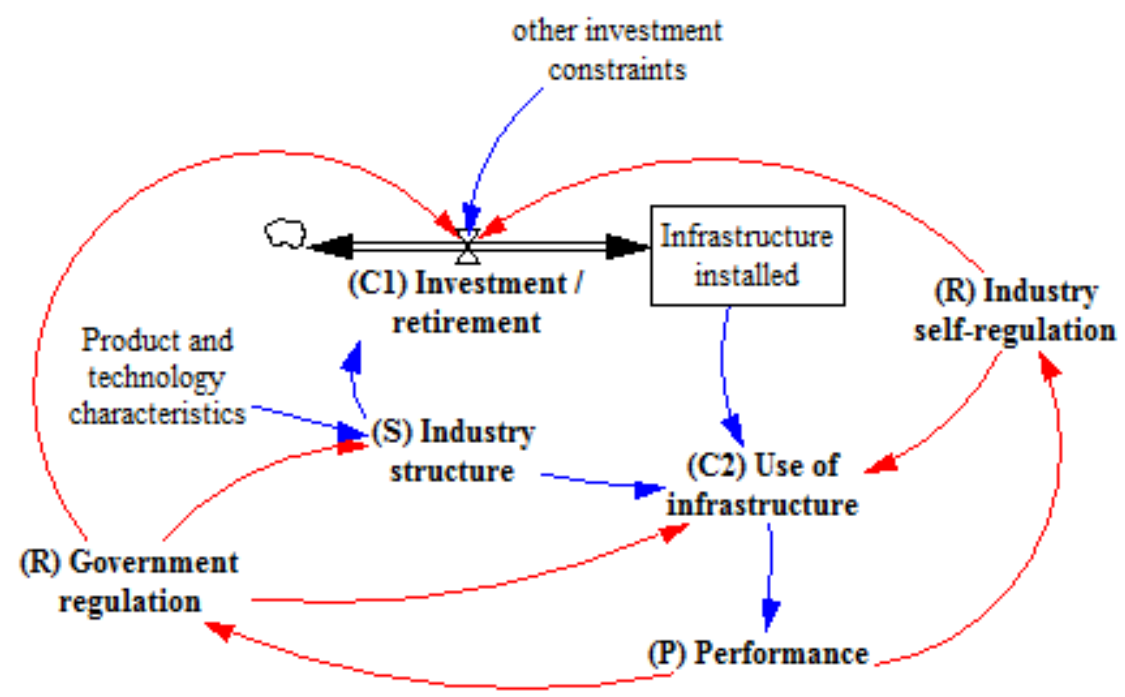

These amendments are applicable to the gas-to-power supply chain, given its heavy dependence on infrastructure, the important lead time required in the setting up and retirement of infrastructure, and the increasingly complex regulatory measures in place in countries with developed mature gas and

A holistic framework for the study of interdependence between electricity and gas sectors 

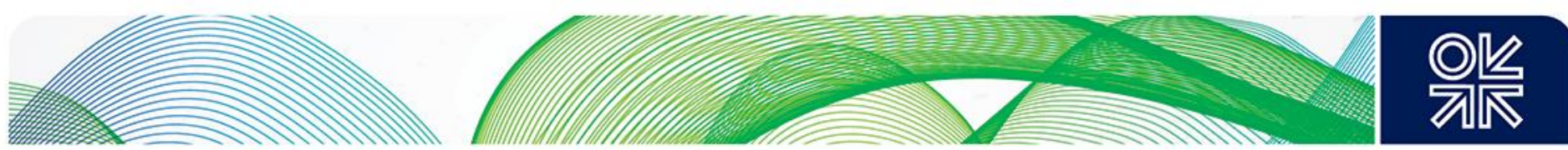

electricity industries. The potential gas and power sector interdependencies that this framework aims to elucidate are:

- Structural: To what extent does the ownership/operational control of the gas and power sectors experience overlap across different segments? And what could be the implications of any such overlap on the investment and operational decisions in the sector?

- Infrastructure: What is the state of the gas-to-power supply chain infrastructure? What is the state of the gas and power demand infrastructure? What could be the potential implications for the absolute and the relative use of gas and power, or on the substitution between gas and power?

- Operational (market): In the case that gas-to-power flow is important, what is its consequence on gas balancing? Is the existing gas sector coordination mechanism adequate to handle it?

- Regulatory: How does the government's energy policy relate to the gas and power sectors? Is it driven by power sector goals, by gas sector goals, or by a mix of the two? How are the government's regulatory measures in gas and power affecting the industry agents? What implications could they have on sector planning and short-term operations?

Application of this framework in the combined gas and power industries is narrated in four parts, which are illustrated in Figure 6. They are then discussed in more detail: in section 3.1, a summary of the two existing structural archetypes (centralized and decentralized) for the extended gas-to-power supply chain is presented. This is followed, in section 3.2, by a segment-based discussion of the technical particularities of the infrastructure involved, the industry ownership structures commonly observed within the segment in question, and their basic considerations for investment in this segment. In section 3.3, the range of factors that affect the balance of supply and demand across the supply chain is presented, as well as the mechanisms through which the agents can coordinate their actions. Finally, in section 3.4, the dynamic relationship between industry performance, regulation, and the remaining elements is discussed. Instead of focusing on a selected segment such as gas production or power generation only, the entire extended gas-to-power supply chain is included in the analysis. This is because the coordination of supply and demand is dependent on the state and combined performance of all segments.

\section{Figure 6: Proposed SCPR framework outline}

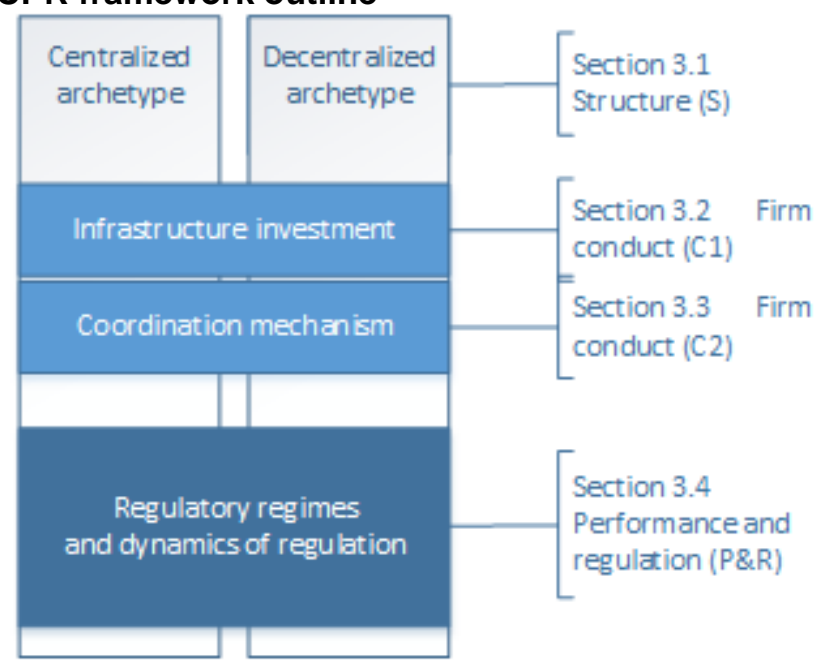

A holistic framework for the study of interdependence between electricity and gas sectors 

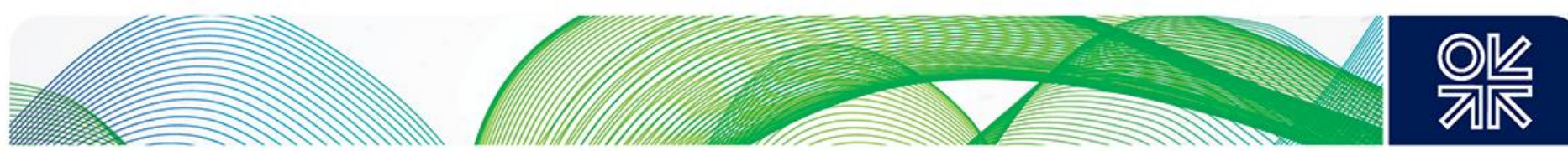

\subsection{Structure archetypes}

A stylized energy balance diagram is used to illustrate the energy supply chain segments to which this framework is applied (Figure 7). The blocks in the extended supply chain diagrams represent the infrastructure that is required to enable the flow of energy from the supply-end to the demand-end. It can be seen that both industries (gas and power) are capital intensive and dependent upon transmission and distribution networks to bridge supply with demand. Two differences within the infrastructure setup should be noted: in the gas supply chain, import and export infrastructures are distinct; in the power supply chain, power interconnectors can accommodate power flow in both directions, allowing imports and exports at the same time. This is because, historically, import and export pipelines, as well as LNG liquefaction/regasification terminals, have been designed to accommodate unidirectional flow from the gas-rich exporting country or transit countries to the gas-poor importing country. Adaptation of pipeline compressor stations to enable bidirectional gas flow and the addition of liquefaction trains to regasification facilities are possible, but such actions are not yet widely practised. The second point relates to storage: gas is not as easy to store as other fossil fuels, which can simply be stockpiled; it can, however, be stored if dedicated infrastructure exists within the gas supply chain. The only instance of large-scale electricity storage, however, is indirect storage via pumped hydro. This converts electrical energy to potential energy in water reservoirs upstream of hydroelectricity generation sites; such storage is therefore commonly conflated with power generation. 


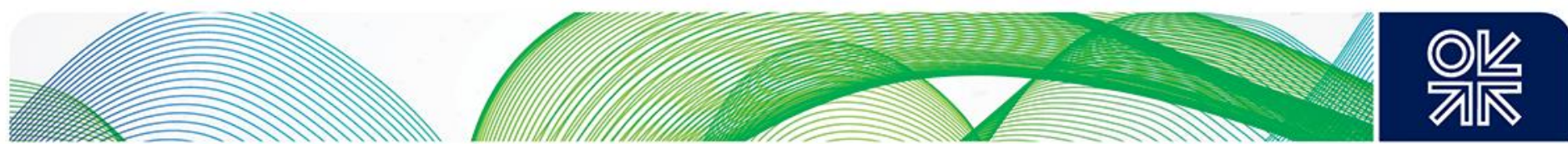

Figure 7: An energy balance-based view of the gas-to-power supply chain

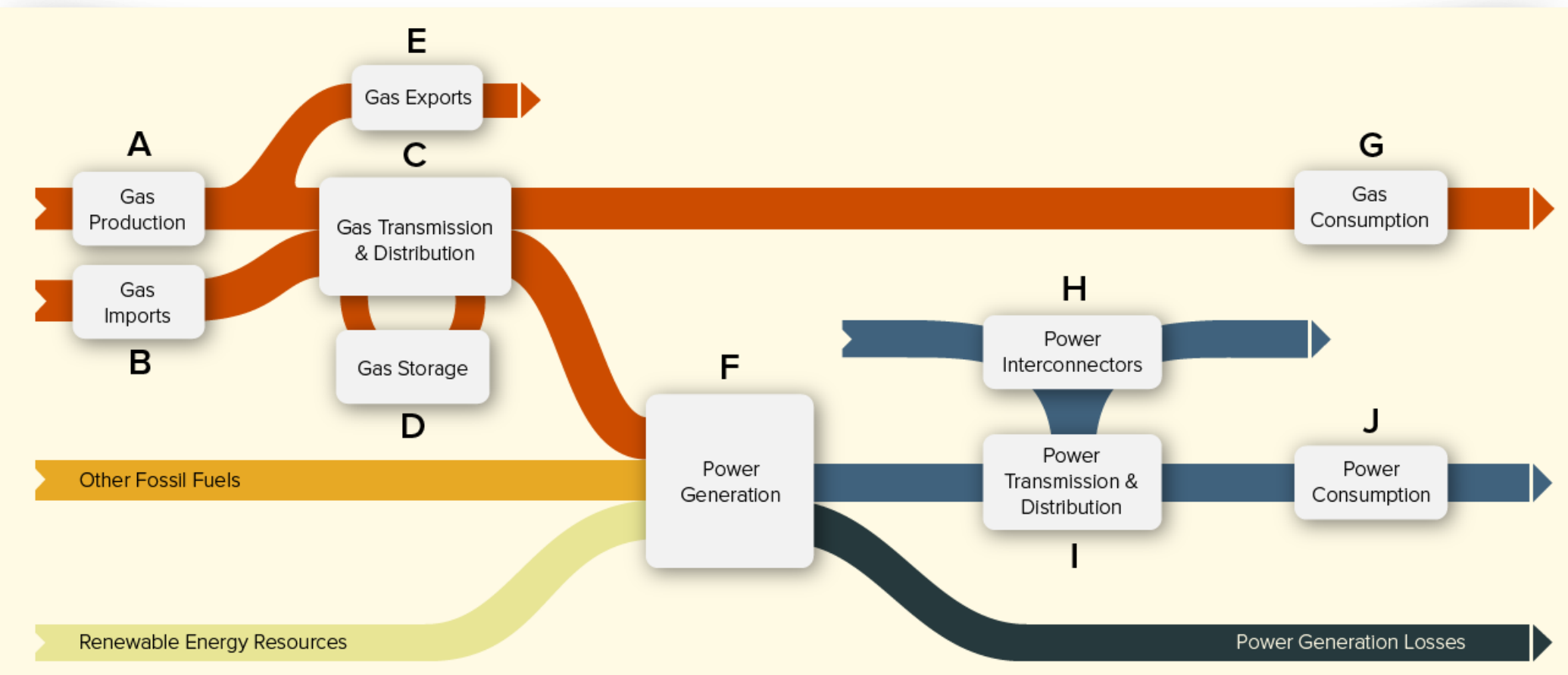



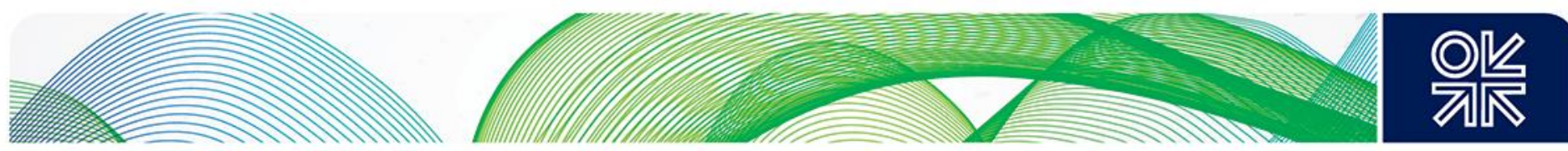

A structure archetype, akin to Platonic ideals, is an idealized representation of the two divergent trends in the organization of gas and power supply chain ownerships: complete centralization and complete decentralization. These serve the purpose of anchoring the spectrum of possible structures that might exist in particular countries, rather than representing the most common models. As a matter of fact, a structure that does exist in a particular country is more likely to be a hybrid of both centralized and decentralized archetypes.

\section{Complete centralization}

In this archetype, state-owner vertically integrated companies/utilities are the owners of all infrastructure (apart from that associated with energy consumption), and act to advance the interest of the national government. Due to their co-occurrence, the production of natural gas and oil are often tied, as is the ownership of their production assets - in the form of a national petroleum company which controls all upstream gas production and export. The downstream processing and distribution of natural gas, once it has been produced, is handled by a separate state-owned utility. Examples are the National Iranian Oil Company/National Iranian Gas Company, Egyptian General Petroleum Corporation/Egyptian Natural Gas Company, and Algeria's Sonatrach/Sonelgaz.

Similarly, a vertically integrated utility for the power sector is in control of its upstream generation assets and all network infrastructure. Examples are Eskom in South Africa, the Korea Electric Power Corporation, and the State Grid Corporation of China (prior to the reform that separated the ownership of its generation and network assets). In the case of Algeria, the downstream gas utility, Sonelgaz, is also an integrated power utility.

Each integrated company/utility is the sole owner of all supply assets within its scope of control; investment in each segment is determined on the basis of an integrated resources plan for all of its holdings. The upstream petroleum company is responsible for the co-planning of (oil and) gas production and exports; the downstream gas utility is responsible for the co-planning of gas import, storage, and distribution; and the integrated power utility is responsible for the co-planning of generation and network expansion.

\section{Figure 8: Centralized archetype for the gas-to-power supply chain}

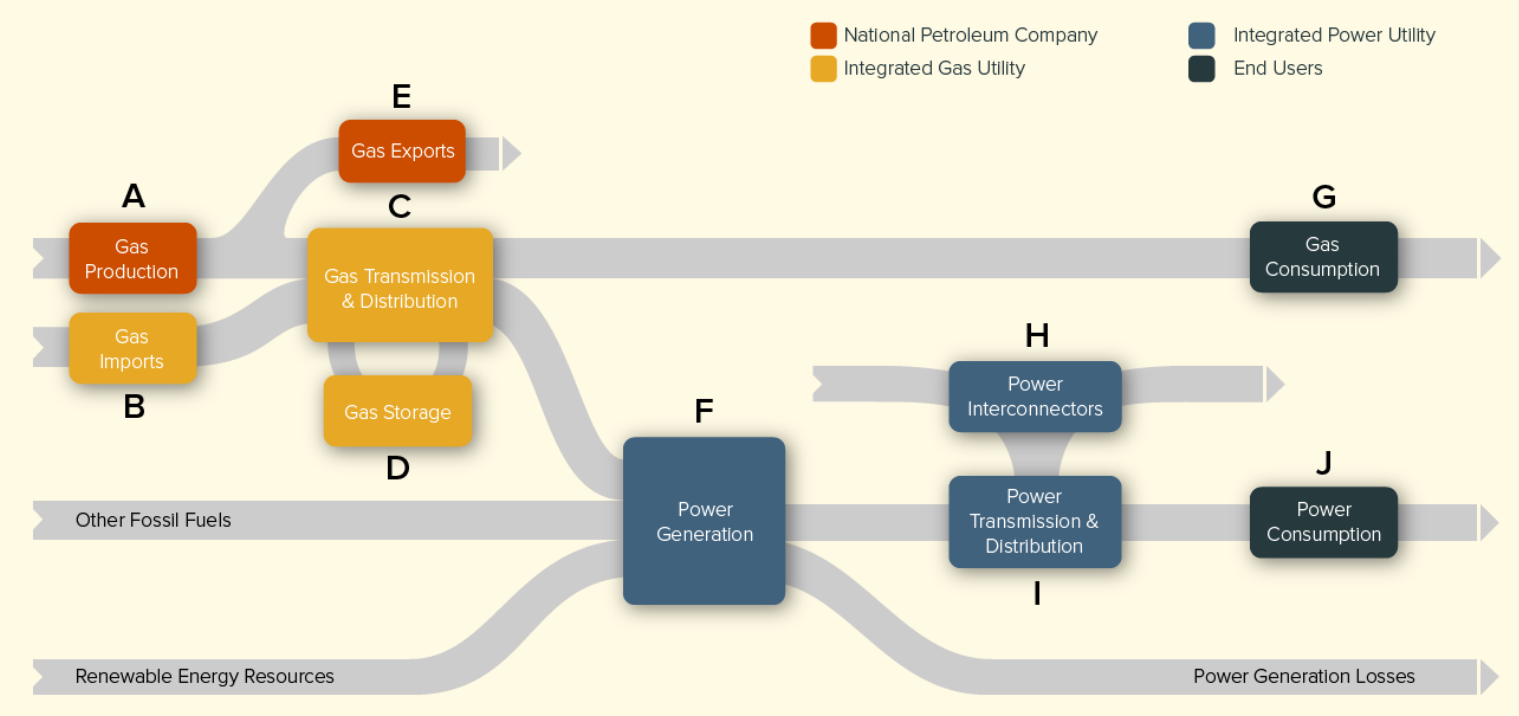

A holistic framework for the study of interdependence between electricity and gas sectors 

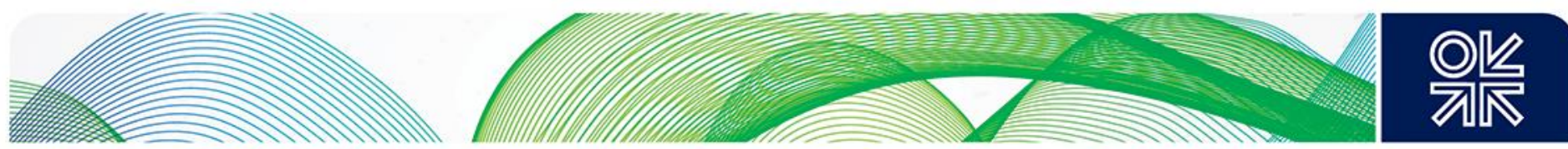

\section{Complete decentralization}

In this archetype, the ownership of the particular segments of the supply chain are divided and this division is mandated by the national legislation. All non-network segments including gas production, import/export (limited co-existence within the same supply chain), gas storage, and power generation have multiple owner participants. However, power and gas networks (transmission and distribution, or T\&D) are owned by regulated monopolies (one national monopoly or multiple regional monopolies), due to their natural monopoly properties. Private ownership in the competitive segments is more likely, even encouraged, but not required. For instance, Norway has a state-owned generation company that actively competes with other generation companies.

The legislative control over supply chain ownership is spurred by privatization and economic liberalization, with the goal of increasing competition (and thereby performance) in the supply of power and gas, along the lines of the SCP paradigm. Unlike generation, the network segments of the natural gas and power industries are natural monopolies, which do not allow competition to emerge spontaneously. Therefore, in order to enable competition in segments which are perceived to be sympathetic to competitive behaviour, ownership of the supply chain is divided to limit the reach of monopoly power.

The coordination of long-term infrastructure between the unbundled segments is achieved mainly through market-based signals, chiefly as price movements. New supply-chain participants who do not own any infrastructure assets - gas shippers and power and gas suppliers, who arrange for the transportation of gas from producers to retailers and mediate between the supply chain and the endusers, respectively - emerge to facilitate coordination across segments. The varied ownership means that the considerations for investment are also varied, as documented in the segment-by-segment discussion below.

\section{Figure 9: Decentralized archetype for the gas-to-power supply chain}

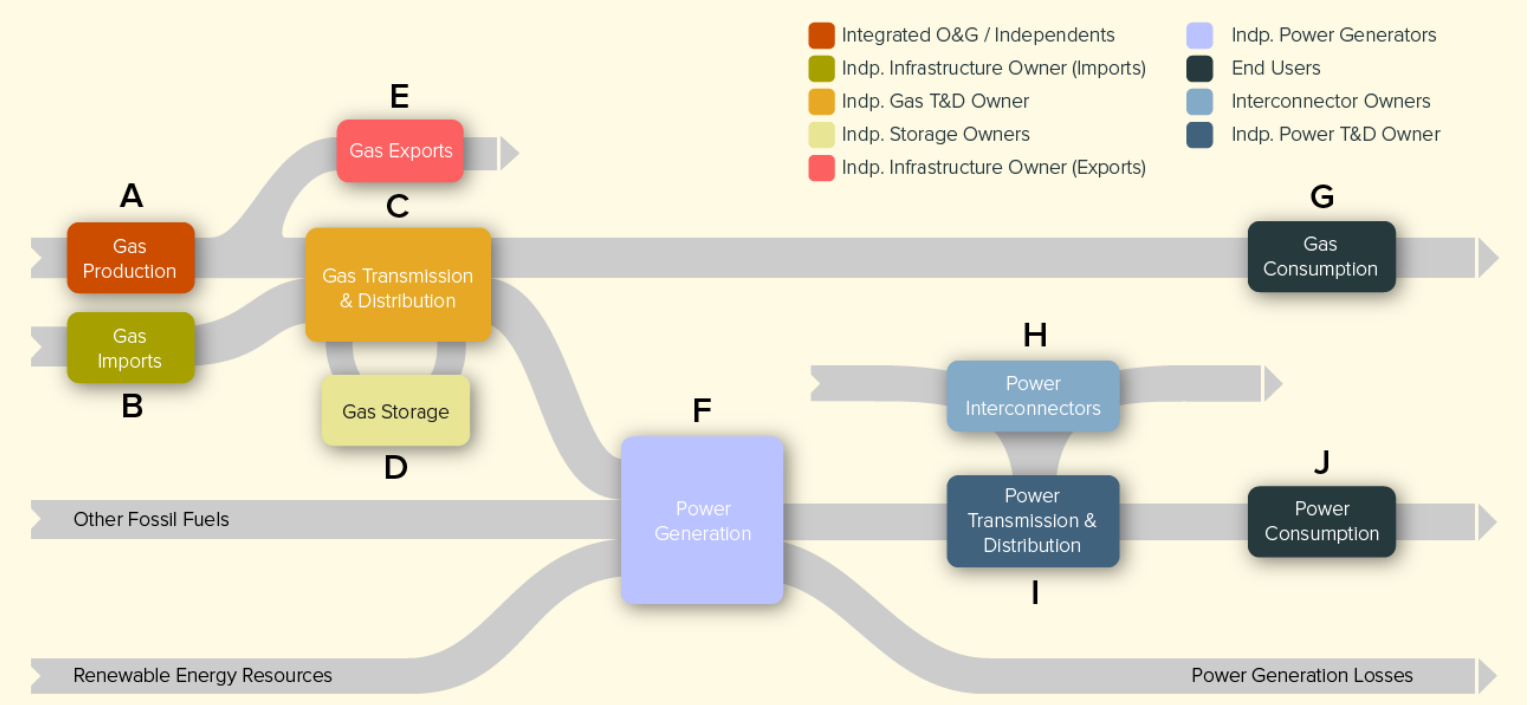

\section{Between the archetypes}

In the early days of the power and gas industries, the structure of the supply was much closer to the fully centralized archetype. Since the 1990s, a number of 'push' and 'pull' factors driving the developing world towards power sector privatization and liberalization have been identified (Sen, 2014). Among developed countries, the EU directives 2009/72/EC for power and 2003/55/EC for gas have set the 

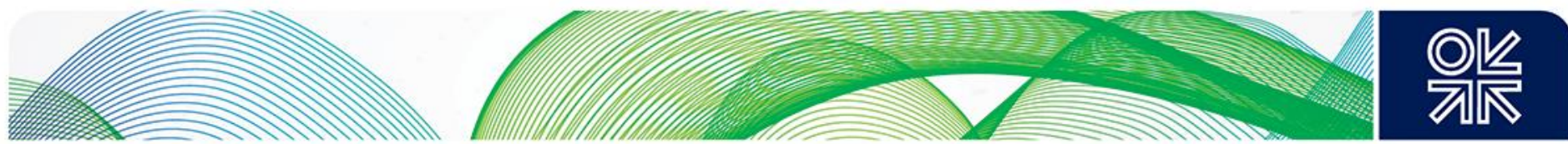

legal framework for the liberalization of these sectors in the entire European Union. However, due to the complexity of the restructuring process, making changes to the regulatory regime overseeing the industry's structure is an incremental process and is path dependent: the initial conditions in place in a country matter; different institutional traditions, historical and cultural experiences, and political priorities may all affect the process of liberalization within a particular country (J. Stern, 1998). The varying efforts towards liberalization and, by extension, decentralization, have resulted in the manifestation of a wide range of hybrid structures in different countries (Besant-Jones, 2006; Haase, 2008). The range of possible power and gas sector structures is illustrated in Figure 10 (power) and Figure 11 (gas).

\section{Figure 10: Power supply industry hybrid structures (Adapted from Besant-Jones, 2006)}

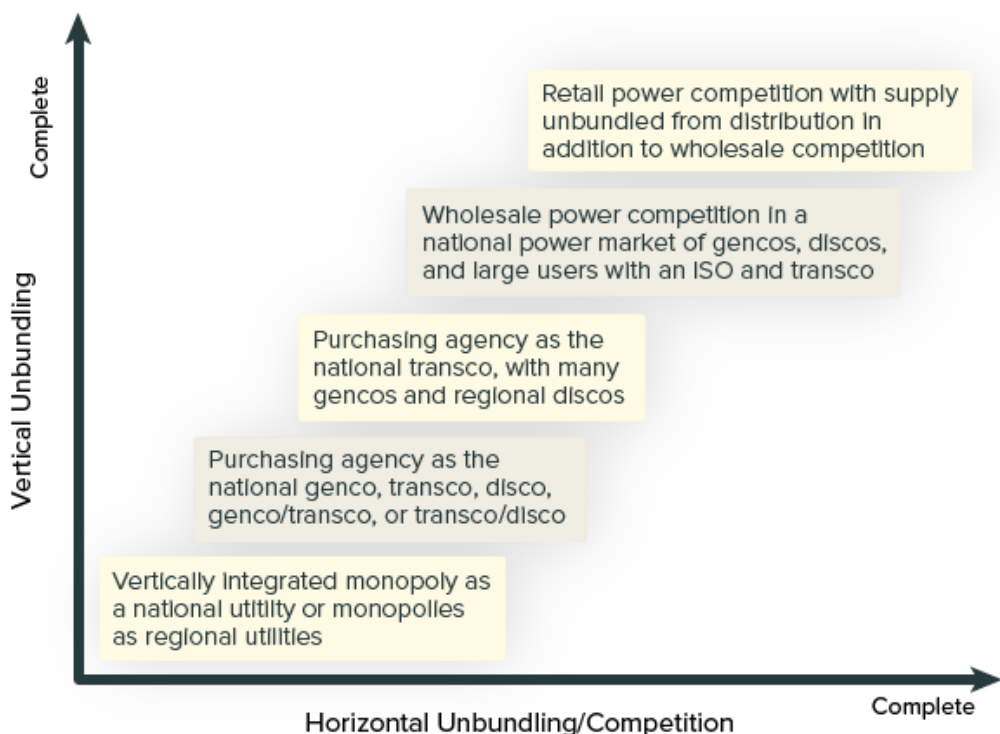

Figure 11: Gas supply industry hybrid structures

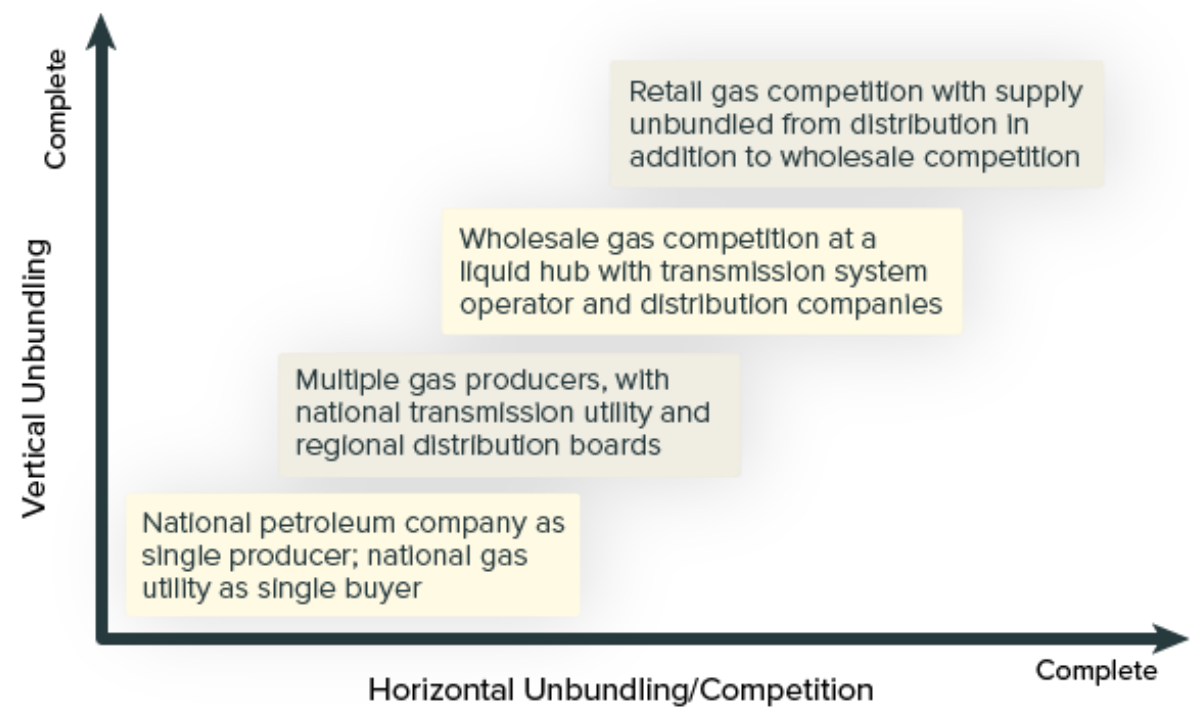

A holistic framework for the study of interdependence between electricity and gas sectors 

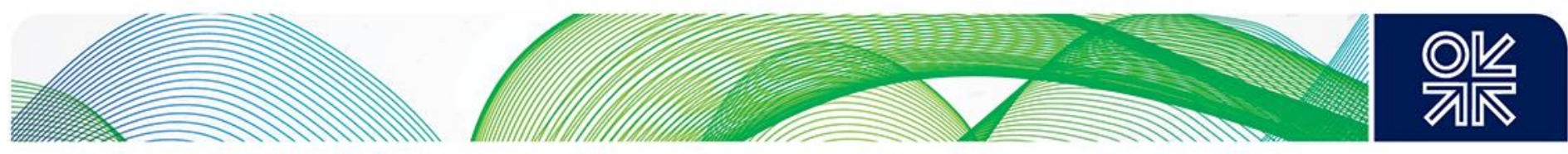

In this section of the paper, the definition and identification of industry structure has been relatively narrow and focused on market concentration and vertical integration. But, broadly speaking, industry structure also includes other elements, which are discussed in the rest of the paper: patterns of institutional context and rules that connect industry agents (regulatory regime in section 3.4.1, industry coordination mechanisms in section 3.3.2), and the objectives that they harbour (section 3.4).

\subsection{Infrastructure investment by segment}

This section provides information to be considered when surveying the established gas-to-power supply chain infrastructure in place in a given country. Care is taken to indicate differences in investment considerations under different organizational structures. The supply chain is retraced from the downstream, contrasting comparable segments in the power and gas supply chains.

\subsubsection{Power and gas consumption devices}

Regardless of upstream industry organizational structure, devices which consume electricity and gas are mostly privately owned and are dispersed among companies, households, and other organizations. The owners are responsible for operating their equipment and for making decisions to acquire them (Table 2).

From the perspective of the owners, the energy consuming devices/installations are acquired to deliver energy services such as heat, power, transport, and light. The evolution of technology has affected the need for energy services in two ways: on the one hand, improved, more efficient technology can substitute the old one; on the other hand, technology can create a whole new segment of energy services need (Fouquet, 2008). Often, one technology can be involved in both processes. For example, consumer electronics - non-existent in the early twentieth century - have emerged to create new energy needs to power entertainment, communications, and office productivity. However, it can also be argued that they are indirectly replacing technology such as papermaking and analogue filmmaking. Thus, an analysis of the current and potential values for power and gas consumption devices in place requires an understanding of the current and potential needs for energy services in the country of interest, and of the technology currently deployed and commercially available for delivering them. Table 3 can be used to guide the process of taking inventory of the stock of electricity and natural gas consuming devices in a country. Currently, natural gas is capable of directly fulfilling the following energy services: space and process heating, cooling, and transport. Natural gas can also be consumed for non-energy purposes: it is the chemical feedstock to produce ammonia, methanol, and hydrogen, if the corresponding manufacturing capacity has been installed; it can also be added into electric arc furnaces to reduce iron ore to iron, as an alternative to the coal/coke-based process. In comparison, electricity is capable of directly fulfilling a wider range of energy services: outdoor and indoor lighting, space heating and cooling, process heating and cooling, transport, and stationary power. The electrochemical manufacturing processes that require electricity as a reactant are: the aluminium smelting process and the chloralkali process (the electrolysis of salt to produce chlorine and caustic soda).

The development potential of natural gas and electricity demand in a country can also be gauged using Table 3, in order to evaluate the demand increase associated with technology diffusion (in the case that some energy services listed are not yet fulfilled by devices existing in the country) and to evaluate the demand change associated with technology substitution (as technologies become more efficient and/or less expensive). In the case that the same energy service can be fulfilled by multiple technologies of varying specifications, and the end-users are to choose between them, the factors that will influence their decisions are manifold and subject to economic and psychological research (Baddeley, 2011; Golove \& Eto, 1996; P. C. Stern, 1992; Wilson \& Dowlatabadi, 2007). 

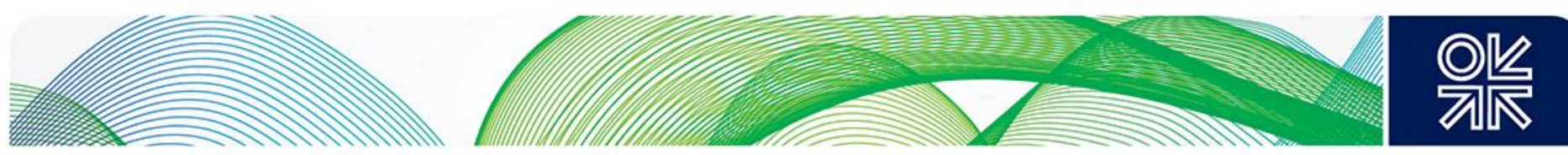

Table 2: Ownership and investment for power and gas consumption devices

Power and gas consumption devices

\begin{tabular}{ll}
\hline Ownership & Independent owners \\
\hline Proposal of investment & Independent owners \\
\hline Approval of investment & N/A \\
\hline Operation & Independent owners \\
\hline Investment remuneration scheme & Fulfilment of new needs or cost savings \\
\hline
\end{tabular}

An important departure from the private ownership of power and gas consuming devices is the centrally planned collective energy consumption in space heating, seen in the form of the extensive district heating systems that were common in the former Eastern Bloc countries. These have not continued or been developed in post-communist years (Buchan, 2010). District heating and cooling has been regaining popularity as a more efficient path towards the provision of energy services in recent years, in conjunction with the use of combined heat and power technologies; however, its deployment has been generally slow (IEA, 2014). 


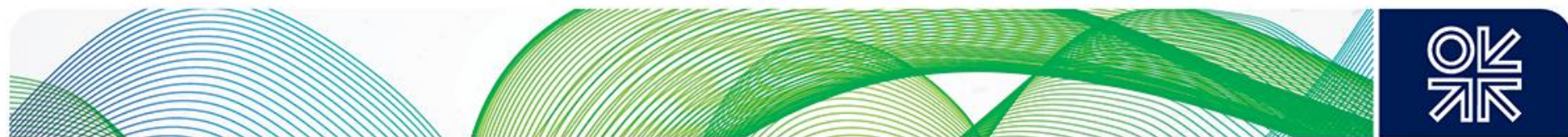

Table 3: Energy services fulfilled by power and gas consuming devices

\begin{tabular}{|c|c|c|c|c|}
\hline & Energy service & Natural gas & Electricity & Other energy inputs \\
\hline \multirow{4}{*}{ 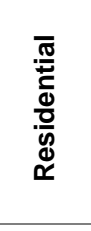 } & Lighting & & Incandescent, halogen lightbulbs, LED, CFL & \\
\hline & Space heating & $\begin{array}{l}\text { NG boiler, } \\
\text { gas-driven heat pumps }\end{array}$ & Resistive heaters, electric heat pumps & Coal, fuel oil, and biomass furnace \\
\hline & Space cooling & Gas chiller, absorption refrigerator & Electric chiller & \\
\hline & Stationary power & & Various home appliances & \\
\hline \multirow{4}{*}{ 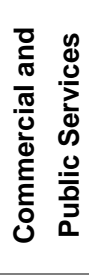 } & Lighting & & $\begin{array}{l}\text { Incandescent, halogen lightbulbs, LED, CFL, } \\
\text { sodium vapour lamp }\end{array}$ & \\
\hline & Space heating & $\begin{array}{l}\text { NG boiler, } \\
\text { gas-driven heat pumps }\end{array}$ & Resistive heaters, electric heat pumps & Coal, fuel oil, and biomass furnace \\
\hline & Space cooling & Gas chiller, absorption refrigerator & Electric chiller & \\
\hline & Stationary power & & Various office appliances & \\
\hline \multirow{4}{*}{ 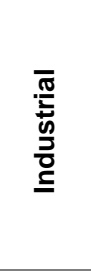 } & Process heating & NG boiler & Electric arc furnace & Coal, fuel oil, or biomass furnace \\
\hline & Process cooling & Gas chiller & Electric chiller & \\
\hline & Stationary power & Gas-driven compressors & Various manufacturing and processing equipment & \\
\hline & Non-energy use & $\begin{array}{l}\text { Ammonia, methanol, and hydrogen manufacturing } \\
\text { facility, electric arc furnace for direct reduction of } \\
\text { iron ore }\end{array}$ & Aluminium smelting and chloralkali process facility ${ }^{2}$ & Coke-based reduction of iron ore \\
\hline 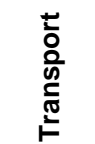 & & NG vehicles & Electric and hybrid vehicles & $\begin{array}{l}\text { Hybrid, fuel cell vehicles, internal } \\
\text { combustion engine vehicles }\end{array}$ \\
\hline
\end{tabular}

${ }^{2}$ In electrochemical manufacturing processes, electricity (in the form of electrons) should be considered as a reactant instead of as a source of energy, since it cannot be substituted by any other form of energy. 

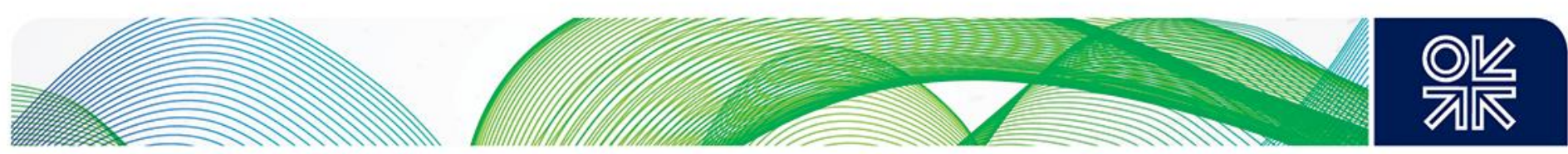

\subsubsection{Power and gas transmission \& distribution networks}

The flow of natural gas and electricity in pipelines and wires have close physical analogies (Table 4), which allow for comparison of the two types of network. The basic quantities that travel along the gas/electricity network to carry energy are molecules/electrons, whose rates are measured as the volumetric flow rate/current. The energy contained by natural gas rests within the chemical bonds of its molecules, and the volume of gas is the energy vector. The energy carried by electricity comes from the electric potential energy, related to the movement of electrons in an electric field. The driving force that moves these basic quantities is the difference in pressure/voltage (or electric potential).

However, there are also areas where natural gas and electricity behave very differently. These areas form the basis of differences both in network flows and, ultimately, in the organizational structures set up to govern them. First of all, in a pipeline, energy flows as mechanical waves through the fluid, is slowed down by friction at the inner surface of the pipes, and travels at $40-60 \mathrm{~km} / \mathrm{h}$. For electricity, energy flows as fields in the space surrounding the wires in an electric transmission line; this propagates at the speed of light, not requiring direct contact of charge carriers. In consequence, energy in a power grid flows much faster than in a natural gas network. Secondly, Kirchhoff's Current Law (which stipulates that due to the conservation of electric charge, the sum of current flows into a given junction of the network is equal to the sum of current flows out of it) does not have an equivalent in natural gas flows. Natural gas is a compressible fluid whose volume changes are dependent on the pressure to which it is subjected; volumetric flow rate is therefore not conserved (as current flow is, according to Kirchhoff's Current Law). This has implications on the balancing of the networks to ensure system integrity: power flows in an electric grid need to be balanced in real time, because failure at one node can trigger a cascading failure of successive parts in rapid succession. Comparatively, gas flows in a gas grid, benefiting from the buffering capacity of its pressure-dependent volume (also known as line-pack), and its slower dynamics, have less stringent balancing needs. However, a gas network does not fail safely: if the level of gas is insufficient in the network, air could enter the network and create a potentially explosive air/gas mixture, leading to incomplete combustion and increasing risk of carbon monoxide poisoning (Le Fevre, 2013). The system would then need to be purged to displace the air/gas mixture.

Table 4: Examples of similar concepts in fluidic and electric flows

\begin{tabular}{lll}
\hline Type & Fluidic & Electric \\
\hline Quantity & molecule & electron \\
\hline Potential & pressure & voltage \\
\hline Flux & volumetric flow rate & current \\
\hline Flux density & velocity & current density \\
\hline
\end{tabular}

The boundary between transmission and distribution network is an amorphous one. There are no physical attributes that clearly delimit the two. Transmission networks typically have fewer interconnections and are operated at high pressure/voltage to connect generation/production facilities with load centres. Distribution networks, which have radial configurations, are responsible for distributing gas/electricity to the decentralized consumption devices situated within businesses, households, and industries.

Under the centralized archetype, the power T\&D network is solely owned by the vertically integrated utility (see Table 5). The utility is thus responsible for planning new grid investments (given known generation expansion plans and demand growth), building the new facilities, and operating them. The planning of grid expansion is done within a framework of integrated resource planning to minimize the costs of providing electricity while meeting certain reliability criteria (Sauma \& Oren, 2009). For most integrated utilities, the approval of the national regulator is needed before proceeding with the planned 

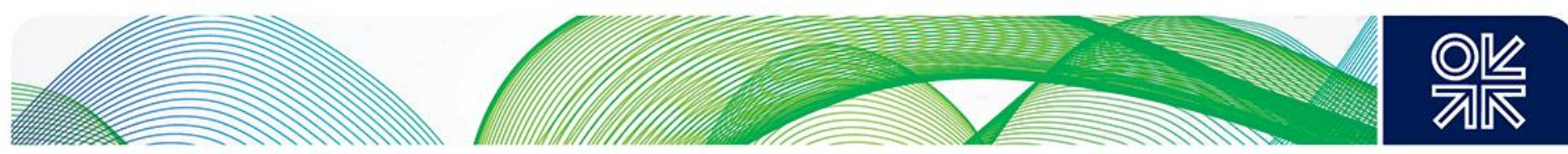

investments; depending on the country, this process can be substantive or mainly formal. Cost recovery for network investment is integrated into the overall electricity tariff, payable by end-users. The gas T\&D network is owned and operated similarly.

Network industries are natural monopolies because of their physical characteristics: they have large economies of scale relative to the size of market, thus efficiency is lowered through duplication or multiplication of the power/gas grid. Operation of a single network is thus more economical (Rivier, Pérez-Arriaga, \& Olmos, 2013). Due to this special characteristic, under the decentralized archetype the network segment is unbundled from the rest of the supply chain, ensuring that the monopoly effect is contained. After unbundling in all transmission and distribution segments other than power transmission, ownership can be dispersed between a number of companies licensed to own and operate the infrastructure. The owners' plans for network expansion need to be approved by the regulator; the value of the investment is recovered via regulated tariffs, payable by users of the network, that take the investment costs into consideration. The power transmission segment is distinct from other segments in that it requires second-to-second balancing of system parameters (frequency and voltage) due to the physical nature of power flows. The stability of a power grid is only achievable if control of the entire network is placed under a single system operator, licensed by the regulator, who might or might not own part of the transmission network. Natural gas transmission pipelines, on the other hand, only need to be balanced in terms of their pressure, and can be balanced locally by pipeline owners/operators, except for hubs located at the junction of multiple pipelines. Some differences also exist in the regulation of transmission versus distribution networks: due to the number of components involved, investments made by a distribution company cannot be controlled and evaluated to the same extent as transmission investments, which are evaluated on a line-by-line basis. Therefore, a more aggregated evaluation mechanism is used to evaluate the adequacy of distribution investments (Gómez, 2013).

Table 5: Ownership structures for power and gas network infrastructure

\begin{tabular}{|c|c|c|c|}
\hline & \multirow{2}{*}{$\begin{array}{l}\text { Complete } \\
\text { centralization } \\
\text { Power and gas T\&D }\end{array}$} & \multicolumn{2}{|c|}{ Complete decentralization } \\
\hline & & Power transmission & All other \\
\hline Ownership & Integrated utility & Independent owners & Independent owners \\
\hline $\begin{array}{l}\text { Plan of } \\
\text { investment }\end{array}$ & Integrated utility & Owners & Owners \\
\hline $\begin{array}{l}\text { Approval of } \\
\text { investment }\end{array}$ & Various & Independent regulator & Independent regulator \\
\hline Operation & Integrated utility & Licensed system operator & Owners \\
\hline $\begin{array}{l}\text { Investment } \\
\text { remuneratio } \\
\text { n scheme }\end{array}$ & $\begin{array}{l}\text { Integrated into the } \\
\text { cost-based tariff } \\
\text { approved by regulator }\end{array}$ & $\begin{array}{l}\text { Integrated into the cost-based } \\
\text { tariff approved by regulator, with } \\
\text { added conditions concerning } \\
\text { performance and access }\end{array}$ & $\begin{array}{l}\text { Integrated into the cost-based } \\
\text { tariff approved by regulator, } \\
\text { with added conditions } \\
\text { concerning performance and } \\
\text { access }\end{array}$ \\
\hline
\end{tabular}

In the case that ownership of the supply chain is decentralized, the model in Table 5 is only one among many possible regulatory models for the transmission and distribution segments. It can be more centralized, having the system operator (rather than independent owners) propose investment. Alternatively, investment proposals could be initiated by network users via capacity auctions, or by merchant investors who, once authorized by the regulator, finance a transmission facility and then charge their users according to pre-established contributions, or per actual use of the facility (Rivier et al., 2013). In either case, the important role of the regulator in approving the investment and determining the regulated rates for the use of the network cannot be understated. 

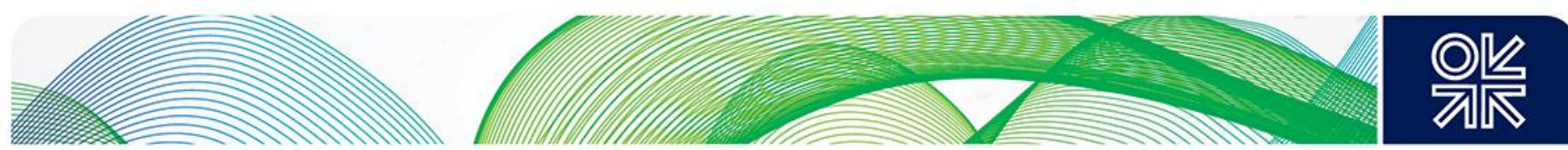

\subsubsection{Gas storage facilities, power storage facilities}

Any energy storage option can be described via two parameters: the quantity of energy that can be stored, and the rate at which energy can be stored/withdrawn (if asymmetrical).Together, they determine the roles that storage facilities play in the wider supply chain. Dedicated storage is the gas and power industries' equivalent of inventory - the stock of energy commodity that buffers imbalances in gas/electricity supply and demand. Facilities that can deliver energy for many days at rated output capacity are commonly used to balance supply-demand imbalance over weeks or months. Facilities that have large output capacity but low storage capacity are used to balance supply-demand imbalance within a day (peak demand shaving).

In practice, natural gas has been stored in solution-mined salt caverns, depleted gas fields, and aquifers. The usable volume of the reservoir and the pressure that it can withstand determine the maximum amount of gas that can be stored (a static parameter), while the rate at which gas can be injected or delivered is dependent on the wellhead pressure and the amount of gas in storage (a dynamic parameter) (Plaat, 2009). Natural gas can also be stored in the form of liquefied natural gas in containers located above ground - although with much smaller storage capacity than the underground alternatives.

In the power sector, storage has been a more problematic issue: the energy commodity that is delivered through the supply chain cannot be directly stored; it must be converted to another form of energy (such as kinetic, potential, or electrostatic). The most common types of technology employed for utility-scale energy storage are: pumped hydro installations, batteries, and flywheels. Others remain at the conceptproving stage (EPRI, 2010). An overall comparison of gas and electricity storage options is presented in Table 6.

The global figure for installed natural gas storage capacity is $270 \mathrm{bcm}$, almost 8 per cent of the world's annual natural gas consumption of $3497 \mathrm{bcm}$; the estimated total peak output capacity for all of these facilities is $5333 \mathrm{mcm} /$ day, or 56 per cent of the world's average daily natural gas demand (IEA, 2015b). For comparison, pumped hydro energy storage (PHES), currently the only commercially proven largescale energy storage technology, has $127 \mathrm{GW}$ installed (pumping/generating) capacity, or 6 per cent of the world's average hourly demand of 2159 GW (EPRI, 2010). The development of installed capacity of batteries and flywheels is very limited.

Table 6: Comparison of natural gas and electricity storage options

\begin{tabular}{l|ll|lll}
\hline & \multicolumn{2}{|c|}{ Natural gas } & \multicolumn{2}{c}{ Power } \\
\hline Storage option & $\begin{array}{l}\text { sub-surface } \\
\text { reservoirs }\end{array}$ & LNG & $\begin{array}{l}\text { Pumped- } \\
\text { hydro }\end{array}$ & Batteries & Flywheels \\
\hline Energy stored & Natural gas & $\begin{array}{l}\text { Liquefied } \\
\text { natural gas }\end{array}$ & $\begin{array}{l}\text { Water with } \\
\text { height } \\
\text { difference }\end{array}$ & Chemical energy & Kinetic energy \\
\hline $\begin{array}{l}\text { Rate of } \\
\text { conversion, or } \\
\text { injection/ } \\
\text { withdrawal }\end{array}$ & $\begin{array}{l}\text { Reservoir } \\
\text { injectability/ } \\
\text { deliverability }\end{array}$ & $\begin{array}{l}\text { Liquefaction/ } \\
\text { regasification } \\
\text { capacity }\end{array}$ & $\begin{array}{l}\text { Pumping/ } \\
\text { generating } \\
\text { capacity }\end{array}$ & $\begin{array}{l}\text { Battery chemistry and } \\
\text { charging capacity }\end{array}$ & Charging capacity \\
\hline $\begin{array}{l}\text { Storage limit } \\
\text { Reservoir volume }\end{array}$ & $\begin{array}{l}\text { LNG tank } \\
\text { and integrity }\end{array}$ & capacity & $\begin{array}{l}\text { Reservoir } \\
\text { capacity }\end{array}$ & Mass of active material & Flywheel \\
& & & & & $\begin{array}{l}\text { geometry and } \\
\text { material }\end{array}$ \\
\hline
\end{tabular}



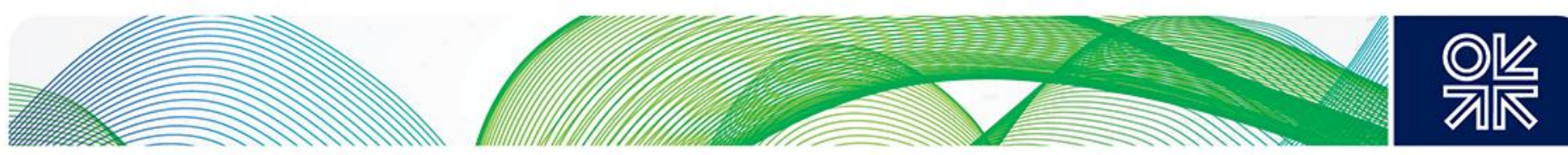

Table 7: Ownership structures for power and gas storage facilities

\begin{tabular}{l|ll|ll|}
\hline & \multicolumn{2}{|c|}{ Gas storage facilities } & \multicolumn{2}{c|}{ Electricity storage facilities } \\
\hline & $\begin{array}{l}\text { Complete } \\
\text { centralization }\end{array}$ & $\begin{array}{l}\text { Complete } \\
\text { decentralization }\end{array}$ & $\begin{array}{l}\text { Complete } \\
\text { centralization }\end{array}$ & $\begin{array}{l}\text { Complete } \\
\text { decentralization }\end{array}$ \\
\hline Ownership & Integrated utilities & Independent owners & Integrated utilities & $\begin{array}{l}\text { Independent owners } \\
\text { /generation owners }\end{array}$ \\
\hline $\begin{array}{l}\text { Proposal of } \\
\text { investment }\end{array}$ & Integrated utilities & Owners & Integrated utilities & Owners \\
\hline $\begin{array}{l}\text { Approval of } \\
\text { investment }\end{array}$ & Various & Independent & Various & Independent \\
\hline $\begin{array}{l}\text { Operation } \\
\text { Investment } \\
\text { remuneration } \\
\text { scheme }\end{array}$ & Integrated utilities & Owners & Integrated utilities & Owners \\
\hline
\end{tabular}

Within the centralized archetype, the requirement for gas storage is planned as part of the overall system design process by the integrated utility, along with other sources of flexibility. The costs of storage investment and operations are embedded within the overall system costs, then passed on to the consumers through regulated tariffs. Within the decentralized archetype, physical storage assets are owned and operated independently, and need to compete for remuneration with other sources of flexibility in the market for flexibility services (Le Fevre, 2013). The regulation of gas storage facilities bears many similarities to that of the transmission network, frequently requiring third-party access, tariff regulation, and legal/functional unbundling.

Under the centralized archetype, PHES facilities are also developed by power sector integrated utilities to balance system supply and demand, receiving compensation through approved tariffs. Under the decentralized paradigm, they are developed and operated by private generation companies: although PHES provides energy storage capacity, it is still primarily considered as another generation facility; no special regulation is dedicated to it (Rangoni, 2012). Therefore, the ownership and operation of PHES is strongly integrated with upstream generation of electricity within the owner's portfolio. This has limited the presence of independent electricity storage owners/operators.

\subsubsection{Power interconnectors, gas import and export infrastructure}

In terms of their physical characteristics, power interconnectors and gas pipelines for international trade are extremely similar to their domestic counterparts. However, because their operation involves more than one country, issues relating to ownership and operations become more complex than those involving intra-national power interconnectors or gas pipelines. As there is often no supra-national regulatory entity to oversee the operation of interconnectors, differences in the institutional, administrative, and technical features of the energy systems involved need to be resolved.

In the natural gas sector, import/export pipelines that stretch over vast distances, crossing multiple countries (importer, exporter, and transit countries), are rather common, while power interconnectors mainly connect two neighbouring countries. One explanation for this difference is the distributions of energy resources: as can be seen in the maps in Figure 2 and Figure 3, on average, the self-sufficiency of countries in electricity generation and consumption is higher than that in gas production and consumption, so more countries are capable of exporting electricity than exporting gas, and trades between neighbouring countries are more common than those between distant countries. Also, transporting electricity across long distances remains expensive despite technological development. 

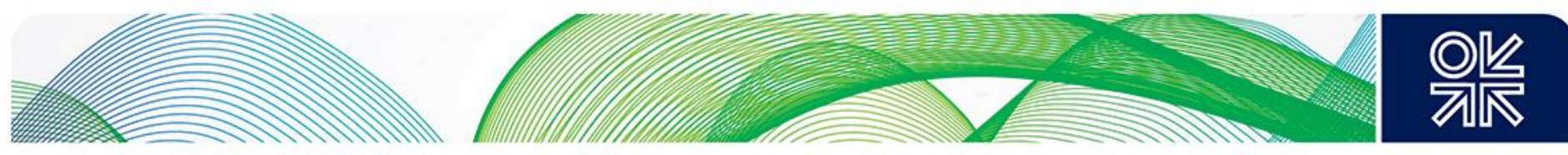

Power interconnectors exist in two main types: alternate current (AC) and direct current (DC) interconnections. Adopting an AC interconnector ties the two power systems involved into a marriage of sorts, since the two systems become linked in a significant way when they operate in synchronism. This requires a high degree of technical compatibility - shared nominal frequency and preferably a common voltage level - and operational coordination - joint administration of frequency regulation, agreement upon reliability standards and constraints. High voltage direct current (HVDC) interconnections allow interconnection over longer distances without stability limits. They carry more power for the same conductor size, and are more efficient to build for distances above $600 \mathrm{~km}$ (United Nations, 2006). They are also preferred for undersea transmission because the structure of the cable does not affect transmission. Finally, when technical incompatibilities are substantial, as in the case of different system frequencies, and synchronous interconnection is not possible, then HVDC becomes the obvious choice.

The most active exchanges of electricity across borders occur between adjacent countries with a history of cooperation and mutual trust. Also, harmonized national power sector structures and coordinated operation are seen to be of great importance to the development of trade via interconnectors (Charpentier \& Schenk, 1995). Norway, Sweden, and Finland are examples of neighbouring countries with decentralized ownership structures. South Africa, Botswana, Lesotho, Mozambique, Namibia, Swaziland, and Zimbabwe form a group of neighbouring countries with centralized ownership structures. The ownership structure for the most common power interconnector structure archetypes ('both centralized' and 'both decentralized') is presented in Table 8. In general, it has been observed that, in the electricity sector, most countries value meeting local demand, diversifying supply, and building a local industry that generates revenues and employment as much, or more, than seeking the profits which could be obtained from electricity exports (Borrmann \& Brunekreeft, 2011). This has limited the development of interconnections between countries with centralized power sector structures. Recently, a number of interconnector projects among countries with heterogeneous industry structures and historically diverging interests have been proposed (Desertec, Medgrid, North-East Asian Super Grid); the resolution of past and present geopolitical disputes will also become important for the power sector (Neuhoff, Sasso, \& Winzer, 2013).

As presented above, due to the uneven distribution of gas reserve and gas demand, international natural gas pipelines connecting gas producers with gas consumers necessarily involve more countries (through transit), and countries with larger institutional differences, than power interconnectors; conflict can arise when profit and rent resulting from the project needs to be shared among many divergent parties. In consequence, except for cases in North America and Western Europe, where the gas industries are similarly structured (decentralized), the rules of the game are clearly defined and accepted, and a history of cooperation exists, cross-border pipelines have a long history of vulnerability to disruption and conflict (UNDP/ESMAP, 2003). The typical ownership structure of pipelines for the two scenarios, 'all decentralized' and 'mixed regimes', are shown in Table 8. It can be seen that in the case of pipelines operating across mixed regimes, there are many different ownership and operatorship arrangements. Compared to the 'all decentralized' scenario, the involvement of national governments and the use of long-term contracts tied to pipelines are common.

LNG terminals, an alternative to gas pipelines, can also be used to transport natural gas from production centres to demand centres. The full equivalent of a pipeline is the ensemble of the liquefaction terminal, LNG tankers, and a reception terminal with liquefied gas storage and regasification plants - a capital intensive supply chain in itself. The economies of scale of the LNG value chain are such that it becomes more economical than a pipeline for transporting gas above distances of $4500 \mathrm{~km}$ (Cornot-Gandolphe, Appert, Dickel, Chabrelie, \& Rojey, 2003). Compared to pipelines, the LNG value chain has less asset specificity: a given liquefaction terminal can process natural gas and ship it to different regasification terminals. Among all possible ownership structures, the most centralized one for the LNG value chain exhibits upstream and downstream integration as shown in Figure 12. 

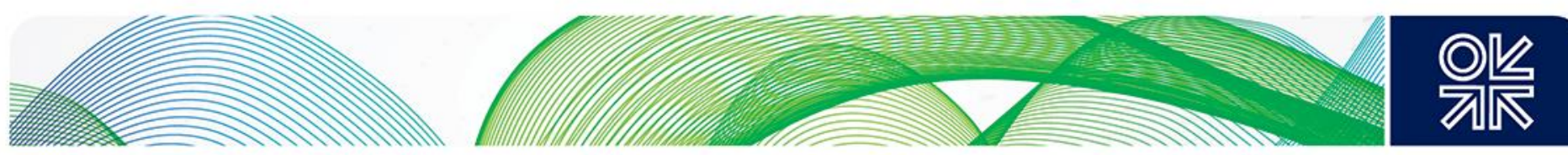

Figure 12: Centralized ownership structure for LNG value chains

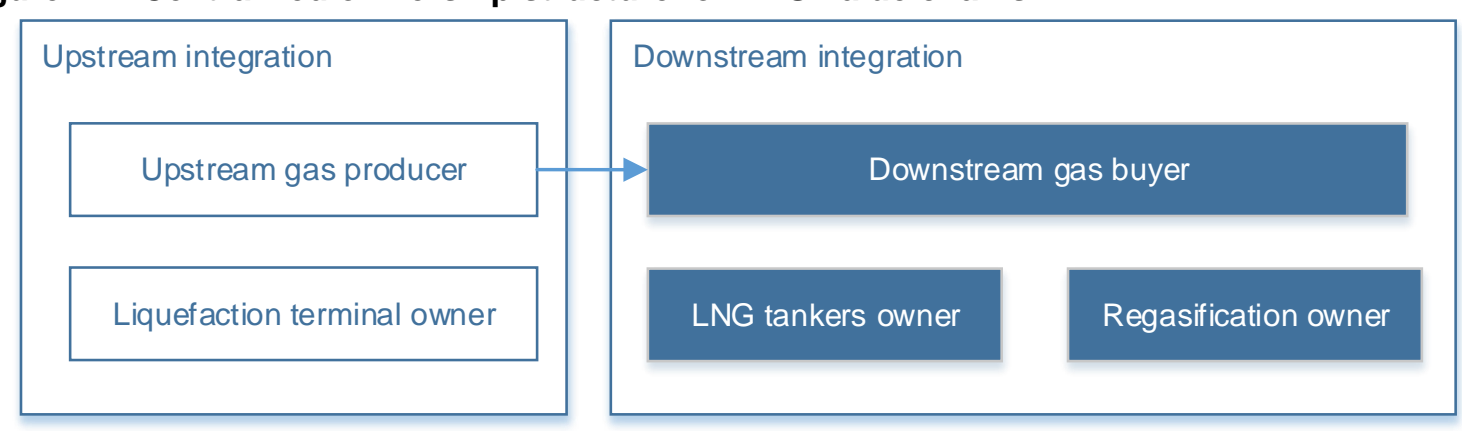

LNG liquefaction terminals, located in producing countries and the most capital intensive link in the chain, are very commonly integrated with upstream production: gas producers become part of the ownership structure of the terminal to ensure the commercialization of their gas (Inniss, 2004). Integrated utilities, on the downstream end, can take ownership of the tankers and regasification terminals. On the other end of the spectrum, a completely decentralized ownership structure for the gas industry is shown in Figure 13: the owners of LNG terminals do not take possession of the gas - the terminals operate as tolling facilities - and tankers are chartered out by independent owners. Because the gas exporting and importing countries do not necessarily share the same industry structure paradigm, mixed ownership structures for the LNG value chain are common. 

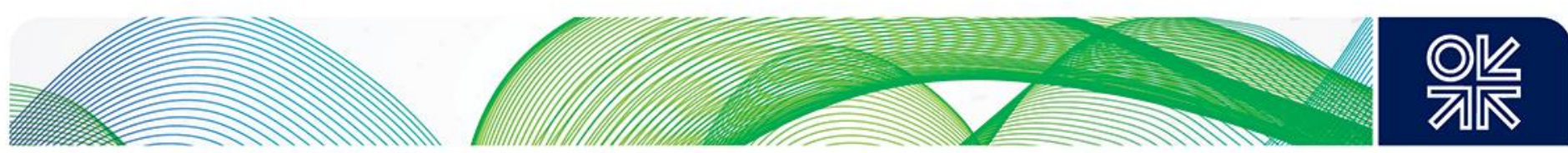

Table 8: Ownership structures for power interconnectors, gas pipelines and LNG terminals

\begin{tabular}{|c|c|c|c|c|c|c|}
\hline & \multicolumn{2}{|c|}{ Power interconnectors } & \multicolumn{2}{|c|}{ Gas pipelines } & \multicolumn{2}{|c|}{ LNG terminals } \\
\hline & $\begin{array}{l}\text { Both } \\
\text { centralized }\end{array}$ & Both decentralized & All decentralized & Mixed regimes & $\begin{array}{l}\text { Fully } \\
\text { centralized }\end{array}$ & $\begin{array}{l}\text { Fully } \\
\text { decentralized }\end{array}$ \\
\hline Ownership & $\begin{array}{l}\text { Integrated } \\
\text { utilities of the } \\
\text { countries } \\
\text { involved }\end{array}$ & $\begin{array}{l}\text { Joint venture of } \\
\text { companies, including } \\
\text { system operators }\end{array}$ & Independent owners & Various & $\begin{array}{l}\text { Gas } \\
\text { producers/gas } \\
\text { buyers }\end{array}$ & $\begin{array}{l}\text { Independent } \\
\text { owners }\end{array}$ \\
\hline $\begin{array}{l}\text { Proposal of } \\
\text { investment }\end{array}$ & $\begin{array}{l}\text { Integrated } \\
\text { utilities of the } \\
\text { countries } \\
\text { involved }\end{array}$ & Owners & Independent owners & $\begin{array}{l}\text { Owners or national } \\
\text { governments involved }\end{array}$ & Owners & Owners \\
\hline $\begin{array}{l}\text { Approval of } \\
\text { investment }\end{array}$ & $\begin{array}{l}\text { National } \\
\text { governments } \\
\text { involved }\end{array}$ & $\begin{array}{l}\text { Regulators of } \\
\text { countries involved }\end{array}$ & $\begin{array}{l}\text { Regulators of countries } \\
\text { involved }\end{array}$ & $\begin{array}{l}\text { National governments } \\
\text { involved }\end{array}$ & Regulator & Regulator \\
\hline Operation & $\begin{array}{l}\text { Integrated } \\
\text { utilities of the } \\
\text { countries } \\
\text { involved }\end{array}$ & Owners & Independent owners & Various & Owners & Owners \\
\hline $\begin{array}{l}\text { Investment } \\
\text { remuneration } \\
\text { scheme }\end{array}$ & $\begin{array}{l}\text { Integrated } \\
\text { into the } \\
\text { approved } \\
\text { tariffs }\end{array}$ & $\begin{array}{l}\text { Integrated into the } \\
\text { approved regulated } \\
\text { tariffs, exemption } \\
\text { from tariff and open } \\
\text { access possible }\end{array}$ & $\begin{array}{l}\text { Integrated into the } \\
\text { approved tariffs }\end{array}$ & $\begin{array}{l}\text { Long-term } \\
\text { purchase/supply } \\
\text { contract associated } \\
\text { with pipeline }\end{array}$ & $\begin{array}{l}\text { Integrated } \\
\text { upstream or } \\
\text { downstream }\end{array}$ & $\begin{array}{l}\text { Tolling, } \\
\text { exemption from } \\
\text { open access } \\
\text { possible }\end{array}$ \\
\hline
\end{tabular}



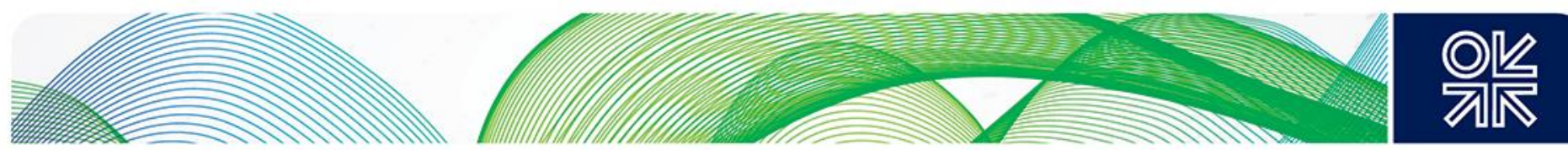

Figure 13: Decentralized ownership structure for LNG value chains

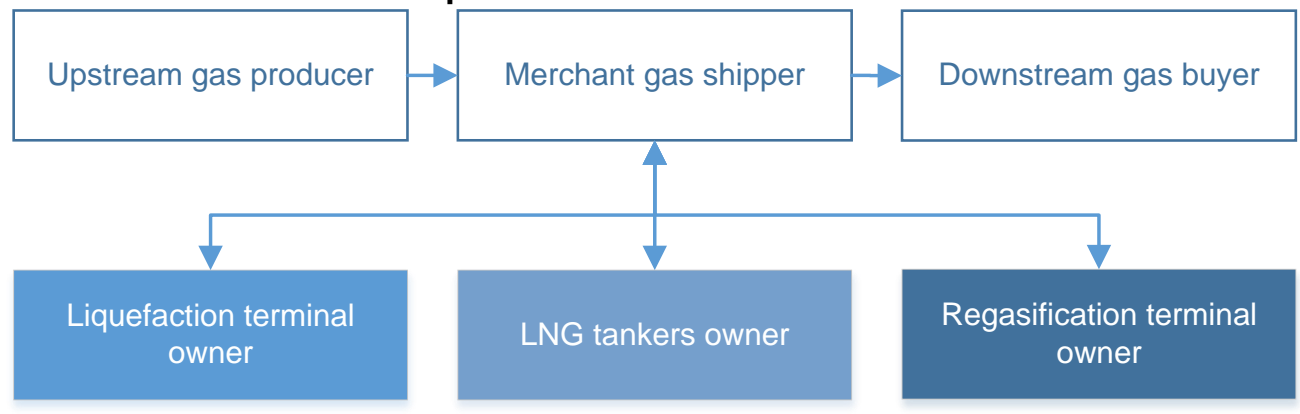

\subsubsection{Power generation and gas production}

Located at the upstream of their respective supply chains, power generation and gas production are the most dissimilar parallel segments. Both of them are capital intensive, but gas production, compared to power generation, involves a higher degree of geological and commercial risk.

Power generation is an aggregate of a diverse range of technologies. Multiple categorizations are possible based on the nature of the energy source used for conversion into electricity, the emissions associated with generation, and the siting requirements for the generation plants.

Generators that are fuelled by fossil fuels or nuclear fission energy, and are driven by steam moving through a closed cycle, are reliant upon the procurement of coal, natural gas, fuel oil, or uranium and this connects them to their respective upstream supply chains. The stockpiling of fuel at the generation site makes continuous and controlled generation of electricity possible (with the exception of natural gas, which depends on 'just-in-time' gas delivery). Historically, power plants have been sited at locations which have convenient access to fuel - near collieries or transport junctions - at some distance from load centres (Momoh, Meliopoulos, \& Saint, 2012). High voltage transmission networks are used to bridge this distance. Large-scale biomass and hydro generation (with reservoir), despite the renewable nature of their fuel and their low emission intensity, bear some resemblance to the first group in terms of generation siting.

Generators that are fuelled by various forms of intermittent energy - wind, solar, tidal, wave, run-ofriver - are dependent upon the flux of energy moving in nature, thus their production is not entirely predictable. Some of them have more stringent siting requirements than others, due to their need for access to the particular form of renewable energy. Small-scale onshore wind turbines and photovoltaic cells are comparatively more flexible in their location, and are frequently sited close to load centres. They are then connected to end-users via the low-voltage distribution network. 

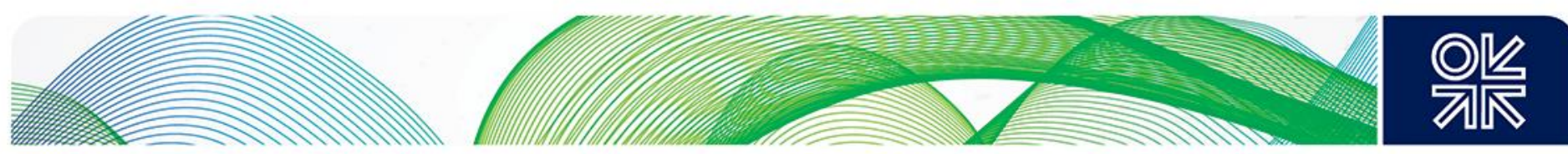

Table 9: Characteristics of groups of power generation technologies

\begin{tabular}{|c|c|c|c|c|c|c|}
\hline & $\begin{array}{l}\text { Large-scale } \\
\text { fossil fuels }\end{array}$ & Nuclear & $\begin{array}{l}\text { Large-scale } \\
\text { biomass }\end{array}$ & $\begin{array}{l}\text { Hydro with } \\
\text { reservoir }\end{array}$ & $\begin{array}{l}\text { Offshore wind, } \\
\text { wave, tidal, solar } \\
\text { thermal }\end{array}$ & $\begin{array}{l}\text { PVs, } \\
\text { onshore } \\
\text { wind }\end{array}$ \\
\hline $\begin{array}{l}\text { Energy } \\
\text { source }\end{array}$ & $\begin{array}{l}\text { Depletable, } \\
\text { storable }\end{array}$ & $\begin{array}{l}\text { Depletable, } \\
\text { storable }\end{array}$ & $\begin{array}{l}\text { Depletable if } \\
\text { reforestation } \\
\text { does not occur }\end{array}$ & $\begin{array}{l}\text { Depletable if } \\
\text { water reservoir } \\
\text { not replenished }\end{array}$ & $\begin{array}{l}\text { Renewable, } \\
\text { intermittent }\end{array}$ & \\
\hline $\begin{array}{l}\text { Emission } \\
\text { from } \\
\text { generation }\end{array}$ & Yes & No & $\begin{array}{l}\text { Not carbon- } \\
\text { neutral if } \\
\text { reforestation } \\
\text { does not occur }\end{array}$ & No & No & No \\
\hline $\begin{array}{l}\text { Siting } \\
\text { requirements }\end{array}$ & $\begin{array}{l}\text { Access to } \\
\text { fuel supply }\end{array}$ & $\begin{array}{l}\text { Access to } \\
\text { fuel supply }\end{array}$ & $\begin{array}{l}\text { Access to fuel } \\
\text { supply }\end{array}$ & $\begin{array}{l}\text { Geological } \\
\text { constraint }\end{array}$ & $\begin{array}{l}\text { Environmental } \\
\text { requirements }\end{array}$ & Distributed \\
\hline $\begin{array}{l}\text { Conversion } \\
\text { technology }\end{array}$ & $\begin{array}{l}\text { Steam/gas } \\
\text { turbine }\end{array}$ & $\begin{array}{l}\text { Steam } \\
\text { turbine }\end{array}$ & Steam turbine & Water turbine & Various & Various \\
\hline
\end{tabular}

Within the centralized archetype, power generation facilities, like the rest of the centralized supply chain, are owned by the integrated utility, which also plans for investments and operates the installed facilities. The generation projects that can be achieved at the lowest costs, while providing an adequate level of reliability, are chosen based on evaluation conducted. Other selection criteria are also possible, examples are: job creation and the use of domestic fuels. Once a project proposal is approved by the regulator and completed, the utility recovers its costs through the regulated tariff, which also includes a fixed profit margin deemed appropriate by the regulator (Mazer, 2007). In a decentralized environment, decisions on the development of generation infrastructure are made by for-profit generating companies that construct, own, and operate them, motivated by estimates of perceived revenue from market operations and available policy incentives. Investment decisions need to be approved by the local planning authority responsible for the area in which the site of generation is located.

Currently, natural gas production is often divided into two types: conventional and unconventional. Conventional gas production refers to the case where the natural gas comes from a commonly exploited type of geological reservoir: hydrocarbons, which have migrated from sedimentary source rocks, are held within porous reservoir rock, and are trapped by an impermeable cap, forming an accumulation. Natural gas also occurs separately as non-associated gas, and together with oil, in solution as dissolved gas or as free gas (associated gas). The primary drive for production is the pressure difference between the reservoir and the well; the flow rate is dependent on this pressure difference, and it is affected by the presence of oil or water, and the permeability of the reservoir rock (Hagoort, 1988).

A number of sources of natural gas are regrouped under the heading of unconventional gas: they range from low-permeability sandstone and limestone formations (also known as tight sands or tight gas formations), shales (hydrocarbons which have not migrated from the source rock), methane-rich coal seams (gas formed at the same time as coal and adsorbed within its solid matrix), and methane hydrates (gas escaping from geological faults, precipitated/crystallized upon contact with cold sea water) found on the ocean floor. They each require different extraction techniques, but have the commonality of being considered uneconomical to produce when the required technology and market conditions are not available (Rogner, 1997). Recent developments in horizontal drilling and hydraulic fracturing, pioneered by gas producers in the USA, have made the extraction of the American shale gas reserves economical, unleashing important production. However, the economic and political feasibility of shale gas production in other world regions remains unclear. Biogas, also referred to as renewable natural gas, is generated by the breakdown of crop and animal waste and can be upgraded to a quality comparable to fossil natural gas. Biogas can be perceived as an equivalent of distributed 

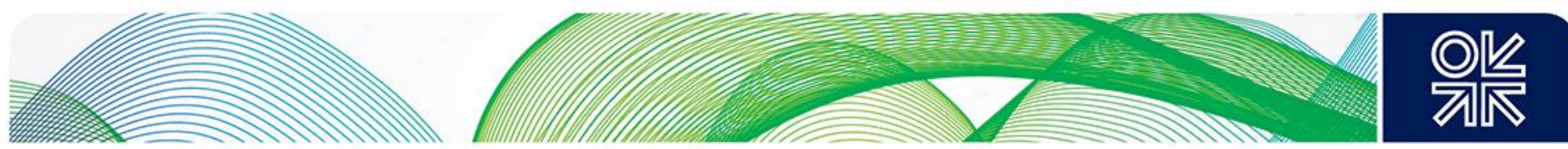

renewable generation for the gas sector: produced from non-depletable energy sources, close to load centres.

Table 10: Characteristics of groups of gas extraction/production technologies

\begin{tabular}{|c|c|c|c|c|c|}
\hline & Conventional gas & Tight/shale gas & $\begin{array}{l}\text { Coal bed } \\
\text { methane }\end{array}$ & $\begin{array}{l}\text { Methane } \\
\text { hydrates }\end{array}$ & Biogas \\
\hline Energy source & $\begin{array}{l}\text { Depletable, } \\
\text { storable }\end{array}$ & $\begin{array}{l}\text { Depletable, } \\
\text { storable }\end{array}$ & $\begin{array}{l}\text { Depletable, } \\
\text { storable }\end{array}$ & $\begin{array}{l}\text { Depletable, } \\
\text { storable }\end{array}$ & $\begin{array}{l}\text { Renewable, limited } \\
\text { storage }\end{array}$ \\
\hline $\begin{array}{l}\text { Emission from } \\
\text { generation }\end{array}$ & Yes & Yes & Yes & Yes & $\begin{array}{l}\text { Carbon neutral as } \\
\text { gas is otherwise } \\
\text { dissipated }\end{array}$ \\
\hline $\begin{array}{l}\text { Siting } \\
\text { requirements }\end{array}$ & Access to reservoir & Access to shale & $\begin{array}{l}\text { Access to coal } \\
\text { seam }\end{array}$ & $\begin{array}{l}\text { Access to } \\
\text { deposit }\end{array}$ & Distributed \\
\hline $\begin{array}{l}\text { Extraction/ } \\
\text { production } \\
\text { technology }\end{array}$ & $\begin{array}{l}\text { Drilling and } \\
\text { controlled reservoir } \\
\text { depletion }\end{array}$ & $\begin{array}{l}\text { Horizontal and } \\
\text { directional drilling, } \\
\text { hydraulic fracturing }\end{array}$ & $\begin{array}{l}\text { Drilling and } \\
\text { water pumping }\end{array}$ & TBD & $\begin{array}{l}\text { Controlled } \\
\text { anaerobic } \\
\text { digestion/ } \\
\text { fermentation }\end{array}$ \\
\hline
\end{tabular}

Oil and gas production requires incremental investments. Exploration takes place to discover accumulations of hydrocarbons located below ground - chance plays a non-negligible role in this process. In the case that a discovery is made, the reservoir is evaluated to determine whether it is economically favourable for development. Development investments involve drilling, the completion of production wells, and installation of the associated equipment, after which production can begin. Ceteris paribus, the production capacity of a given well declines as production goes on, because the reservoir pressure (part of the driving force for gas production) decreases as the amount of gas in the reservoir is depleted. Therefore, later in the lifetime of the reservoir, continued investment in recovery enhancing technology such as: fracturing (to increase the porosity of reservoir rocks), drilling of additional wells, and water or gas injection, becomes necessary. Thus, the developmental stage of reservoirs needs to be considered when analysing conventional gas production capacity, as the cost of production depends on it (Adelman, 1993).

Due to the common origin of oil and gas (referred to together as petroleum) in the history of upstream exploration and production, most companies have discovered gas reserves while drilling and hoping to discover oil, which is deemed the more valuable energy commodity. This is why gas is either produced as a by-product of oil production, or is produced from non-associated fields by firms whose primary business is oil. Thus, in addition to being correlated with gas reserve, natural gas production in a given country is also correlated with oil production (Figure 14 and Figure 15). The issue of ownership of gas production facilities is mingled with that of ownership of oil production assets, a highly political subject, since oil and gas are highly integrated upstream, especially in countries with mostly associated gas production (relatively high oil reserve with respect to gas reserve, see Figure 16). Also, because gas production is an extractive activity, the issues of mineral rights and their transfer need to be considered, especially when investments are motivated by potential revenues. 

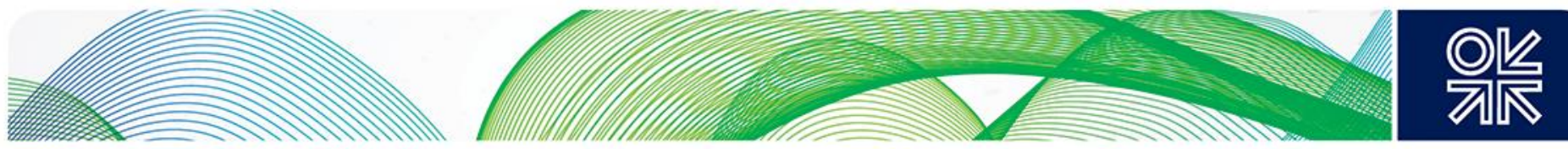

Figure 14: Correlation between world country gas production and oil production $\left(R^{2}=0.66\right)$

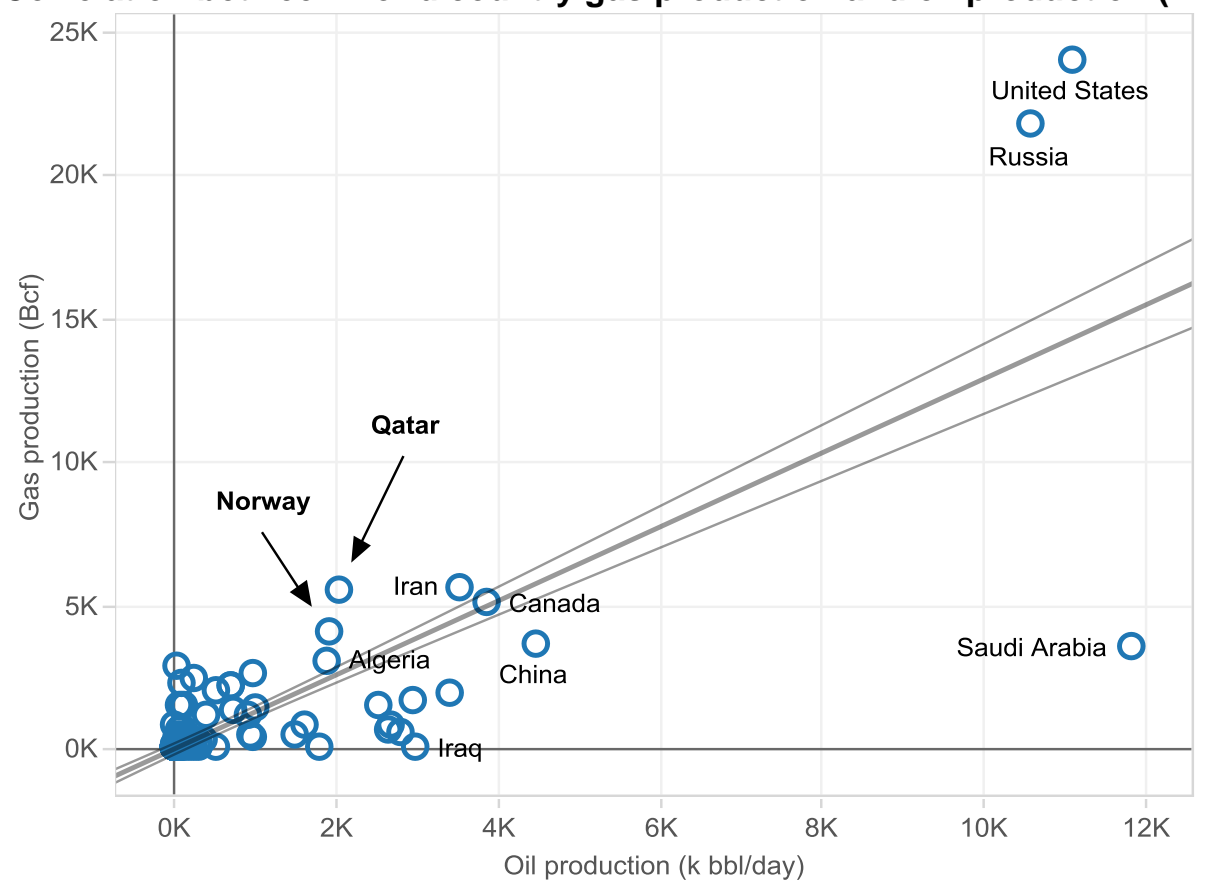

Source: Own analysis based on 2012 Data from EIA

Figure 15: Correlation between world country gas production and gas reserve $\left(R^{2}=0.53,0.78\right.$ after excluding the USA)

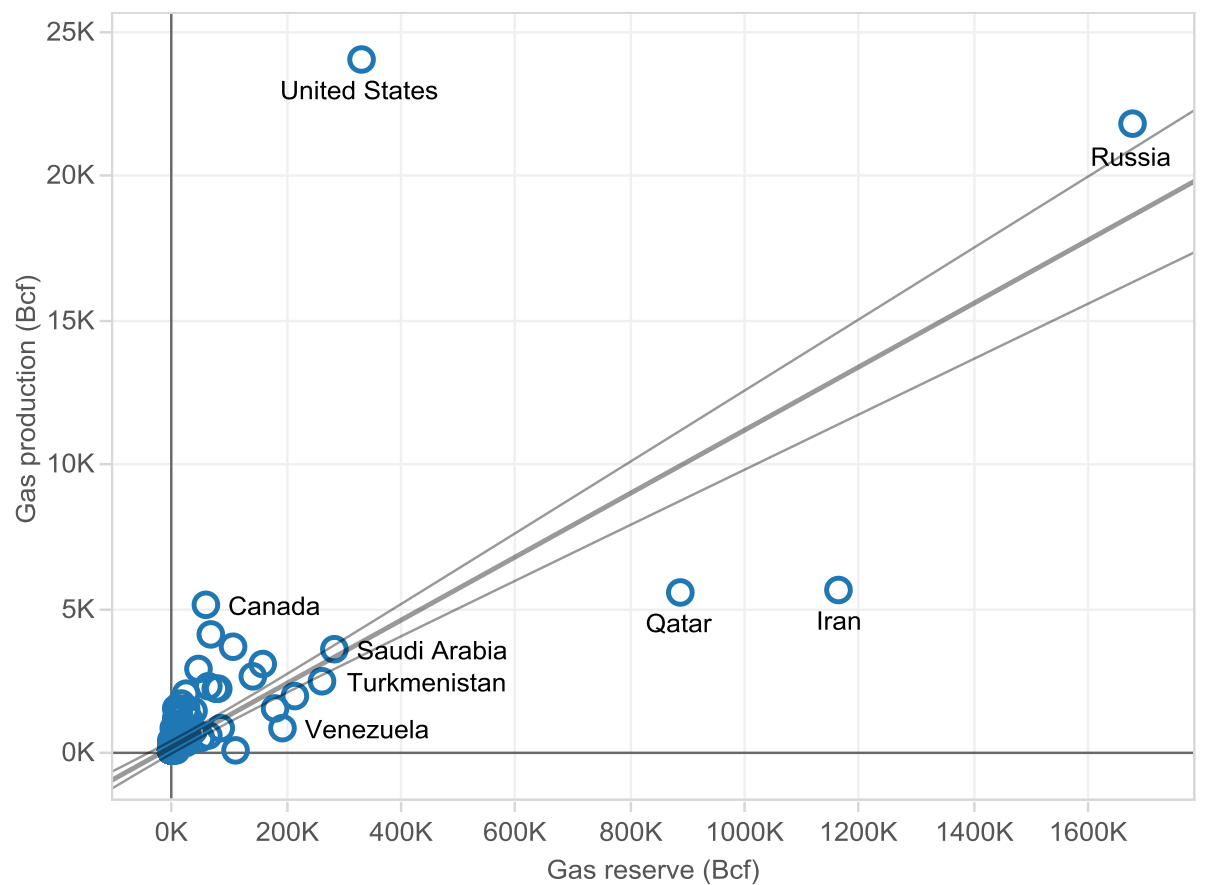

Source: Own analysis based on 2012 data from EIA

A holistic framework for the study of interdependence between electricity and gas sectors 

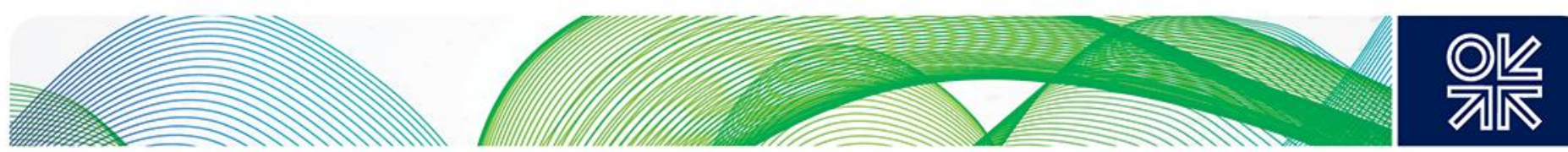

Figure 16: Correlation between world country gas reserve and oil reserve $\left(R^{2}=0.18\right)$

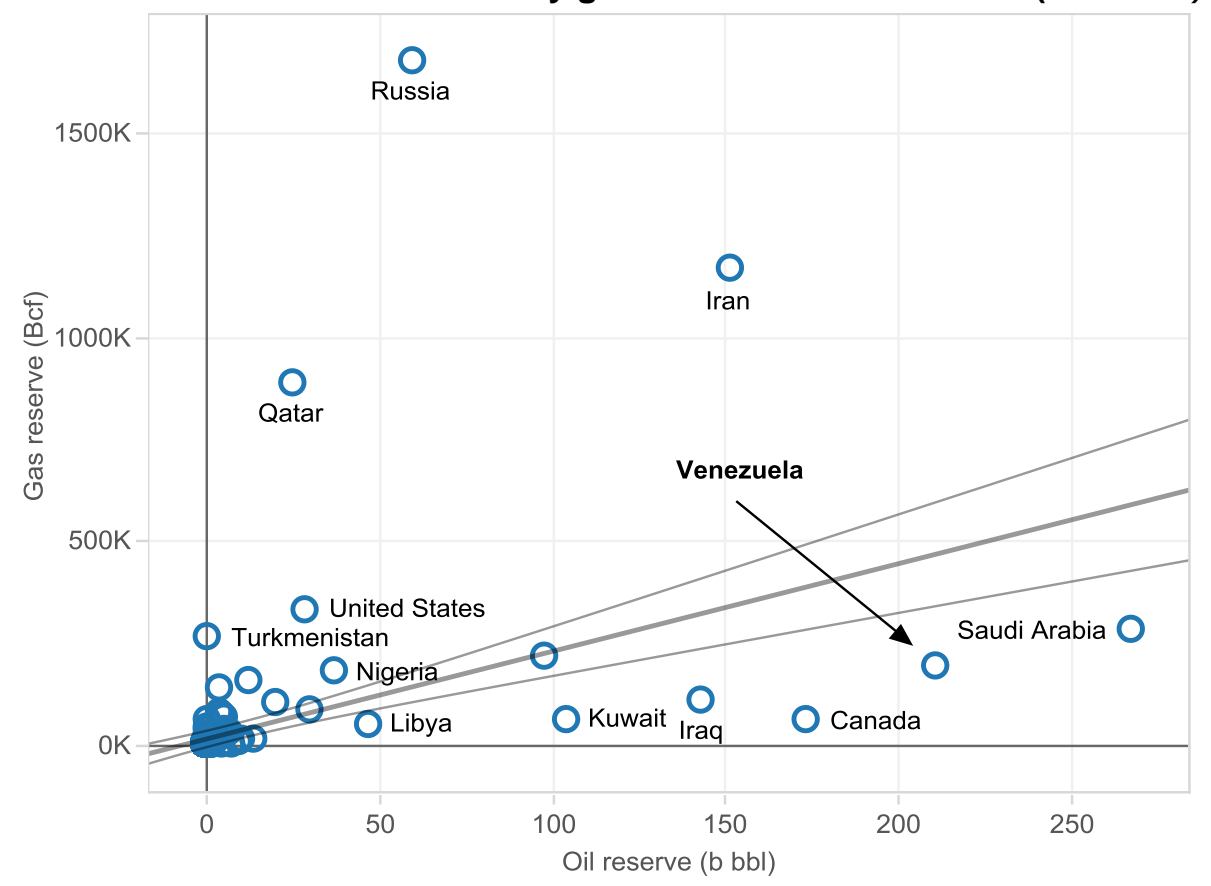

Source: Own analysis based on 2012 data from EIA

Within the fully centralized archetype, which also coincides with full integration with upstream oil, rights to natural gas and the production facilities are entirely owned by the nationalized petroleum company. Decisions within the oil (and gas) industry (both investment and operation decisions) are part of an overall policy to maximize contributions to the national mission to ensure the popularity of the government, and to generate oil-related revenues, often an important portion of the government budget (Warshaw, 2011). Due to the importance of oil to the world economy, in the case that the state-owned petroleum company can exert market power in the global market, it can use this ability as an instrument of foreign policy.

Within an entirely decentralized archetype, gas production facilities are owned by a variety of private companies, from vertically integrated international oil and gas companies to small-scale independent producers, seeking returns on their investments. Rights to minerals, including gas, are held by the owner of the surface; such rights can be transferred to gas producers through a lease ${ }^{3}$. Approval from the regulator is needed in the form of land use development permits and drilling permits.

For both scenarios, there are two pathways towards monetizing gas production: sales to domestic consumers for power generation, heating, or petrochemical production (given that local transmission and distribution infrastructure exists), or sales to other countries, bound by the availability of exporting infrastructure. If neither infrastructure exists, then gas is re-injected to enhance oil recovery or it is flared.

\footnotetext{
${ }^{3}$ United States is the only country that conforms to the decentralized archetype concerning the ownership of oil and gas rights. In all other countries, the central governments or monarchs own the mineral rights, not the owner of the surface land.
}

A holistic framework for the study of interdependence between electricity and gas sectors 

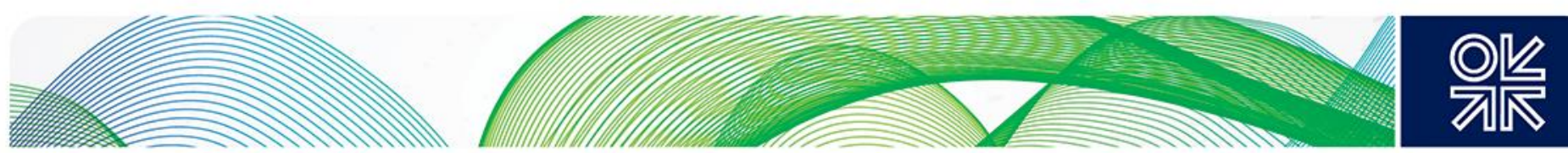

Table 11: Ownership structures for power generation and gas production facilities

\begin{tabular}{|c|c|c|c|c|}
\hline & \multicolumn{2}{|c|}{ Gas production facilities } & \multicolumn{2}{|c|}{ Power generation facilities } \\
\hline & $\begin{array}{l}\text { Complete } \\
\text { centralization }\end{array}$ & $\begin{array}{l}\text { Complete } \\
\text { decentralization }\end{array}$ & $\begin{array}{l}\text { Complete } \\
\text { centralization }\end{array}$ & $\begin{array}{l}\text { Complete } \\
\text { decentralization }\end{array}$ \\
\hline $\begin{array}{l}\text { Ownership of } \\
\text { energy vector }\end{array}$ & $\begin{array}{l}\text { Non-transferrable } \\
\text { sovereign ownership }\end{array}$ & $\begin{array}{l}\text { Transferrable } \\
\text { private/state ownership }\end{array}$ & $\begin{array}{l}\text { Procured from } \\
\text { upstream or N/A }\end{array}$ & $\begin{array}{l}\text { Procured from } \\
\text { upstream or N/A }\end{array}$ \\
\hline $\begin{array}{l}\text { Ownership of } \\
\text { facility }\end{array}$ & $\begin{array}{l}\text { State-owned } \\
\text { integrated petroleum } \\
\text { company }\end{array}$ & $\begin{array}{l}\text { Integrated O\&G } \\
\text { company, independents }\end{array}$ & Integrated utility & $\begin{array}{l}\text { Independent } \\
\text { owners }\end{array}$ \\
\hline $\begin{array}{l}\text { Proposal of } \\
\text { investment }\end{array}$ & $\begin{array}{l}\text { State-owned } \\
\text { integrated petroleum } \\
\text { company }\end{array}$ & Owners & Integrated utility & Owners \\
\hline $\begin{array}{l}\text { Approval of } \\
\text { investment }\end{array}$ & Various & Independent regulator & Various & $\begin{array}{l}\text { Local planning } \\
\text { authority }\end{array}$ \\
\hline Operation & $\begin{array}{l}\text { State-owned } \\
\text { integrated petroleum } \\
\text { company }\end{array}$ & Owners & Integrated utility & Owners \\
\hline $\begin{array}{l}\text { Investment } \\
\text { remuneration } \\
\text { scheme }\end{array}$ & $\begin{array}{l}\text { Domestic and export } \\
\text { sales }\end{array}$ & $\begin{array}{l}\text { Domestic and export } \\
\text { sales }\end{array}$ & $\begin{array}{l}\text { Integrated into the } \\
\text { approved tariffs }\end{array}$ & Sales \\
\hline
\end{tabular}

\subsection{Use of infrastructure - operation}

Now that the range of structures and investment incentives that exist across the extended gas-to-power supply chain has been established, the performance of the system - the efficient use of infrastructure to balance supply and demand, constrained by the infrastructure available and the coordination mechanism in place - can be examined. The long-term adequacy of investment in infrastructure, a factor that underpins shorter-term system performance, as a function of coordination mechanism and corresponding regulation, is also discussed.

In conventional supply chains, given a variable demand, several strategies are available to manage supply and demand:

- Level production: maintain constant supply, no matter the level of demand, the consequence being temporary shortage and surplus of supplied goods in stocks;

- $\quad$ Chase demand: exactly matching the level of supply to the level of demand;

- $\quad$ Demand management: adjusting demand to better match supply through measures such as price increase/reduction.

The chase demand strategy has been the operating tenet for the gas and power supply chains; this is because the consequence of level production (periodic shortages of energy provided) is not socially acceptable, energy services being considered as essential. Surplus of supply, stored in stocks, is also infeasible for power and gas industries, given the difficulty of storing the energy vectors. Finally, imbalances of gas and power supply and demand are detrimental to the network infrastructure used to deliver them. Historically, managing demand has been difficult for several reasons (Kirschen, 2003). First, most consumers operating power consumption devices are sheltered from changes in price at the timescale of their activity cycles (within a day and a week) by a flat rate, so any signal from the supply side does not reach them. Secondly, gas and power demand makes up only a small portion of the total cost of living or of the production cost of most industrial goods. Therefore, the demand for power and 

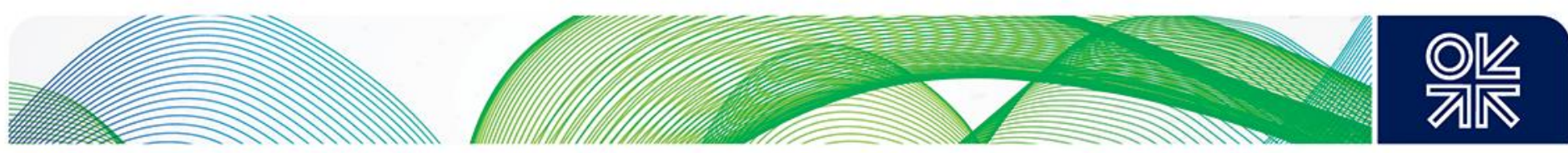

gas has very little responsiveness with respect to price. Finally, from the point of view of coordination, the control of supply is relatively centralized in the gas and power industries, whereas the control over demand is disaggregated, especially at the level of small users who are responsible for demand in the residential and commercial sectors; thus adjusting supply to demand has been logistically more manageable.

The remainder of this section is divided into two parts. The first part presents the external factors (the causes of imbalance) that lead to variations in supply and demand of power and gas, as well as the internal degrees of freedom that allow supply and demand to vary from a predetermined path (the sources of flexibility). The second part discusses the ways in which the sources of flexibility are utilized to accommodate the sources of imbalance, under different industrial structures, which implies that different methods are used to coordinate the sources of flexibility to react to imbalances.

\subsubsection{Causes of imbalance and sources of flexibility}

The mid to short-term variations present in the consumption of gas and electricity are tied to the energy services that these energy vectors provide. An important fraction of gas is used for space heating in many countries, and heating demand is directly related to the ambient temperature, which varies within a day and, more importantly, with the passing seasons. Temperature also affects electricity demand in countries with high adoption of resistive heaters and air conditioning units. Electricity demand, in countries where most aspects of society have been electrified, is highly correlated with the general activity level during any hour of the day, with troughs during the night and peaks during rush hours. As they are both involved in manufacturing, gas and power demand are also influenced by the weekday and weekend/holiday division. Important public events, broadcast live by mass media, are known to alter the electricity usage pattern of the general public. The degree to which gas and power consumption can be altered upon command is uncertain. From past and present experience, it is possible to reschedule some non-continuous manufacturing activities and some non-time-sensitive daily activities of households and businesses and this may be an important quantity when aggregated. These issues are summarized in Table 12.

Table 12: Demand-end causes of imbalance and sources of flexibility

\begin{tabular}{lll}
\hline Segment & Causes of imbalance & Sources of flexibility \\
\hline Gas consumption & Seasonal temperature cycle, weekly work cycle & Manufacturing schedule \\
\hline Power consumption & $\begin{array}{l}\text { Seasonal temperature cycle, daily activity cycle, } \\
\text { weekly work cycle, public events }\end{array}$ & Manufacturing schedule, daily activities \\
\hline
\end{tabular}

Many factors influence the mid to short-term variations in the supply of natural gas and electricity. The possible causes of supply-side imbalance, other than physical failure of infrastructure, are: declining productivity of gas fields as the reservoir approaches depletion, disruption of pipeline supply for nontechnical reasons, and the diversion of LNG supply away from its original route (enabled by flexible destination clauses). In the power sector, the most important cause of imbalance on the supply-side is intermittent renewable energy generation (Laughton, 2012).

The main supply-side sources of flexibility in the gas sector are: variable domestic gas production, pipeline contract swing volume (dependent on contract clauses), and additional gas procured through uncontracted import pipeline capacity, flexible LNG supply procured by diverting shipments from other routes and from the spot market, line-pack buffering capacity, and the use of gas storage facilities (IEA, 2002). The extent to which gas production can be varied depends on the operating philosophy of the producer and the characteristics of the field: gas production associated with oil typically has less flexibility, for the production policy is geared towards the optimization of oil production; gas production from mature fields may also have limited ability to vary due to the limited driving force that can be leveraged. Line-pack and the ability of storage facilities to absorb or deliver additional gas depend on 

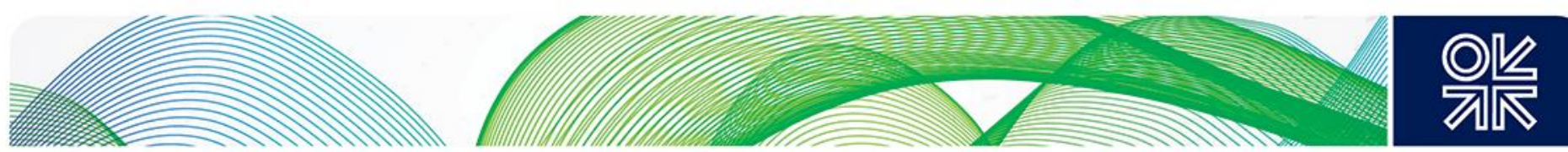

existing store of gas within the pipelines/storage reservoir. Flexible supply options are subject to the constraints set out in the import contract clauses (swing volume) and to the alternative commercialization opportunities available to the exporter. The main supply-side sources of flexibility in the power sector, a widely debated issue, are considered to be: the ability of thermal and hydro generators to ramp up/down from their existing generation level, indirect energy storage through pumped hydro facilities and other storage technologies, the curtailment of renewable intermittent production, and power exchange with interconnected grids. ${ }^{4}$ The flexibility of generation units to change their output depends on their existing state (on/off, current generation level with respect to minimum and maximum stable loads). The ability of PHES to absorb and deliver power depends on its maximum and existing capacity. The exact nature of cross-border flow is dependent on the coordinated actions of agents in both countries. In summary, the sources of flexibility within a system are relative and are dependent on the state of the system.

Table 13: Supply-end causes of imbalance and sources of flexibility

\begin{tabular}{|c|c|c|c|}
\hline Segment & Sub-segment & Causes of imbalance ${ }^{5}$ & Sources of flexibility \\
\hline Gas production & & Declining productivity of wells & Variation in production \\
\hline \multirow[t]{2}{*}{ Gas export } & Pipelines & & \\
\hline & $\begin{array}{l}\text { Liquefaction } \\
\text { terminals }\end{array}$ & & \\
\hline \multirow[t]{2}{*}{ Gas import } & Pipelines & Disruption of supply & $\begin{array}{l}\text { Dependent on pipeline contract clauses } \\
\text { and uncontracted pipeline capacity }\end{array}$ \\
\hline & $\begin{array}{l}\text { Regasification } \\
\text { terminals }\end{array}$ & $\begin{array}{l}\text { Dependent on LNG supply contract } \\
\text { clauses }\end{array}$ & $\begin{array}{l}\text { Dependent on LNG supply contract } \\
\text { clauses }\end{array}$ \\
\hline Gas T\&D & & & Allowable variation in line-pack \\
\hline Gas storage & & & Variation in injection and withdrawal \\
\hline \multirow{5}{*}{$\begin{array}{l}\text { Power } \\
\text { generation }\end{array}$} & Nuclear & & Limited variation in generation \\
\hline & $\begin{array}{l}\text { Coal and } \\
\text { biomass }\end{array}$ & & Allowable variation in generation \\
\hline & Gas & & Allowable variation in generation \\
\hline & $\begin{array}{l}\text { Hydro with } \\
\text { reservoir }\end{array}$ & & Allowable variation in generation \\
\hline & $\begin{array}{l}\text { Wind, solar and } \\
\text { run-of-river }\end{array}$ & $\begin{array}{l}\text { Intermittent renewable energy } \\
\text { generation }\end{array}$ & Curtailment of production \\
\hline Power storage & Pumped hydro & & Variation in pumping and generation \\
\hline \multicolumn{4}{|l|}{ Power T\&D } \\
\hline \multirow[t]{2}{*}{$\begin{array}{l}\text { Power } \\
\text { interconnector }\end{array}$} & $A C$ & & $\begin{array}{l}\text { Automated frequency regulation by } \\
\text { interconnected grid; energy trade } \\
\text { dependent on market coupling scheme }\end{array}$ \\
\hline & DC & & Dependent on market coupling scheme \\
\hline
\end{tabular}

\footnotetext{
${ }^{4}$ Most discussions on power system flexibility tend to focus on only one of the many elements included herein: flexible generation (Eurelectric, 2011); storage (Blarke \& Lund, 2008; Hedegaard \& Meibom, 2012; Loisel, 2012); demand response (Rosso, Ma, Kirschen, \& Ochoa, 2011); interconnectors (Neuhoff, Barquin, et al., 2013; Spiecker, Vogel, \& Weber, 2013). ${ }^{5}$ Physical failure is a possible cause of imbalance for all infrastructure, therefore it is not listed individually.
}

A holistic framework for the study of interdependence between electricity and gas sectors 

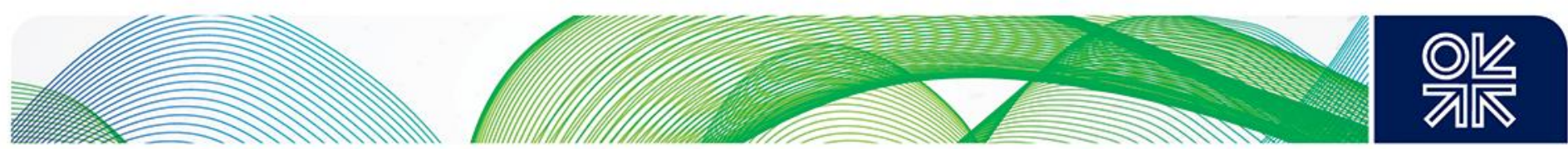

\subsubsection{Coordination mechanisms}

In order to counter the imbalances in supply and demand outlined above, it is necessary to have a short-term coordination mechanism that mobilizes all sources of flexibility, and to have sufficient investment in infrastructure to be able to provide such flexibility. The following section deals with these issues.

For the centralized archetype, most of the coordination decisions occur within organizations via administrative procedures. Information about the availability, variable costs, and technical parameters of the infrastructure assets required for coordination is centralized. There are relatively few entities involved in the supply of power and gas, and they are tied via long-term agreements that specify the exact terms of their coordination.

The national petroleum company, which manages the production of gas given existing capacity, makes operational decisions to dispatch the gas produced to export facilities and the national T\&D network. The allocation of available production, in the short term, is bounded by the contractual agreements in place with the downstream gas utility and importing countries. But, in the longer term the allocation of production between these two demands (domestic utilization or export) is contingent upon the national government's energy strategy.

The gas utility, in control of all gas storage facilities, pipelines, and midstream compression stations that exist in the country, is responsible, through internal decisions, for the balancing of the entire transmission and distribution network; it directs the flow of gas through the network given supply inflow and demand outflow at given nodes of the network. All domestic and imported supply, together with the sources of flexibility associated with their procurement, is at the disposal of the gas utility. Information about the operational state and technical constraints of all infrastructure assets is available to the utility. In the mid term, the gas utility needs to plan for the building up of inventory in large storage facilities, so that they can be used to accommodate prolonged higher levels of demand better than just relying on production swing.

The integrated power utility, which contracts gas from the gas utility at regulated wholesale tariffs, is similarly endowed with the knowledge of the states and technical parameters of all power generation, transmission, and distribution assets in its possession. It is responsible for meeting all power demand in the national system by dispatching the portfolio of generators at its disposal. In the mid term, the utility is also responsible for planning unit maintenance, procuring fuel for thermal generators, and for long-range coordination between thermal and hydro units with uncertain water influx. 

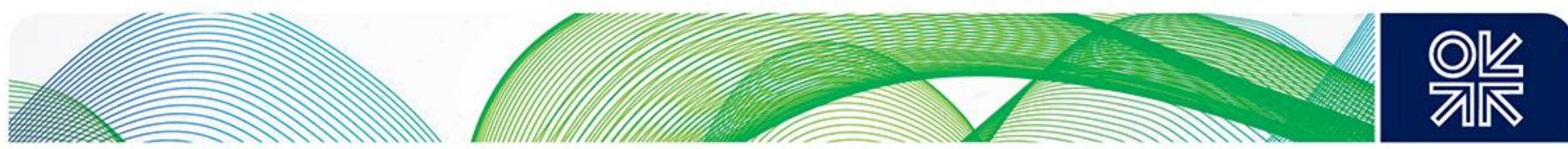

Figure 17: Long-term planning based coordination mechanism for centralized power and gas sectors

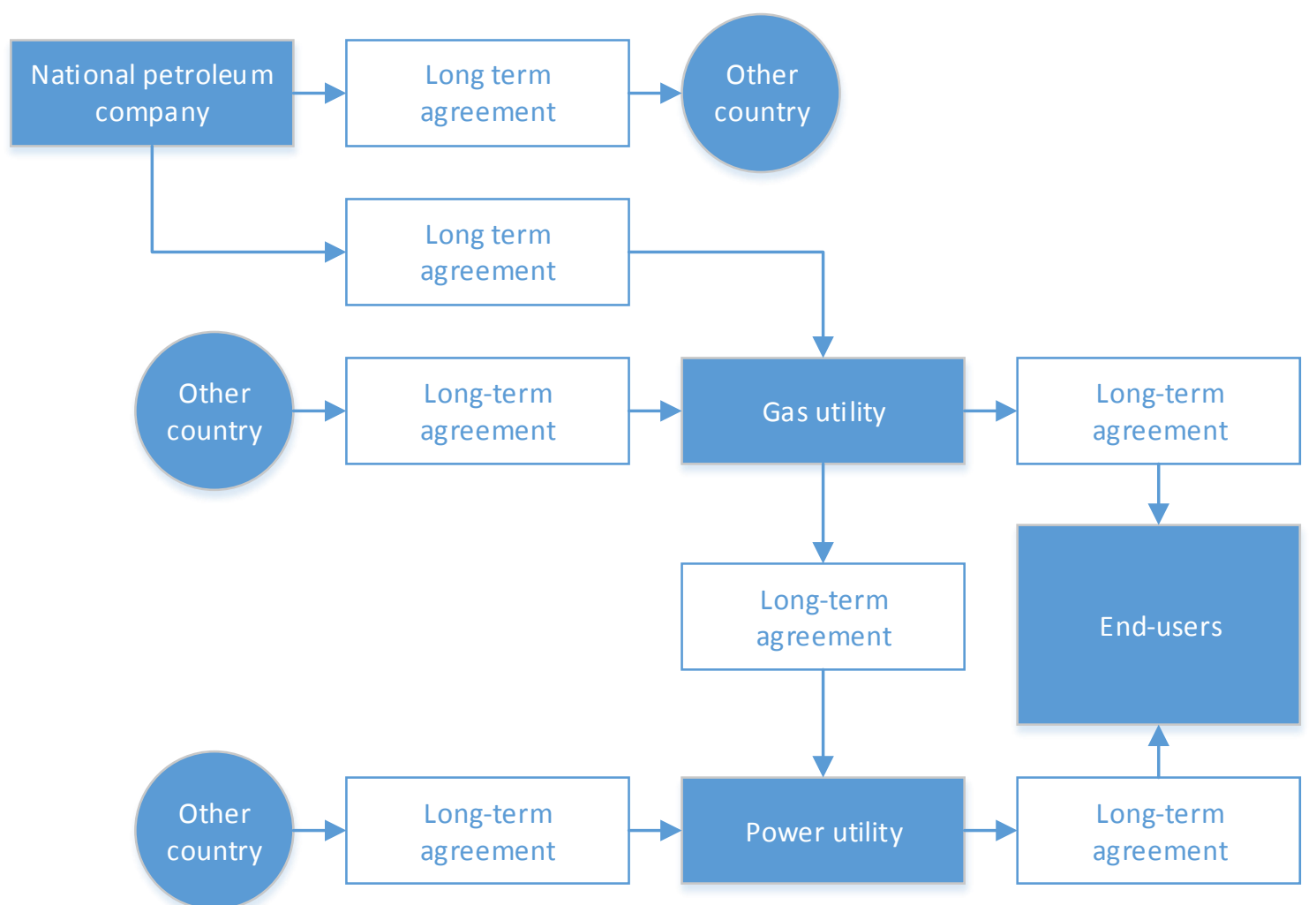

For the decentralized archetype, most of the coordination decisions occur as transactions between organizations. Information required for coordination is decentralized and is communicated as bids and price movements via market mechanisms. The number of agents involved in coordination mechanisms for decentralized power and gas sectors (Figure 18) is much more significant than in the centralized case (Figure 17).

Gas producers, integrated oil and gas companies operating internationally, or independent gas producers in the decentralized archetype, seek to commercialize their gas production in the gas forward and spot markets, or through long-term contracts. These commercial arenas can be domestic/regional or international, depending on the development of decentralization in other countries and the availability of export infrastructure. Depending on the arena, the conventional delivery point, delivery date, volume level, price level, and duration of the trade can differ. The counterparties that trade with gas producers are: gas suppliers, entities that procure gas to sell in the retail market to small consumers, or large gas consumers such as power generating companies. Trade between gas producers and pure shippers those mediating between gas producers and suppliers/large consumers, arranging for the transportation of gas between delivery point and city gate/consumption point - is also possible. Gas producers and gas suppliers/large consumers can also become shippers and arrange for the transport of gas through the transmission network by themselves. All gas shippers pay the owners of the transmission network according to their usage and a regulated tariff. They also participate in the balancing of the network at a particular point (physical hubs) or for a transmission zone with several entry/exit points (virtual hubs) together with the hub operator (physical hubs) or the transmission system operator (virtual hubs), to maintain it within acceptable pressure limits. The particular mechanism for gas balancing depends on the market design.

A holistic framework for the study of interdependence between electricity and gas sectors 

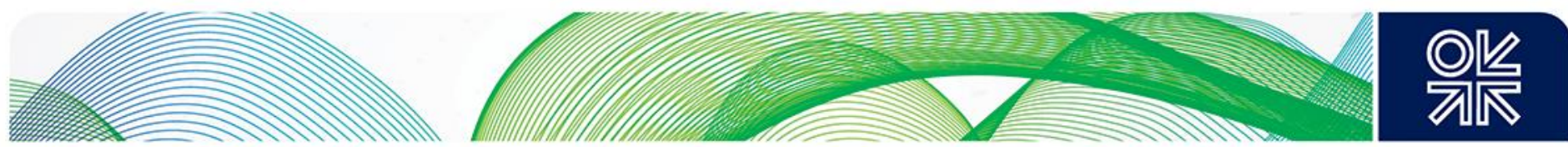

It is possible for any gas shipper to contract capacity with the independently owned gas import, export, and storage facilities. This can be done through a long-term contract or by shorter-term transactions on the secondary market, when those that hold long-term rights sell or sublet their rights. The owners of import, export, and storage facilities do not take possession of the gas that passes through their facilities; they charge fees for the services that they render, through mechanisms approved by the regulator.

In the retail market, small-scale consumers of natural gas enter into contracts with gas suppliers for gas to be delivered to their point of consumption. Suppliers make use of the distribution network and pay the gas distribution network owners for their usage according to the regulated tariff.

Overall, the decentralized power sector follows a similar organizational pattern to the decentralized gas sector, with the difference that the balancing coordination mechanism represents a greater technical challenge: the gas network only requires to be maintained within a range of pressure, while the power network needs to maintain frequency and voltage across the network within narrow margins of design specifications in order to be functional. Electricity needs to be balanced on a real-time basis. For balancing needs that cannot be contracted within the balancing markets - the variations in demand and pre-scheduled supply that occur within the minimal settlement period allowed on the balancing market - the transmission system operator needs to acquire further balancing services in the ancillary services market, where only select generators/large-consumers can tender for contract. Finally, the role of shipper is not necessary within the electricity market: the transportation of electricity within the network does not need to be, and cannot be, arranged; it only follows physical laws - travelling within the circuits whose parameters are carefully tuned by the system operator. ${ }^{6}$

The stage of development and the relative significance of a range of aspects of gas and power markets - long-term supply contracts (5-30 years duration), short term trades with varying delivery dates ahead of agreement (up to 3 years ahead), and primary and secondary sales of access rights to competitive import, export, and storage assets - are different for gas and power sectors in different countries, given the different degrees of decentralization and the time it takes for markets to mature. Other than the temporal differentiation mentioned above, power and gas markets can also be differentiated based on their level of spatial integration, depending on the accessibility of import and export infrastructure: crossborder and even longer-distance trade occurs if the foreign supply is deemed competitive after accounting for the cost of transport. Currently, global trade of natural gas occurs via LNG, regional trade of natural gas takes place in Europe, North America, and Asia. The bulk of electricity trade is still confined within national borders due to limited interconnector capacities, although there are some exceptions exist.

\footnotetext{
${ }^{6}$ In DC interconnector systems there is the possibility of control over direction of flows. In AC transmission there are experimental procedures, through FACT devices, to increase control over power flows.
}

A holistic framework for the study of interdependence between electricity and gas sectors 


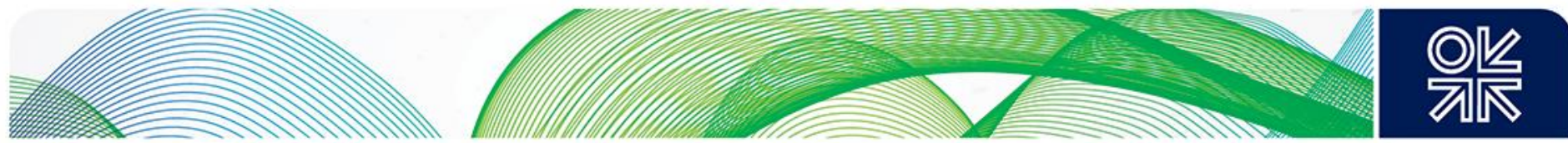

Figure 18: Market-based coordination mechanism for decentralized power and gas sectors

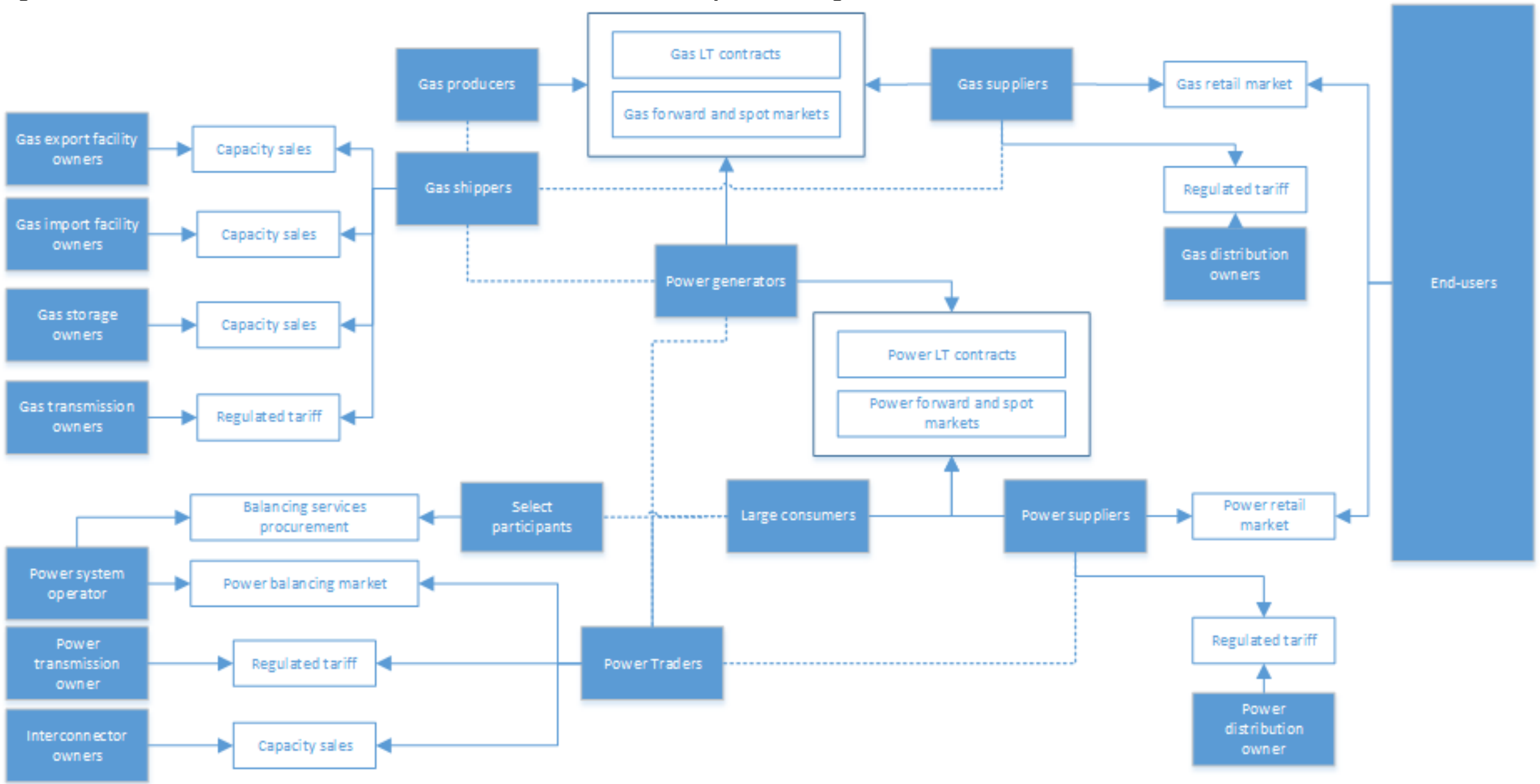



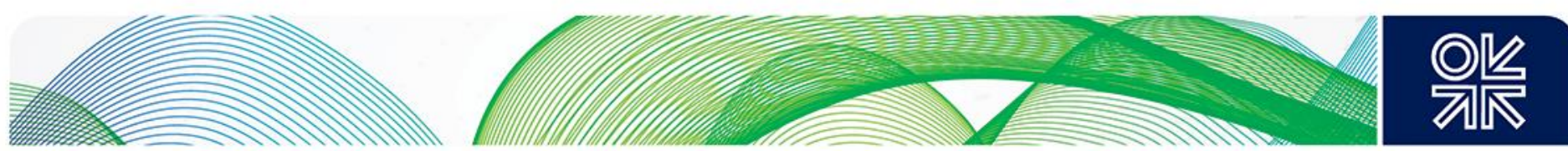

Not all sources of flexibility are equal. The degree to which various sources can be used to accommodate variations in other part of the supply chain is limited by their ability to respond, driven by technical and commercial determinants, and the costs for doing so (Table 14). If the coordination mechanism employed leads to economically efficient results, then the sources of flexibility would be dispatched based on their marginal cost (from the least costly to the most costly) unless overwritten by technical and commercial constraints. For sources of flexibility for which spatial and temporal arbitrage is possible (supplying power or gas in another spatial market or delivering energy at a different time), the marginal cost that should be considered is the opportunity cost. Under both the centralized and the decentralized archetype, the dispatch of sources of flexibility to counterbalance causes of imbalances is part of the day-to-day operation of the gas and power sectors, with the difference that under the decentralized archetype, the coordination is achieved within markets, not administratively within the same integrated utility. Thus, short-term market dynamics, mainly in the form of price fluctuations, are fundamentally affected by the sources of flexibility and imbalances involved, accessible via the existing infrastructure (Staffell \& Green, 2015; Timera Energy, 2013). Long-term evolution of market price (the annual moving average price, rather than highly volatile daily or hourly prices), is dependent on the underlying long-term supply options and end-user demand, embodied in the change in supply and demand infrastructure. 

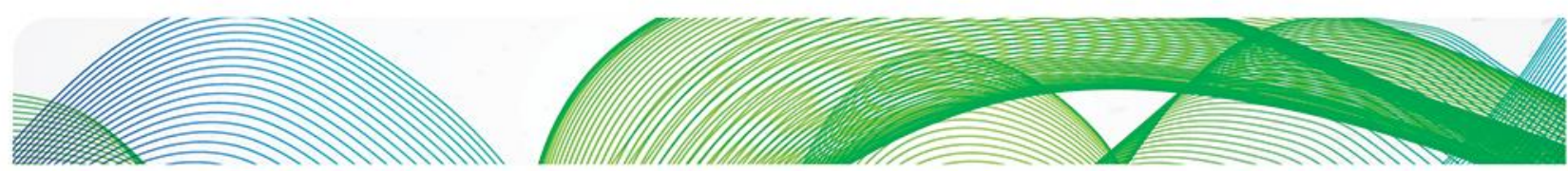

Table 14: Responsiveness, availability and delivery/uptake rate for various sources of flexibility

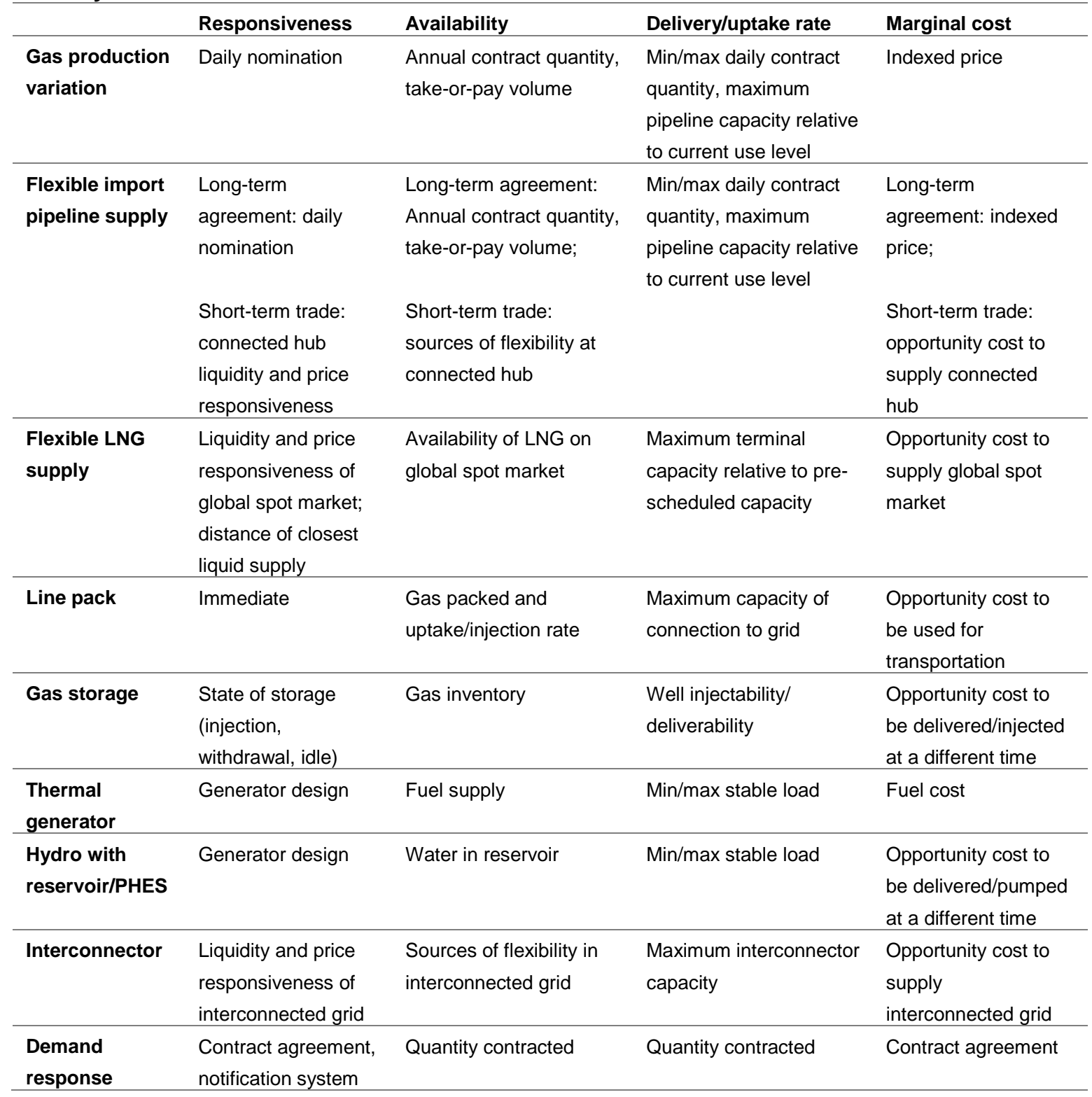

\subsection{Performance and regulation}

The performance of a country's power and gas industries has multiple dimensions - physical, financial, economic, environmental, and social, to name but a few. In the framework proposed, change is brought about by the industry and the government through firms' behaviour and government regulation (Figure 5). It is suggested that the particular measures that each party decides to adopt depend on the deviation of current performance (or even of forecast performance) from the goals of the industry and government, among options available to them, given limitations due to industry structure and the regulatory regime in place. Approaches based on game theory, which have long been used to study competition and cooperation between companies, can also be used to study the complex interaction

A holistic framework for the study of interdependence between electricity and gas sectors 

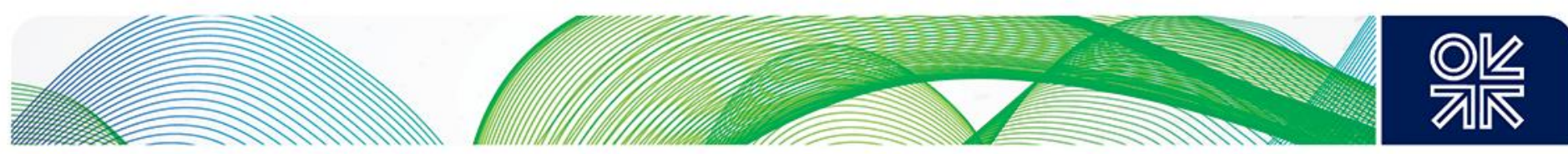

between the regulator and firms, and the resulting performance (Gilbert \& Newbery, 1988; Shaton, 2014). The following sections discuss common regimes for the centralized and decentralized archetypes, as well as the objectives of the agents involved, and provide examples of the dynamics of industry/government regulation.

\subsubsection{Regulatory regimes}

The pattern of industry and government objectives is fundamentally tied to the ownership structure of the sector. In the case of state-owned companies, the objectives of the industry, to a great extent, converge with those of the national government. It follows that, within the decentralized archetype, the objectives of the industry are dependent on the companies that constitute it - these objectives are separate, and sometimes opposite from, the objectives of the national government. The regulatory regime in place in each of these archetypes reflects this difference.

The regulatory regime for the centralized archetype is an administrative supervisory relationship between the government branch responsible for energy (dedicated or subsumed within commerce and industry) and the state-owned companies. The regulatory body's role is to approve the overall tariff, to design the structure that allocates the costs of energy provision among different sectors of the society, and to set objectives for the industry (economical and/or political).

Given the porous boundary between the industry and the government under the centralized archetype, governmental goals are, explicitly or implicitly, specified by the state for the industry. Within the context of the gas and power sectors, this objective is most commonly operationalized as the meeting of gas and power demand at least cost. Depending on the political independence of the state-owned companies, state ownership might mean that such companies are often faced with political pressures to pursue objectives other than social welfare optimization (Wolak, 2014).

Within the decentralized archetype, the ownership of the industry is dispersed among many different agents, large and small. Publicly-owned companies might or might not be present; but even in the case that they are, they are likely to embrace the raison d'être of private companies, that of maximizing the generation of economic value to shareholders. This objective is commonly operationalized as maximizing risk-adjusted return upon investment, but other operationalized goals are also possible, based on the company strategy (for example: market share maximization, growth maximization, and environmental impact minimization).

In the regulatory regime for the decentralized archetype, the government, via the activities of several regulation authorities, interacts with the many companies that form the gas-to-power supply chain. Typical institutions include: the ministry concerned, a regulatory authority more or less independent from the ministry, and the competition authority. Primary legislation exists to grant regulatory authorities the power to design and enforce secondary regulation and to set forth the standards with which such regulation needs to conform. The regulatory authorities, on behalf of the government, are responsible for:

- the day-to-day monitoring of the structure of the industry (ensuring, for example, that it is sufficiently decentralized to allow competition),

- the coordination occurring within markets (ensuring, for example, that market behaviour conforms to the behaviour of an efficient market and is compliant with secondary regulation), and

- the industry performance (ensuring that it conforms to government expectations).

They are also responsible for enforcing the regulations in case of infringement. 

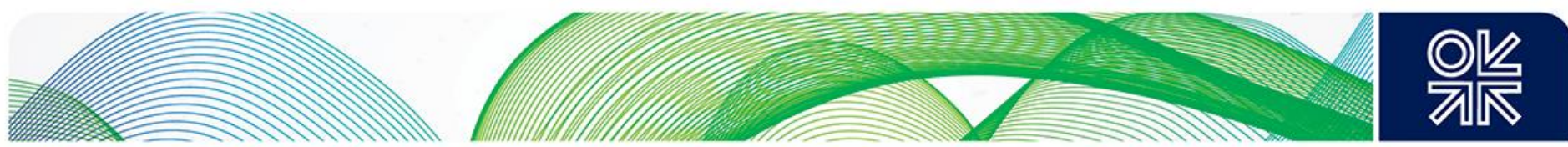

\subsubsection{Dynamics of regulation}

The interaction between government regulation and industry self-regulation is relatively simple for the centralized archetype, because the effect of government regulation over industry behaviour is direct. The available government regulation tools are: the design and approval of the regulated tariff and the direct setting of industry standards (the so-called 'command and control approach'). In terms of selfregulation, an integrated utility uses operational and investment decisions for all infrastructure assets within its possession to regulate its own performance, according to objectives that the government has specified and according to its own organizational objectives (such as operational and investment cost recovery/revenue maximization).

Within the integrated utilities, state-of-the art operational and investment decisions are supported by optimization models and multi-criteria decision-making methods (Sánchez Dominguez, 2008). Their operational decisions are based on short-term demand forecasts, and the known status and costs of the infrastructure in place. Their investment decisions are based on their expectation of operational needs in the future, given increasing/unmet demand and the obsolescence of existing infrastructure. Uncertainty in operations and planning is relatively controlled, especially if cost-based regulation is used. Most information required for such optimization - operation schedule for planned expansion, technical parameters for installed infrastructure, expected demand - is known by the utilities from their activities throughout the supply chain. Also, uncertainty has little impact upon organizational revenues, for the exogenous changes in production/purchase cost of fuel are passed on to the end-users through the regulated tariff, as long as the method of tariff calculation is maintained constant.

The main dynamics in regulation for the centralized archetype are the interactions between government objectives, industry objectives, and the regulated tariff that mediates among them (Figure 19). The dynamics mentioned here apply to vertically integrated utilities and regulated monopoly segments in a decentralized supply chain.

\section{Figure 19: Regulation dynamics for the centralized archetype}

A) Cost-based regulation

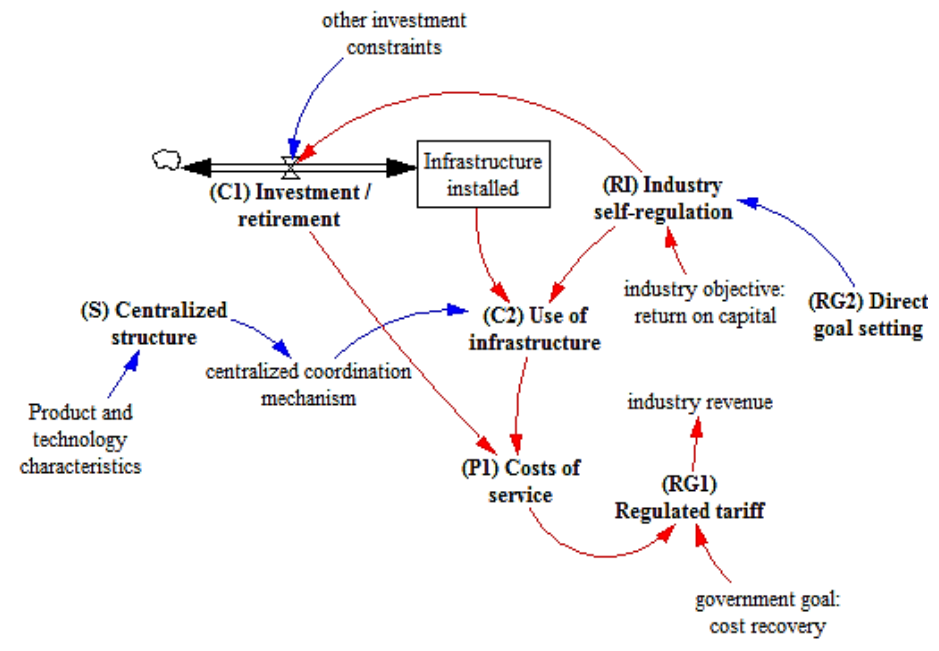

A holistic framework for the study of interdependence between electricity and gas sectors 

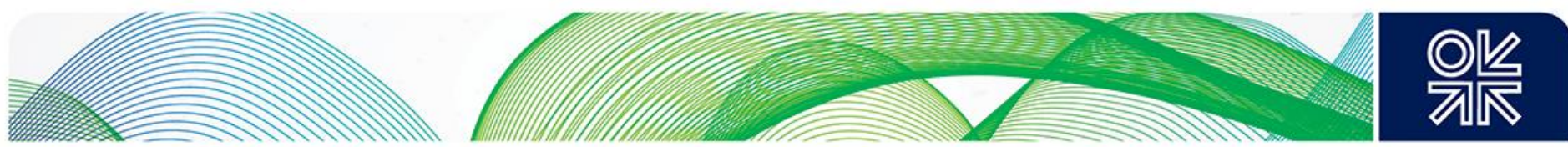

B) Incentive regulation (revenue cap)

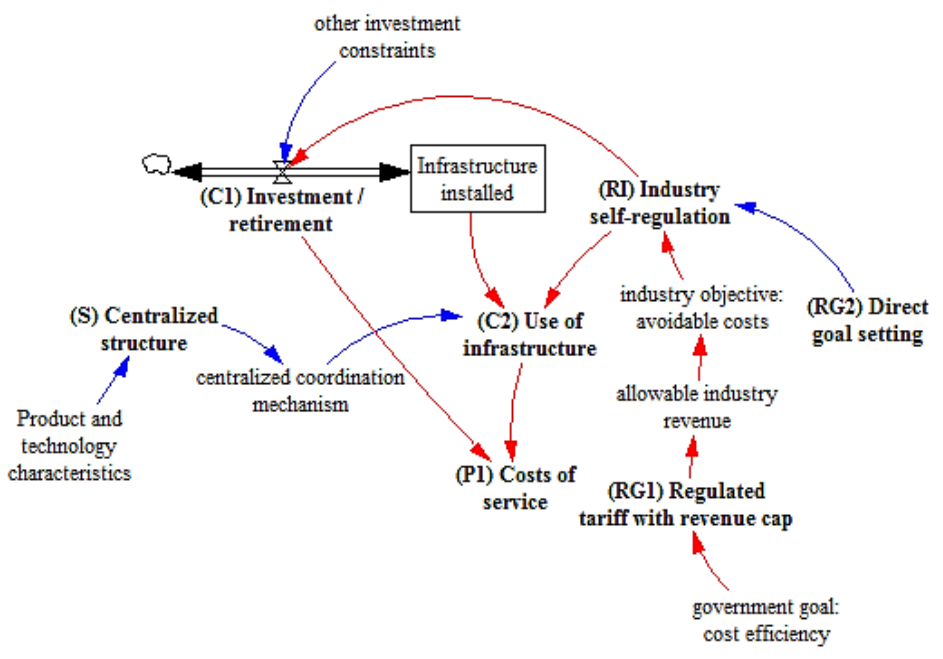

If the operational and investment costs incurred for meeting government-set objectives are fully passed on to end-users via the regulated tariff, determined ex post (cost-based regulation), management selfregulation might not be driven to meet these objectives at the least cost, because cost recovery is ensured. In the case that the rate of return from investment is guaranteed, it has been observed that integrated utilities invest more than is economically efficient to meet performance objectives, in order to increase their own returns (the Averch-Johnson Effect).

To address the lack of incentive for cost efficiency facing the integrated utility, incentive regulation can be adopted - a widely practised example being a revenue cap. In this case, the regulator determines the regulated tariff ex ante, setting a cap on the maximum allowable revenue to be recovered through the tariff; this incentivizes the integrated utility to decrease all avoidable costs while meeting government-set objectives. Another variety of incentive regulation also connects government-set objectives to the regulated tariff through rewards and penalty (performance-based regulation).

The main challenges for the government regulator, if an active role is pursued via the application of incentive regulation, is in the determination of any revenue cap and the rewards/penalties associated with performance objectives. This is because there is information asymmetry between the regulator and the integrated utilities concerning the costs of providing power and gas efficiently. But, it can be (partially) overcome through repeated games (regulator audits the costs ex post and makes adjustments), benchmarking costs, and other performance parameters with comparable utilities (yardstick competition).

Within the decentralized archetype, the possible range of self-regulation measures available to industry firms to meet their own objectives is much wider: first of all, private companies have the option of entering or exiting all competitive segments of the gas-to-power supply chain. In addition, operational decisions of the firms include bidding to trade in the many different power and gas wholesale and balancing markets and bidding in derivative markets (not shown in Figure 18, because power and gas derivatives are financial instruments used to hedge risk rather than to coordinate physical delivery). In the longer term, the firms evaluate and finance infrastructure investment and manage long-term contracts. 

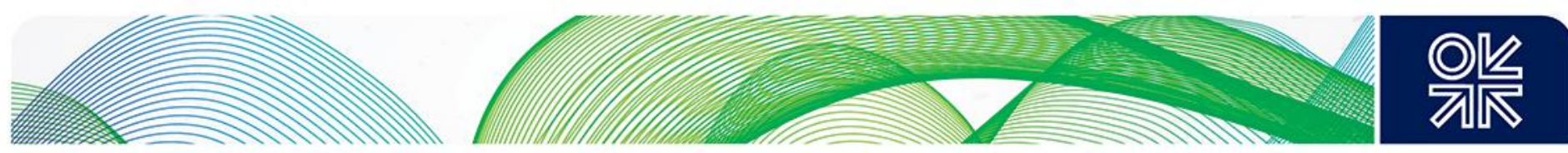

Privatization and liberalization change the mechanisms of influence at the state's disposal, but the state remains a major player, just as within the centralized archetype (Helm, 2002). The moves that regulatory authorities adopt, in a pure decentralized archetype, are those that promote effective competition by addressing market failures in the form of imperfect competition, imperfect information, and externalities. Within the power and gas sectors, this means:

- unbundling and regulation of the network (natural monopoly) segments of the gas and power industry,

- liquidity and competitiveness checks for other segments,

- provisions to correct information asymmetry between suppliers and consumers, and

- internalization of negative and positive externalities resulting from the gas-to-power supply chain.

The main dynamics in regulation for the decentralized archetype are harder to track, because the impact of government regulation is on the competitive environment (industry structure and coordination mechanisms), which eventually trickle down to change industry behaviour by realigning them with respect to industry objectives. It needs to be noted that, within the decentralized archetype, the coordination of infrastructure use to meet demand is achieved mainly via information conveyed through price movements in the markets. Therefore, the information required for evaluating operational and investment decisions - expected price in the particular market(s) and the level of use of the asset - is uncertain for firms, varies according to coordination occurring in the markets, and estimated based on knowledge of the markets in which they participate (Weron, 2014). Uncertainty, and its impact on return upon operations and investment, is an important consideration for industry agents within the decentralized archetype, for they alone are responsible for the risks associated. Government regulation design in the decentralized archetype requires even more care than in the centralized archetype, both in substance and in delivery method, because it not only impacts the perceived profitability of different industry conduct, it also affects its risk profile. ${ }^{7}$

The main challenge for the government regulator among its four key concerns has been the internalization of market externalities. An example is given to illustrate the application of market-based government regulation: the internalization of negative externalities from sulphur dioxide emissions through tradable permits (Figure 20). This is arguably one of the most successful cases of implementation of market-based instruments and it has provided inspiration for other environmental trading programmes (Burtraw \& Szambelan, 2009). Despite its success, however, close examination of the $\mathrm{SO}_{2}$ cap-and-trade programme reveals that the outcome of the policy was dependent on the unintended consequences of other policies (positive interaction: effects of rail deregulation; negative interaction: state and source-specific emission constraints), and that politics trumps science and economics, in most cases, in setting targets for even market-based mechanisms (Schmalensee \& Stavins, 2013).

7 For this reason, the entire framework has avoided using the term 'deregulated' to refer to the decentralized archetype.

A holistic framework for the study of interdependence between electricity and gas sectors 

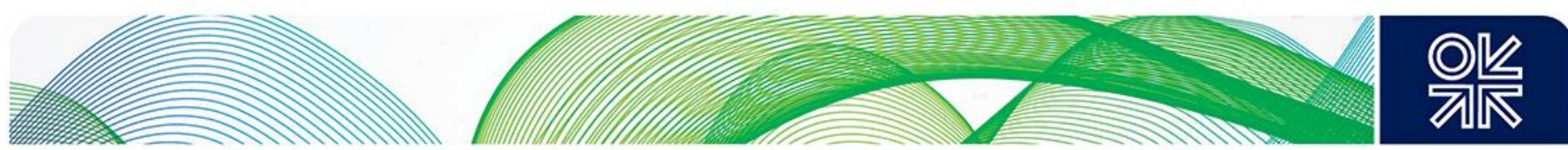

Figure 20: Example of regulation dynamics for decentralized power sector

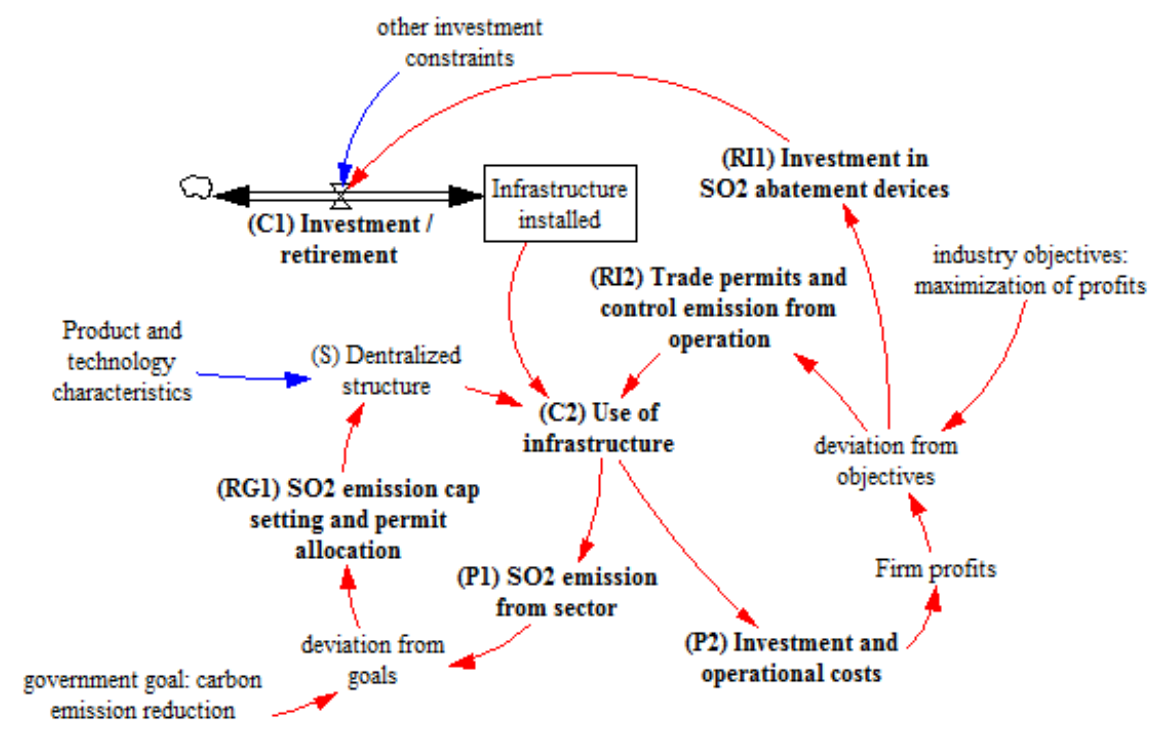

So far, the discussion of regulation dynamics has been confined to the two theoretical structural archetypes. However, as mentioned when the two archetypes were first introduced, structural reform itself is one of the most important tools that a government can adopt to regulate the gas and power industry, based on its ever changing energy agenda and bound by its historical and cultural context. And, as the exact structure of the power and gas industry in a given country can be a hybrid, the government regulation adopted can also be a mix of command-and-control approaches with marketbased mechanisms which, together, result in increasingly complex interactions.

An example of these complex regulatory interactions is the case of the merit-order effect in Germany. Germany is a country with developed electricity forward and spot markets. In 2000, 62.3 per cent of its power generation fuel was of fossil fuel origin, with 33.2 per cent coming from nuclear energy, and only 4.4 per cent from renewable energy (RE) resources. By 2012, the contribution of renewable energy resources to power generation input had increased by 12.4 percentage points to 16.7 per cent, compared to an increase of 2 percentage points within the period 1990-2000(IEA, 2013a). The rapid increase in use of renewable power generation technology has been promoted by fixed feed-in tariffs (FiTs) guaranteed for a period of 20 years, motivated by the government's goal of achieving 80 per cent renewable energies in electricity supply by 2050 (Leepa \& Unfried, 2013). The market-based procurement of electricity in Germany is illustrated in Figure 21, and the mechanism by which FiT 

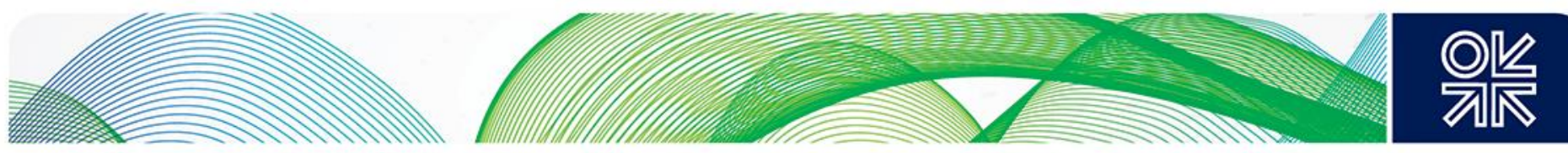

Figure 21: Market-based supply of electricity in Germany

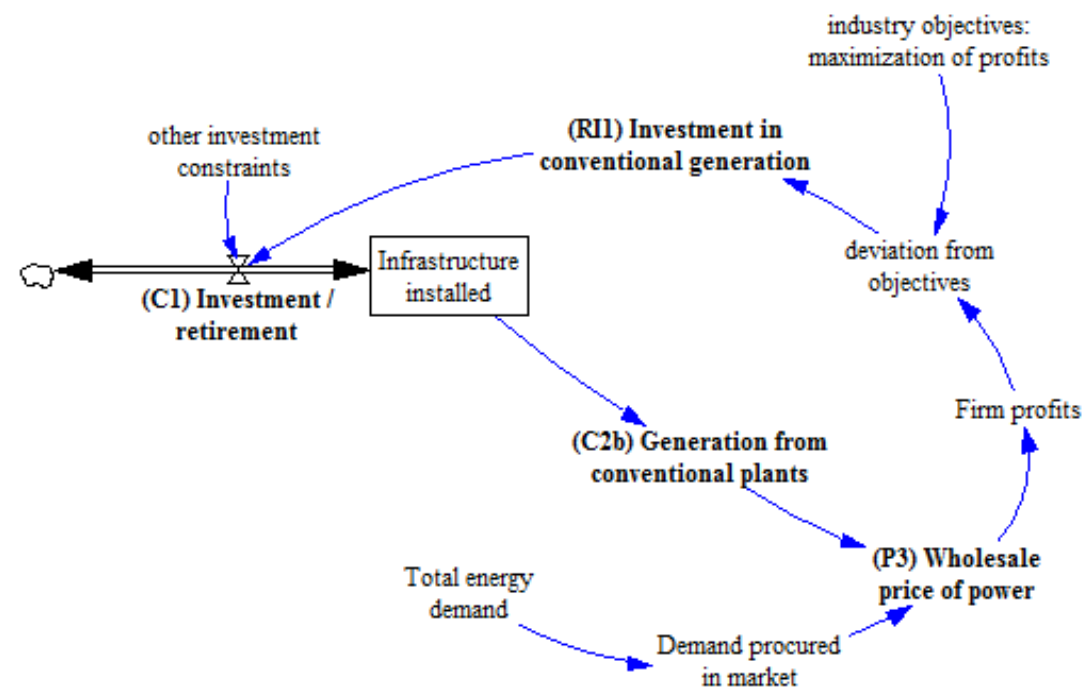

Figure 22: FiT incentive for RE generation in Germany

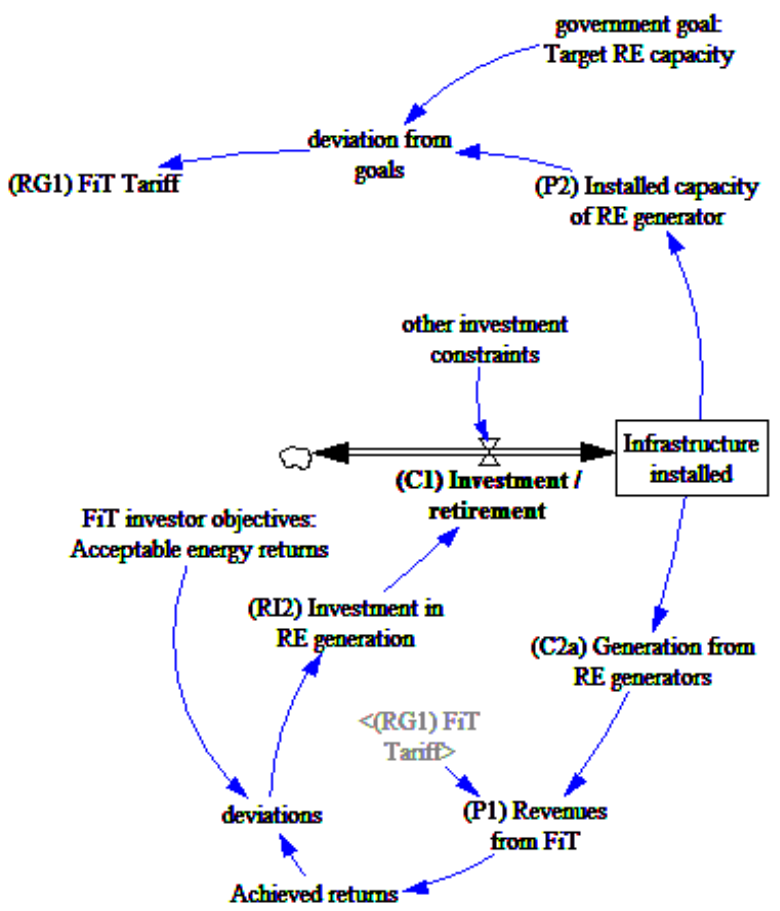

However, what was not anticipated when FiT was first designed was its effect over the wholesale power market price; this is now known as the merit-order effect, and it has since been observed and quantified in the research literature (Cludius, Hermann, Matthes, \& Graichen, 2014; Sensfuß, Ragwitz, \& Genoese, 2008; Tveten, Bolkesjø, Martinsen, \& Hvarnes, 2013). By design, German grid operators are required to buy electricity generated by specified renewable energy sources under 20 year-long FiT

A holistic framework for the study of interdependence between electricity and gas sectors 

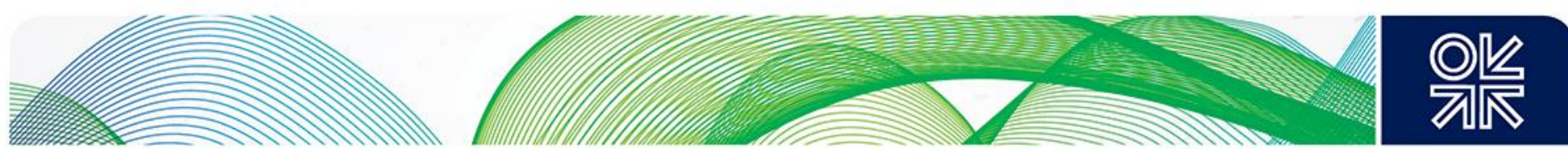

contracts; the electricity is then sold to suppliers according to their market share on the day-ahead market. The payments to the FiT contract owners are passed on to the end-user through the suppliers. Given that the suppliers are mandated to uptake the electricity from RE generators with FiT contracts, the supply of electricity that needs to be sourced to meet the remaining load, through the day-ahead market, is decreased. The reduced demand in the market, for a power system that has a positive sloped supply curve (increasing marginal cost), leads to lower wholesale prices. The reduction in price is particularly high for peak hours, since solar generation peaking during the afternoon decreases the relative scarcity in the system, reducing the scarcity markup that otherwise would have resulted (Sensfuß et al., 2008, fig. 3). The lowered market price has two implications: firstly, it lowers the profit margins of conventional generation capacity operators, decreasing their inclination to invest in such technologies; secondly, the lower price is not passed on to all electricity consumers, as the retail price of electricity is boosted by the surcharges required to fund the FiT payments. Thus, new generation investment, instead of coming from the owners and operators of conventional generators, is levied from power consumers. The combined effect, consolidating the views from the two figures above, is shown in Figure 23.

Figure 23: Interaction between FiT and power prices in Germany

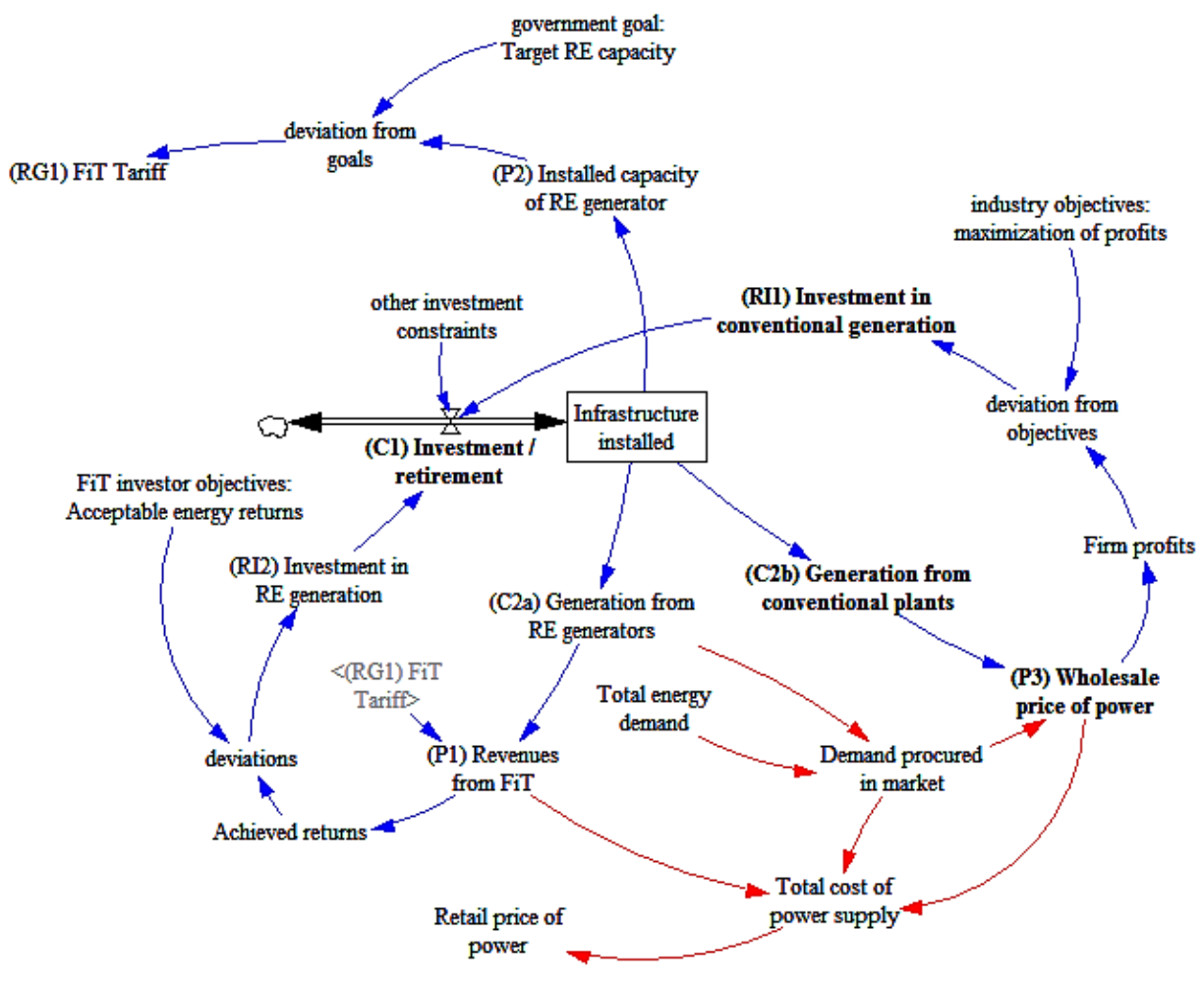

Interaction among support systems for electricity from renewable energy sources, between the RE support schemes, and the EU Emission Trading Scheme (EU-ETS), have been described (del Río González, 2007; Fischer \& Preonas, 2010; Rathmann, 2007). This evidence supports the view that greater consideration needs to be given to the interrelationships among regulatory instruments, which are increasingly complex. 

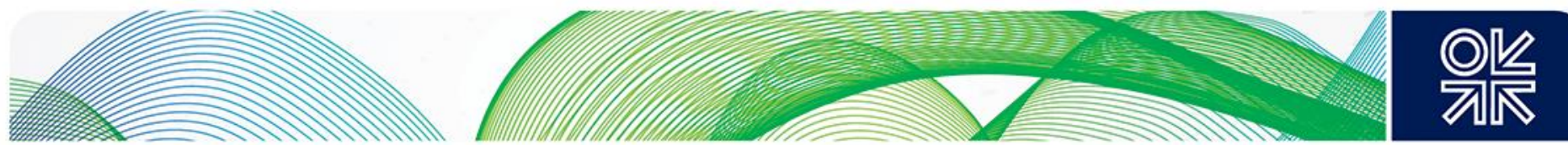

\section{4. $\quad$ Case study of the UK}

The structure of this case study follows that of the framework. Firstly, the existing state and historical development of natural gas and electricity use in the UK are reviewed, with a focus on the following points: the scale of gas and electricity use in the UK's entire energy system, the country's selfsufficiency with respect to natural gas, and the role of natural gas in its power generation. Secondly, the ownership structure of the UK's gas and power industries is identified. Following that, the maturity of the country's supply chain infrastructure and the available coordination mechanisms are assessed. The performance of the UK's gas and power industries, the industry/government agenda, and the interaction of their regulatory activities are then discussed. Finally, the insights that this analysis provides over the interdependencies and future of the UK's natural gas and electricity supply and demand are summarized at the end of the case study.

\subsection{Historical development}

Today, in the UK, a blend of domestically supplied and imported petroleum (oil and its derivative products), gas, and electricity form three pillars that supply the final energy use in the country (Figure 24). Between 1970 and 2013, solid fuel (defined as coal and its derivatives) continued to see its final use outside of electricity generation diminish. The share of energy supplied by petroleum has also fallen. It has withdrawn from all sectors except for transportation, which consumes 86 per cent of all oil supplied.

\section{Figure 24: Final energy consumption by fuel, 1970 to $2013^{8,9}$}

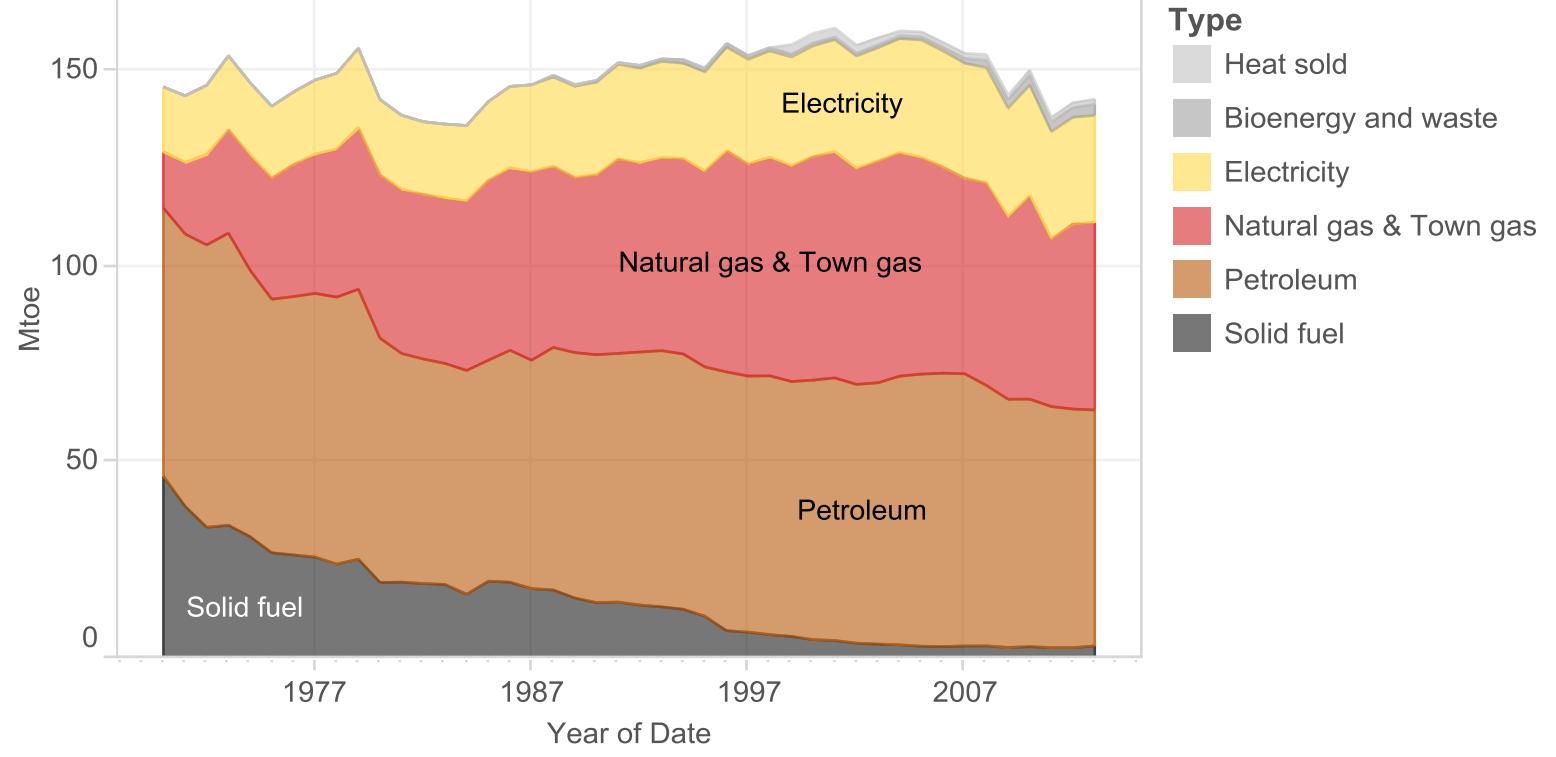

Source: Own analysis based on DECC data

\footnotetext{
${ }^{8}$ Primary fuel consumed for electricity generation is accounted for under 'electricity'.

${ }^{9}$ The use of town gas was marginal in 1970s, ending completely in 1979. Its exact quantity can be seen in Figure 27 , as gas supplied from other sources.
}

A holistic framework for the study of interdependence between electricity and gas sectors 

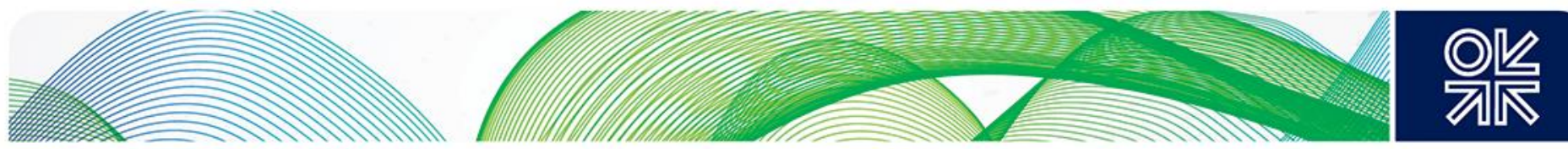

Natural gas has been the UK's most important primary energy source since 1996. Its current share represented 35 per cent of total supplies in $2013 .{ }^{10}$ During the 1970 s and 1980 s, gas consumption by the domestic and service sectors increased steadily. Then, from the early 1990s until 2000, the 'dash for gas', a sudden rise in gas-fired power generation (under industry use) drove up total gas consumption rapidly (Figure 25). Consumption by the service sector also picked up pace during this period. The year 2004 marked the beginning of decline in total gas consumption, registering consumption declines in all sectors, but the decline within the industrial sector began before that.

Figure 25: Primary natural gas consumption in the UK and changes in sectoral use

Primary consumption of natural gas

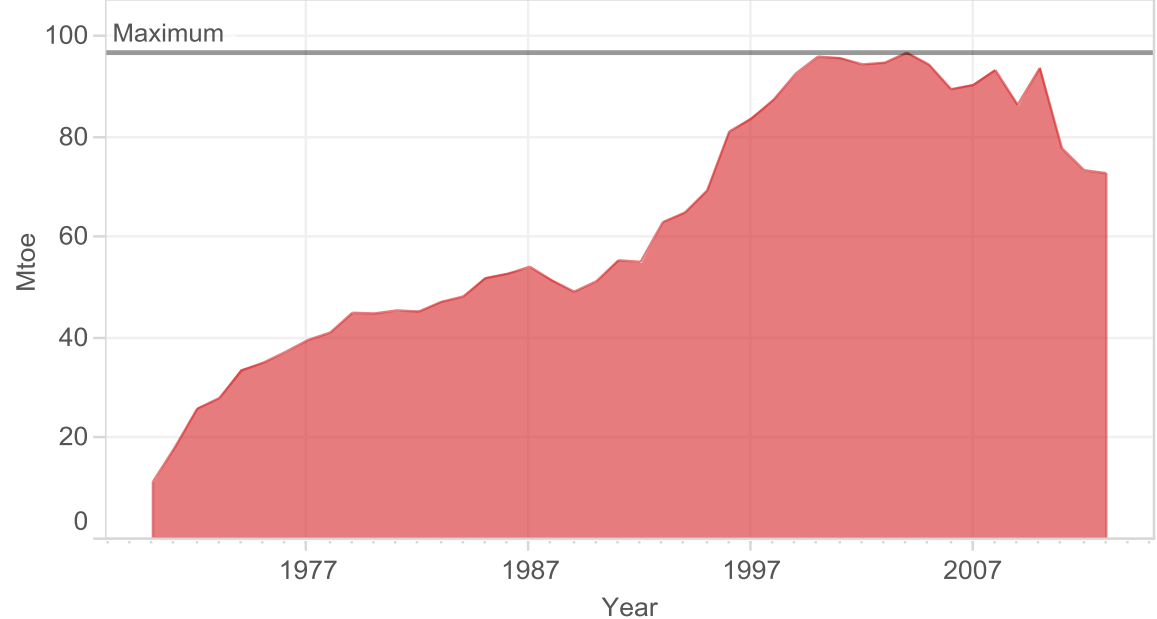

$\%$ Change in primary consumption of gas by sector

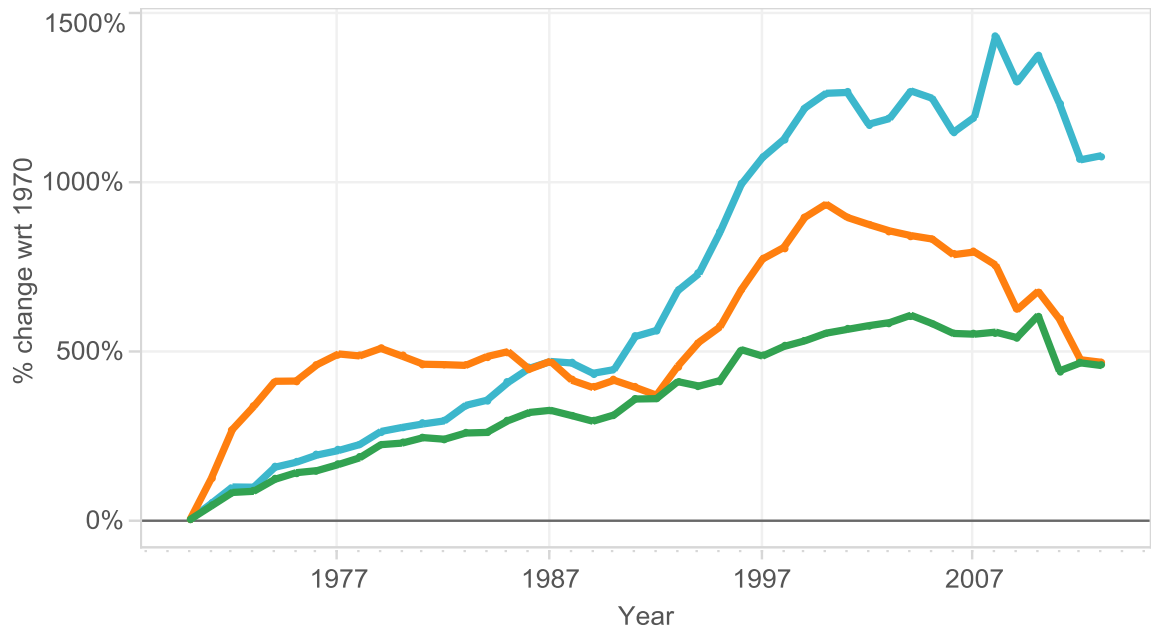

Source: Own analysis based on DECC data

The net consumption of electricity, which includes both primary and secondary electricity production and excludes industry's own use and transmission losses, more than doubled between 1970 and 2005. In 2013 , net electricity consumption - including primary and secondary electricity production - was 13

\footnotetext{
${ }^{10}$ Primary energy use includes use as a power generation fuel.
}

A holistic framework for the study of interdependence between electricity and gas sectors 

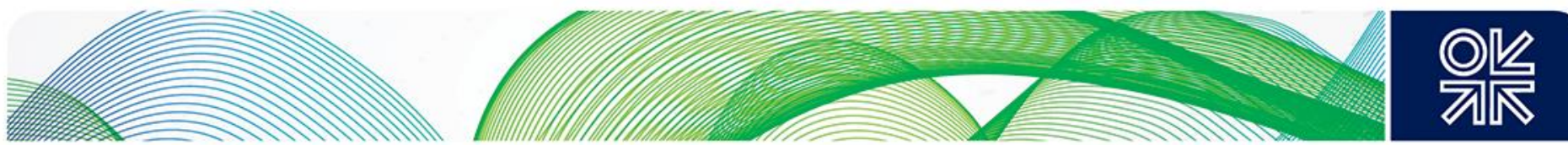

per cent of total primary energy consumed. The greatest increase was seen in the sector labelled 'other' (this includes public administration, transport, agricultural and commercial sectors), as can be seen in Figure 26. The domestic and industrial sectors were also sources of growth up to the mid-2000s. Since then, electricity consumption in the high-growth 'other' category has stabilized, while that for the domestic and industrial sectors has begun to decline.

Figure 26: Net electricity consumption in the UK and changes in sectoral use

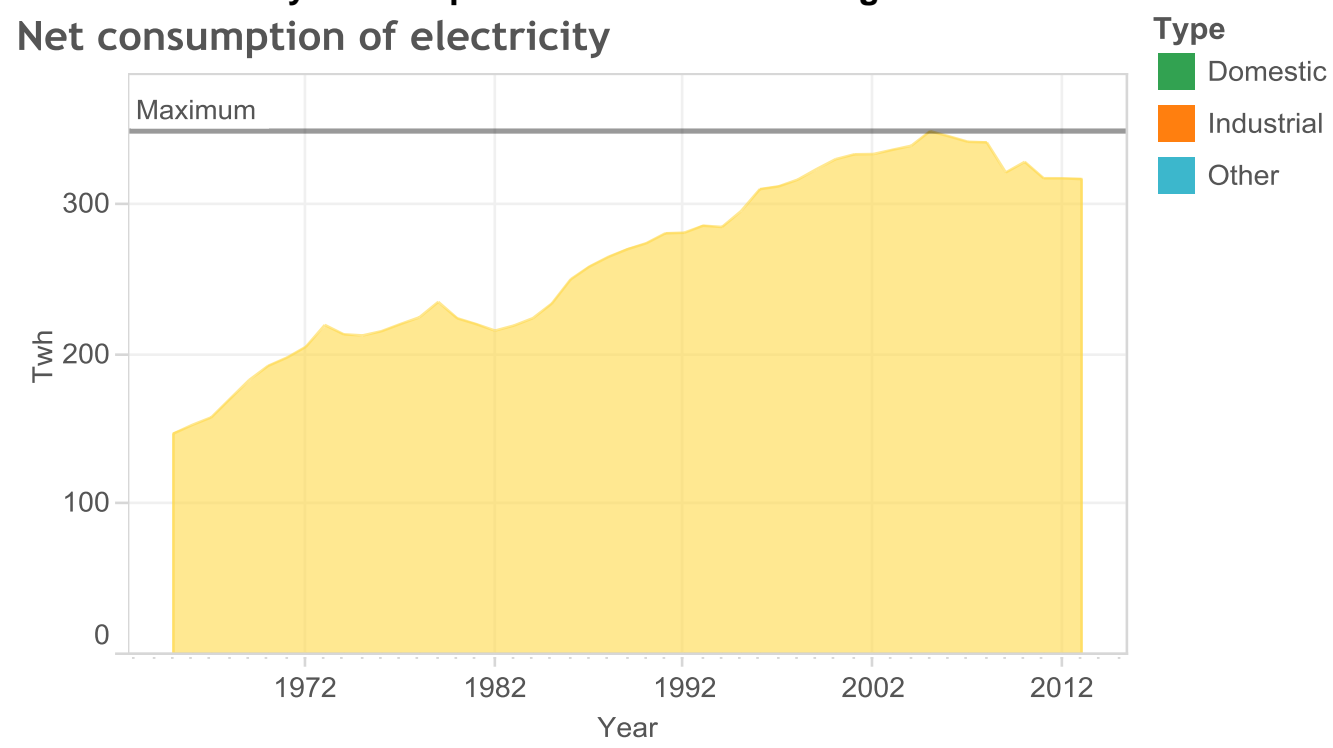

\% Change in consumption of electricity by sector

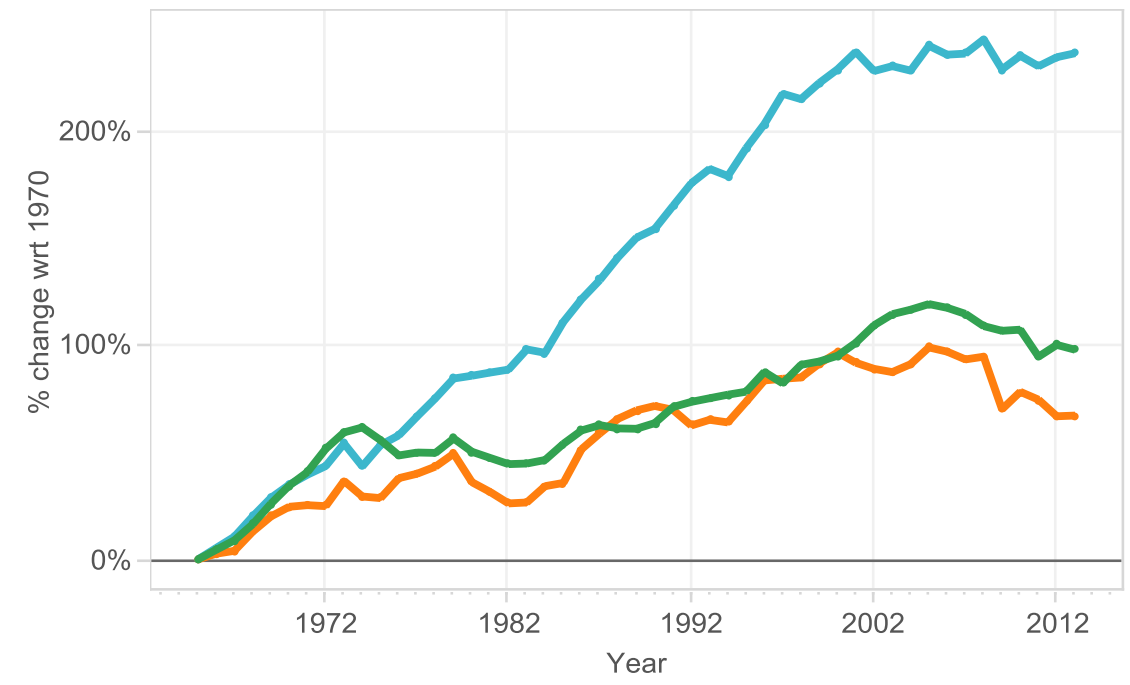

Source: Own analysis based on DECC data

The first instances of gaseous fuel consumption in the UK were associated with town gas, which was manufactured from coal. The discovery of natural gas fields in the North Sea in the 1960s enabled a complete phase-out of manufactured gas, which was replaced by methane. Import of natural gas was negligible until the discovery of the Frigg field; this field straddles the UK-Norway border and contributed

A holistic framework for the study of interdependence between electricity and gas sectors 

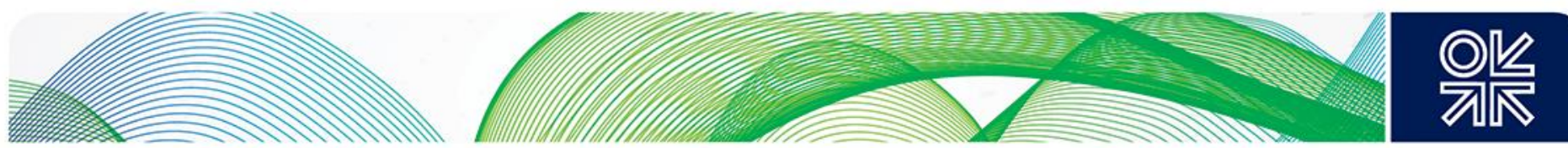

up to a quarter of total supply by 1984. In 1985, the government blocked an agreement to purchase further Norwegian imports from the Sleipner field. ${ }^{11}$ Import levels then decreased, as the production from Frigg declined, to extremely low levels by 1998, while domestic production increased rapidly. The reversal of the trend occurred even faster: domestic production began to decline by 2001 and imports accounted for more than half of gas supply by 2013 (Figure 27).

\section{Figure 27: Sources of UK natural gas supply}

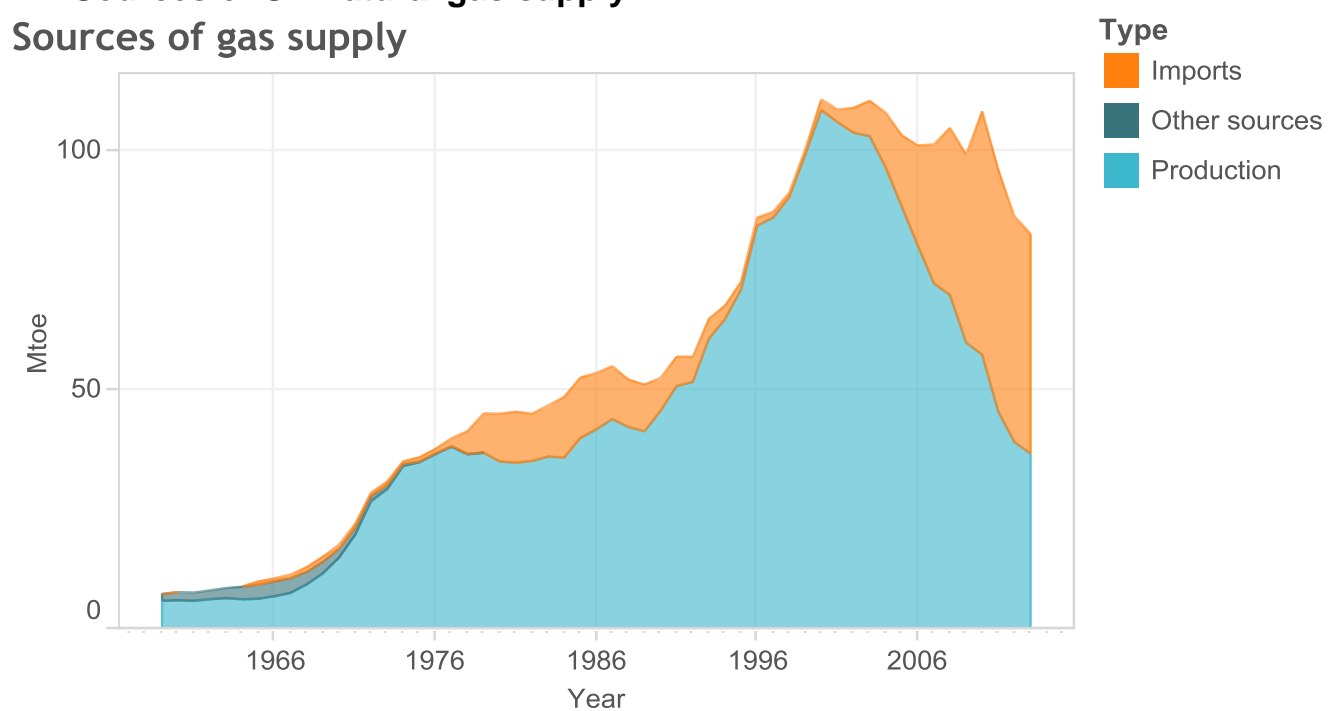

\% Change of supply by source

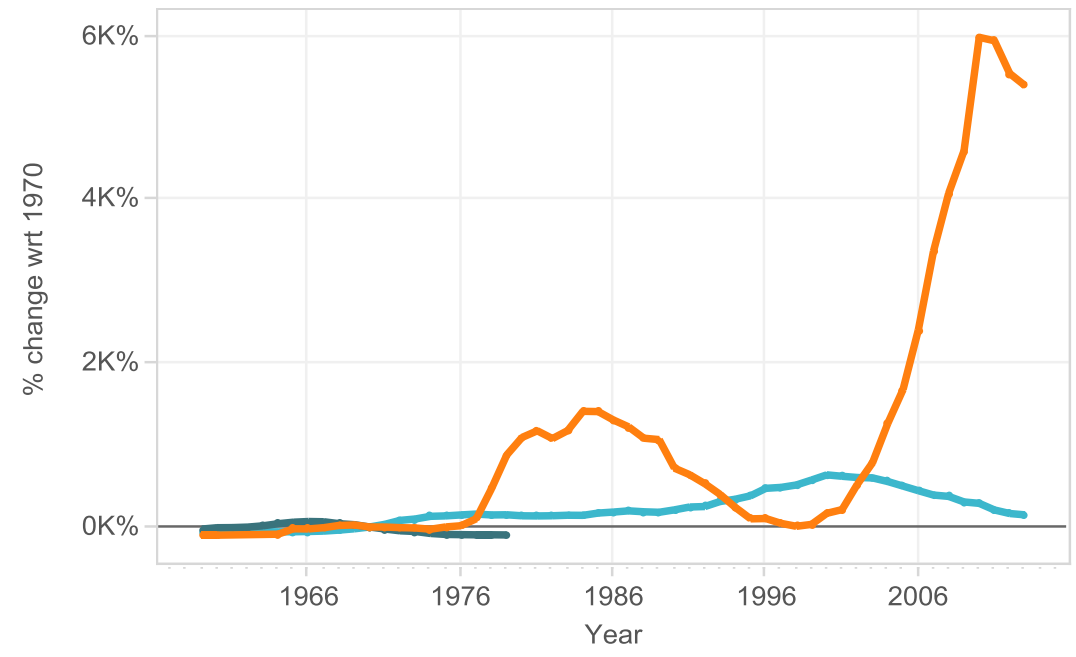

Source: Own analysis based on DECC data

In order of importance, the most important fuels for power generation in 2013 were coal, natural gas, and nuclear energy. The share of nuclear generation has settled at around 20 per cent since the 1980 s,

\footnotetext{
${ }^{11}$ The government's motivation in blocking the deal was to secure a market for the development of domestic gas reserves. Balance-of-payments considerations also played a role (Haugland, Bergesen, \& Roland, 1998).
}

A holistic framework for the study of interdependence between electricity and gas sectors 

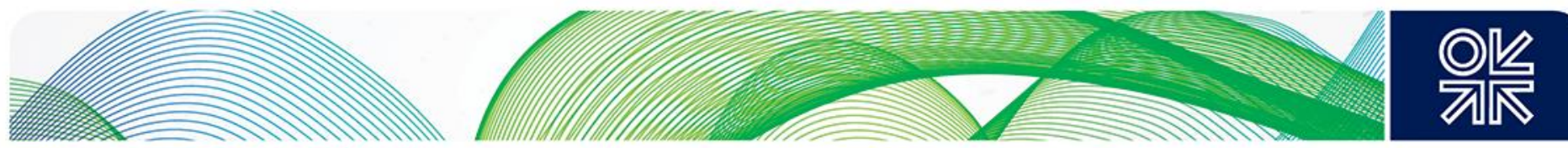

while natural gas, through the dash-for-gas, suddenly captured a large share of generation at the expense of coal. During recent years, inter-fuel competition between coal and gas has been seen. The contribution from oil-fired generation has, overall, been negligible since 2000. Pumped hydro and renewable resources other than wind have been aggregated under the 'Other fuels' category. Together with natural flow hydroelectricity generation and wind, they accounted for 13 per cent of total power generation in 2013 (Figure 28).

\section{Figure 28: Fuel for power generation in the UK}

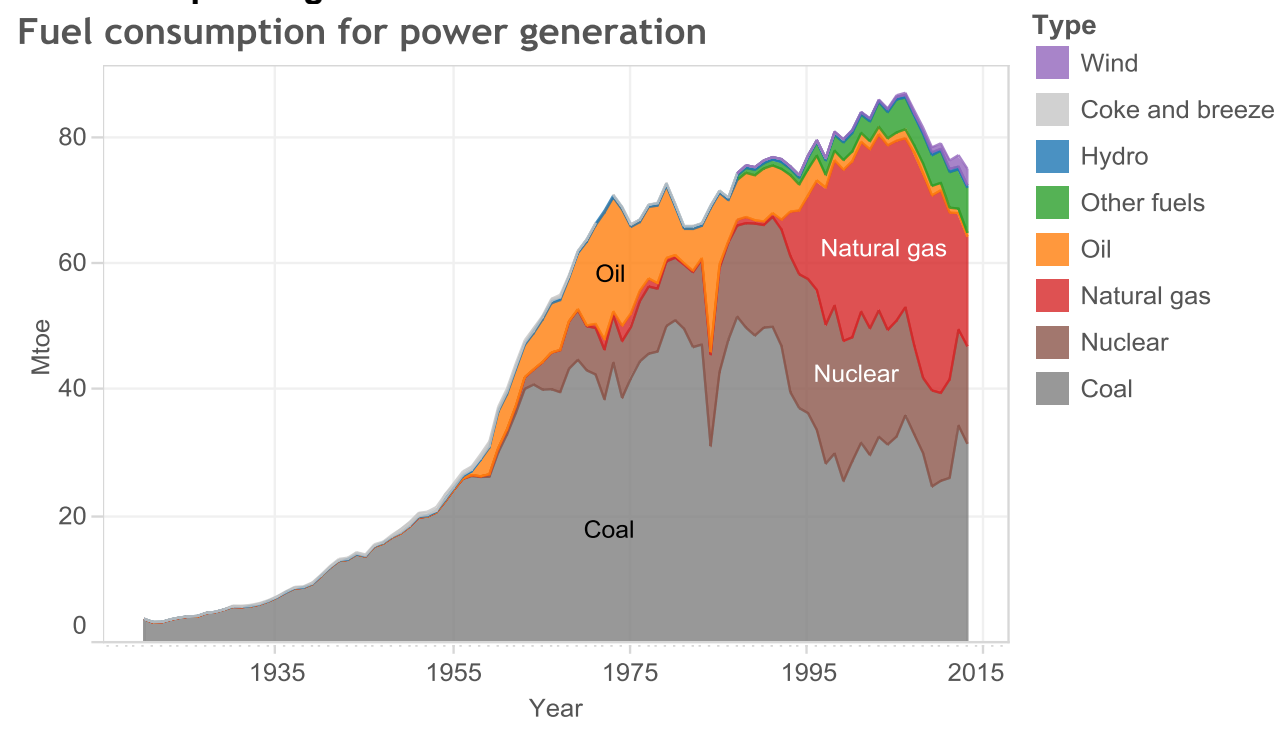

Composition of power generation supply fuel

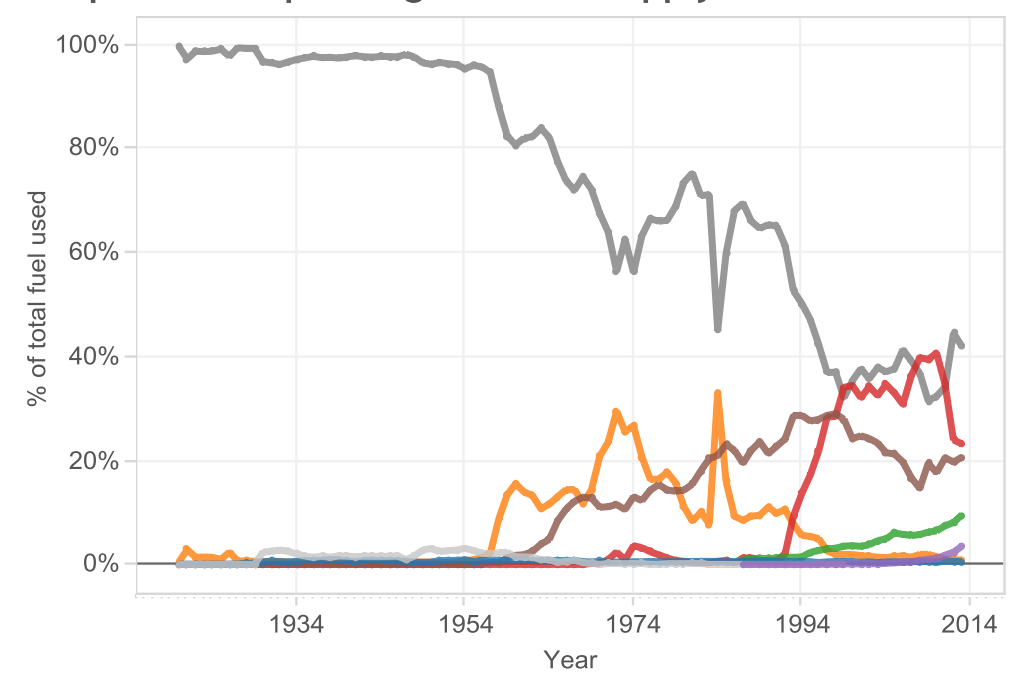

Source: Own analysis based on DECC data

Natural gas dependence and power dependence, two ratios defined in the energy balance screening method (see Section 2), are computed for the UK between 1970 and 2013. In Figure 29, it can be seen that the country's dependence on natural gas has grown in two phases: 1970 to 1992, where the rate of increase suggests the logistic function commonly associated with diffusion of technology, and 1992 to 2008 , which represents sustained quasi-linear growth. Starting from 2008 , the trend becomes jagged 

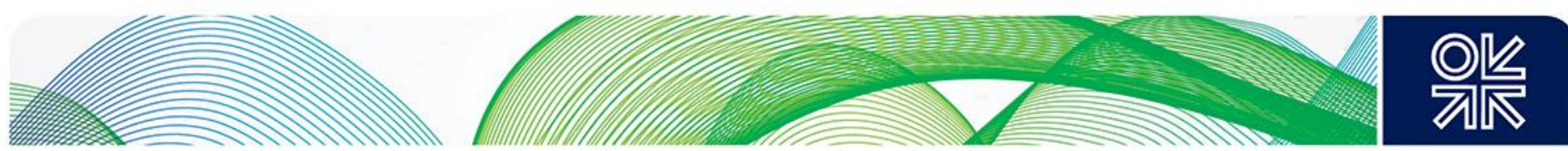

and uncertain. On the other hand, dependence on (net) consumption of electricity has increased steadily at the same pace for the past 30 years. Note that the post 2005 decline in both power and gas consumption is not visible through the dependence measures normalized using total primary energy supply. This suggests that the decline observed in both energy vectors is proportional with the systemwide contraction.

Figure 29: Measures of natural gas and electricity dependence

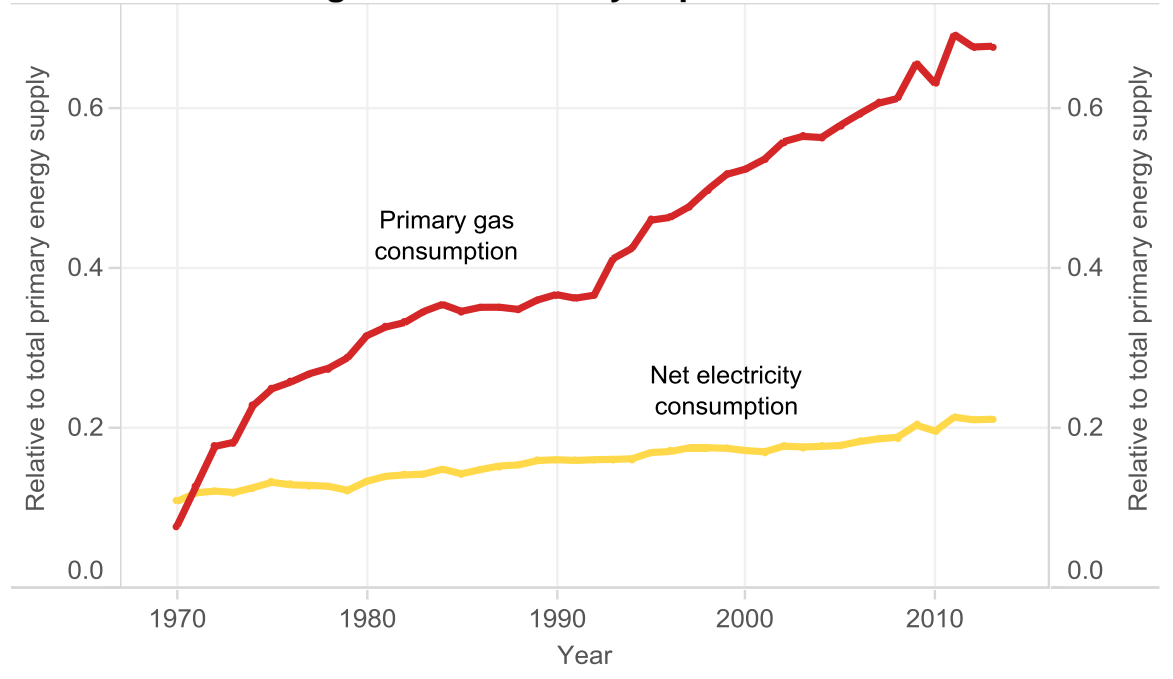

Source: own calculations based on DECC data

The gas-to-power interdependence index and its two components - the relative importance of natural gas-fired generation to the energy system and the inverse of the self-sufficiency ratio - are both determined between 1970 and 2013 (Figure 30). It can be seen that between 1970 and 1992, the interdependence index is non-existent due to the absence of natural gas in power generation. Then, before 2005, it was underpinned by the development in power generation; after 2005, the selfsufficiency ratio of the UK irrevocably deviated from 1, the value around which it cycled between 1970 and 2005, and further pushed up the interdependence index. Several factors interacted together to enable the 'dash for gas': the surplus of domestic production during the 1990s, riding on a trend toward increasing UKCS production since 1985 (credited to changes in the tax and licensing regimes for gas production in the late 1980s - itself a reaction to the collapse of the oil price in 1986); gas generation technology development; and the realignment of power sector investors' objectives under the impetus of the power sector privatization and liberalization (Keay, 2006; Thomas, 2003; Wright, 2006).

Extrapolation of the current trend in Figure 30 suggests that reliance upon natural gas imports will increase while natural gas-fired generation will continue its ascent. However, the likely future evolution of gas-to-power interdependence is also dependent on latent forces of change, which will be identified using the SCPR framework. 

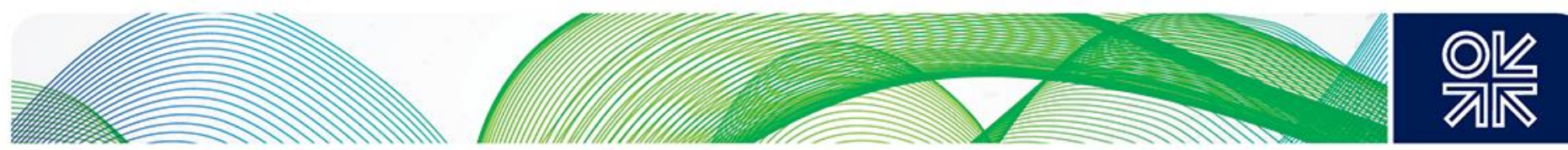

Figure 30: Measures of gas-to-power interdependence

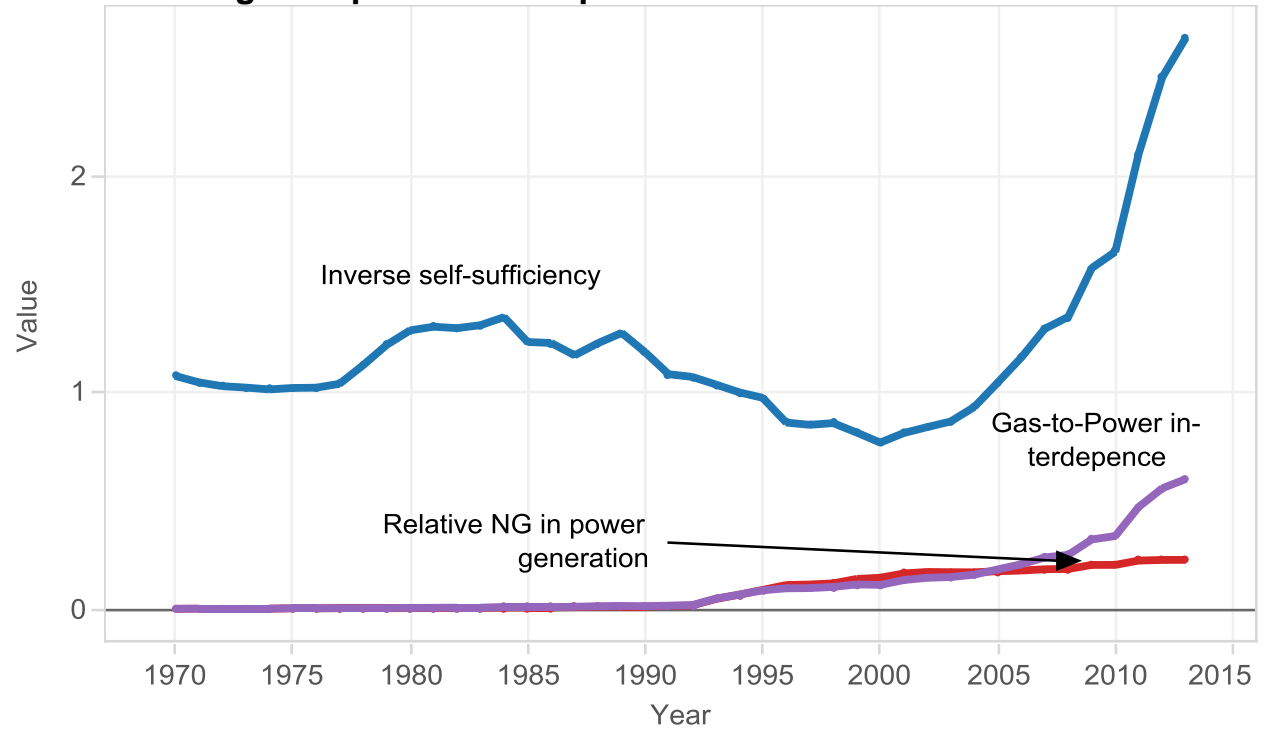

Source: own calculations based on DECC data

\subsection{Structure}

In terms of industry structure, the UK is a country at the forefront of the privatization and liberalization movement. Both the natural gas and power industries underwent structural reform between the late 1980s and early 1990s. For the gas industry, the Gas Act 1986 made provisions for the privatization of the British Gas Corporation, then a state-owned entity, and established a framework to regulate the privatized industry, creating the Office of Gas Supply (Ofgas). This was amended by the Gas Act 1995, which developed a new licensing regime, introducing competition into the downstream gas market. On the other hand, the Electricity Act 1989 established the Office of Electricity Regulation (Offer) and a licensing regime for the power sector. The Utilities Act 2000 combined the Ofgas and the Offer to establish the institution currently in charge of power and gas sector regulation: the Gas and Electricity Markets Authority (GEMA) and its supporting arm, the Office for Gas and Electricity Markets (Ofgem) (Simmonds, 2002). It should be noted that the upstream gas industry is regulated differently from its downstream counterpart under a licensing regime established through the Petroleum Act 1998; this applies to oil and gas exploration and production in the UK. The highly decentralized structure is presented in Table 15, and the companies which are active in several segments are highlighted. The group of six companies active in both the gas and electricity sectors, also known as the 'Big Six' (those companies - with the exception of National Grid - that are highlighted in Table 15), dominate gas supply, and power generation and supply. Each area of activities requires a separate licence that comes with a set of conditions that must be met by the licensee; these conditions are set by the regulator, Ofgem.

Three of the Big Six were also recently active in upstream gas production, but two of them (E.ON and RWE) have decided to dispose of their upstream assets in the North Sea as part of wider restructuring efforts, while UK-based Centrica is said to be planning to downsize its exploration and production arm to focus on the North Sea and East Irish Sea (Adams, 2015a, 2015b; Reuters, 2015). 


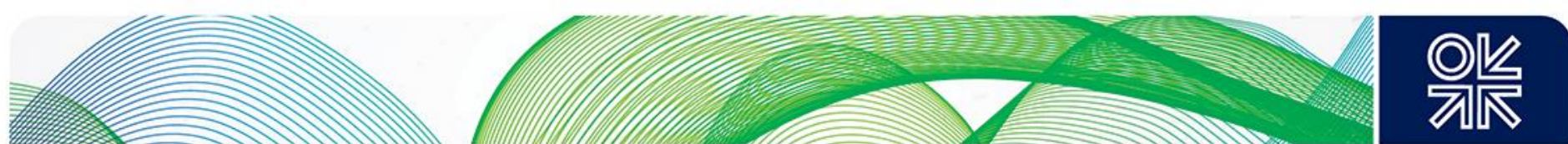

Table 15: Ownership structure of the UK gas-to-power supply chain

\begin{tabular}{|c|c|c|c|c|c|c|c|c|c|c|c|c|}
\hline Company & $\begin{array}{c}\text { Gas } \\
\text { production }\end{array}$ & $\begin{array}{l}\text { Gas } \\
\text { export }\end{array}$ & $\begin{array}{l}\text { Gas } \\
\text { import }\end{array}$ & $\begin{array}{c}\text { Gas } \\
\text { transmission }\end{array}$ & $\begin{array}{c}\text { Gas } \\
\text { distribution }\end{array}$ & $\begin{array}{l}\text { Gas } \\
\text { storage }\end{array}$ & $\begin{array}{l}\text { Gas } \\
\text { supplier }\end{array}$ & $\begin{array}{c}\text { Power } \\
\text { generation }\end{array}$ & $\begin{array}{c}\text { Power } \\
\text { transmission }\end{array}$ & $\begin{array}{c}\text { Power } \\
\text { distribution }\end{array}$ & $\begin{array}{c}\text { Power } \\
\text { interconnector }\end{array}$ & $\begin{array}{l}\text { Power } \\
\text { supplier }\end{array}$ \\
\hline BG & Yes & & Yes & & & & & & & & & \\
\hline Centrica & Yes & & & & & Yes & Yes & Yes & & & & Yes \\
\hline BP & Yes & & & & & & Yes & & & & & \\
\hline Celtique Energy & Possible & & & & & & & & & & & \\
\hline Chevron & Yes & & & & & & & & & & & \\
\hline ConocoPhillips & Yes & & & & & & & & & & & \\
\hline Cuadrilla & Possible & & & & & & & & & & & \\
\hline Dart Energy & Possible & & & & & & & & & & & \\
\hline Eni & Yes & & & & & & Yes & & & & & \\
\hline ExxonMobil & Yes & & Yes & & & & & & & & & \\
\hline L1 Energy & Yes & & & & & & & & & & & \\
\hline Perenco & Yes & & & & & & & & & & & \\
\hline Shell & Yes & & & & & & & & & & & \\
\hline Third Energy & Yes & & & & & & & & & & & \\
\hline Total & Yes & & & & & & Yes & & & & & \\
\hline UK Methane & Possible & & & & & & & & & & & \\
\hline Interconnector (UK) Ltd. & & Yes & Yes & & & & & & & & & \\
\hline Bord Gais & & Yes & & & & & & & & & & \\
\hline National Grid & & & Yes & Yes & Yes & Yes & & & Yes & & Yes & \\
\hline BBL Company & & & Yes & & & & & & & & & \\
\hline Excelerate & & & Yes & & & & & & & & & \\
\hline Qatar Petroleum & & & Yes & & & & & & & & & \\
\hline Gassco & & & Yes & & & & & & & & & \\
\hline Northern Gas Networks & & & & & Yes & & & & & & & \\
\hline SGN & & & & & Yes & & & & & & & \\
\hline Wales \& West Utilities Ltd. & & & & & Yes & & & & & & & \\
\hline Scottish Power & & & & & & Yes & Yes & Yes & Yes & Yes & & Yes \\
\hline E.ON & Yes & & & & & Yes & Yes & Yes & & & & Yes \\
\hline EDF & & & & & & Yes & Yes & Yes & & & & Yes \\
\hline
\end{tabular}




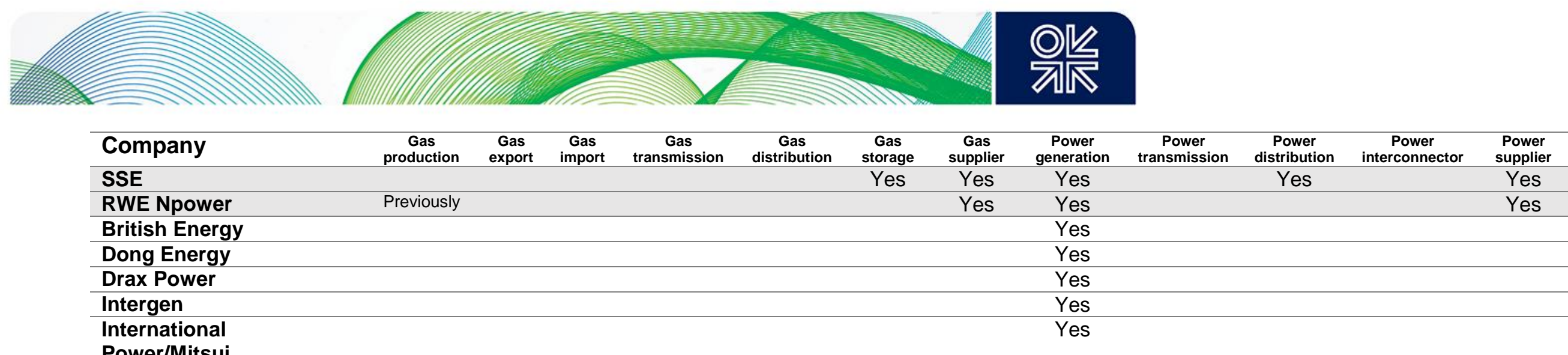

International

Scottish Hydro Electric

Yes

Transmission

Electricity North West

Ltd.

Northern Powergrid

UK Power Networks

Foreign TSOs

EirGrid

Mutual Energy Ltd.

Source: Company and Ofgem websites 

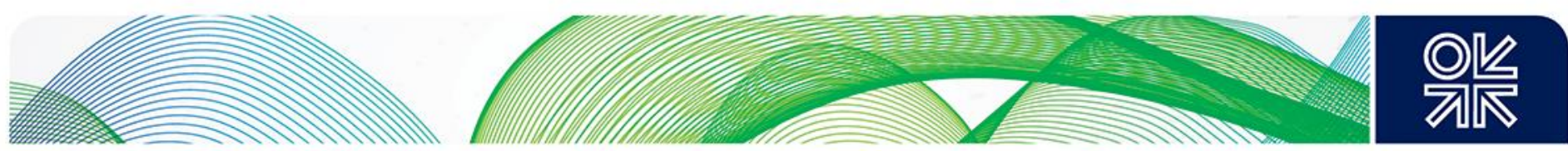

\subsection{Infrastructure and its use}

Due to the long history of natural gas and electricity use in the country, the UK has very mature downstream gas and power sector infrastructure. The adequacy of upstream infrastructure in gas, especially in the power sector, is subject to debate in the current energy policy debate, framed by the concept of the 'energy trilemma'. Therefore, the retail markets and the transmission and distribution networks are omitted from this study to improve focus. A description of the existing infrastructure is presented first; there is then a discussion of coordination mechanisms. This is followed by a section concerned with the management of imbalances and flexibility.

\subsubsection{Existing infrastructure}

The UKCS is a mature hydrocarbon basin. Total installed production capacity for all the platforms is not known, but a figure of $120 \mathrm{mcm}$ per day is inferred from the peak production rate in 2014 (Le Fevre, 2015). The reserves that remain are, relative to previous production, more expensive and challenging to produce. Total known reserves (total remaining reserves plus cumulative production) have slowed since the late 1990s (Figure 31). Gradual decommissioning of fields that are no longer profitable, together with their associated offshore pipelines, is taking place.

\section{Figure 31: Evolution of UKCS total known reserves}

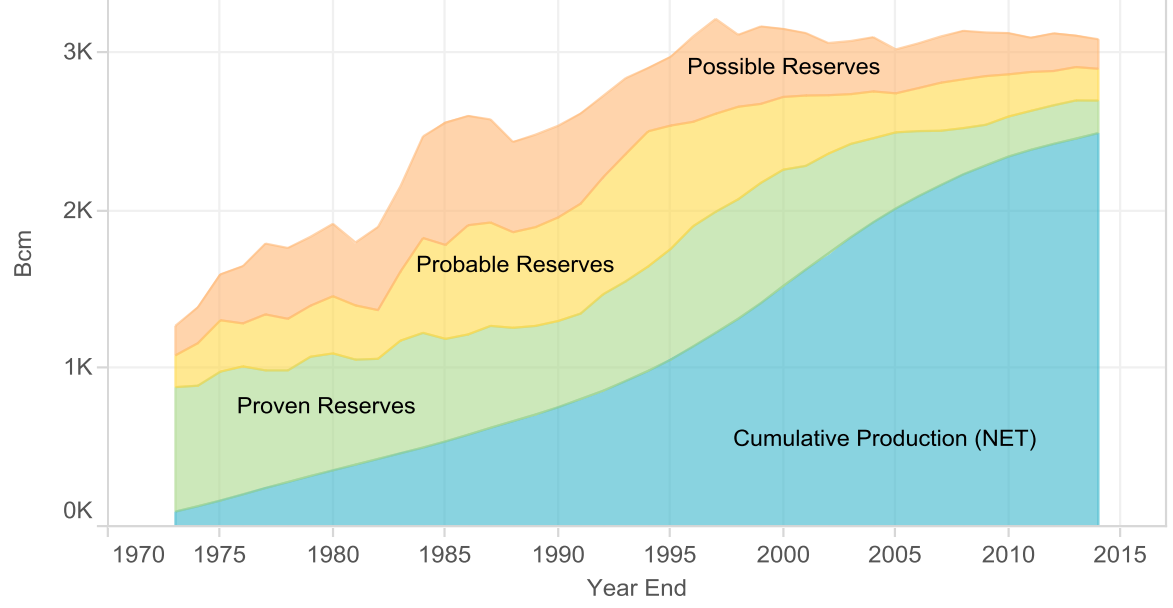

Source: Own analysis based on Oil and Gas Authority data

Unconventional gas reserves such as shale gas and coal bed methane exist in the UK; however, the industry is still in its infancy, with several companies holding exploration licences, but no commercial production has begun. A large number of exploration wells are needed before any realistic estimate of potential resources can be made (Le Fevre, 2015). In reaction to domestic production decline, a wave of investments was made into import pipelines (BBL; Langeled; Tampen Link; Gjøa) and LNG import terminals (Dragon, South Hook, LNG Grain, Teesside GasPort) in the 2000s. These facilities, combined with the existing infrastructure, can deliver imports at a maximum rate of $229 \mathrm{mcm}$ per day. Gas export capacity is more limited, in the form of the Interconnector, which is capable of bi-directional transport between the UK and Belgium, and the UK-Ireland gas interconnector, at $89 \mathrm{mcm}$ per day. When benchmarked against other European countries, the UK has low storage capacity with respect to its gas consumption level: combined storage capacity of the eight existing facilities is $4.6 \mathrm{bcm}$ or 6 per cent of annual consumption, and the maximum delivery rate is $154 \mathrm{mcm}$ per day (Bradshaw \& Watson, 2014).

Among the generation portfolio of the 38 major power producers, representing 85 per cent of total generation capacity ( $80946 \mathrm{MW}$ ), CCGTs have the greatest installed capacity in the UK, followed by coal (including co-firing with biomass), nuclear, and wind (Figure 33). The past few years have seen 

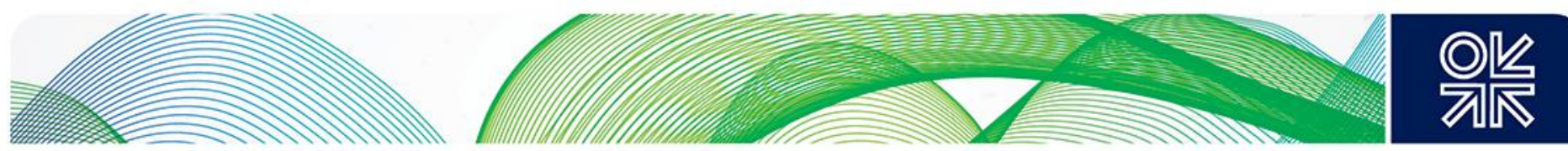

the retirement of about $12000 \mathrm{MW}$ of coal-fired and oil-fired power plants, due to compliance with the Large Combustion Plant Directive (LCPD). Most of the nuclear power plants have planned decommissioning dates between now and 2035, given that most of them were commissioned before the 1990s. The remaining power generators, with much more disaggregated ownership, consist mainly of renewable energy generators such as solar photovoltaic panels and wind turbines (Figure 32). At 14 $482 \mathrm{MW}$, they represent 47 per cent of existing renewable generation capacity in the UK.

The UK has established power interconnection with France (Interconnexion France-Angleterre), Northern Ireland (Moyle), Republic of Ireland (East-West), and the Netherlands (BritNed), with a combined capacity of $4000 \mathrm{MW}$. Further interconnectors with France (IFA2), Denmark (Viking Link), Norway (NSN Link), and Belgium (Nemo Link) are currently planned, to be commissioned by 2020, an addition of $4800 \mathrm{MW}$ (National Grid, 2015). A $1000 \mathrm{~km}$ long interconnector, supplying power from Iceland to the UK, is also under consideration (The Economist, 2014).

Figure 32: Non major power producer installed capacity of power generator, by fuel type in the UK

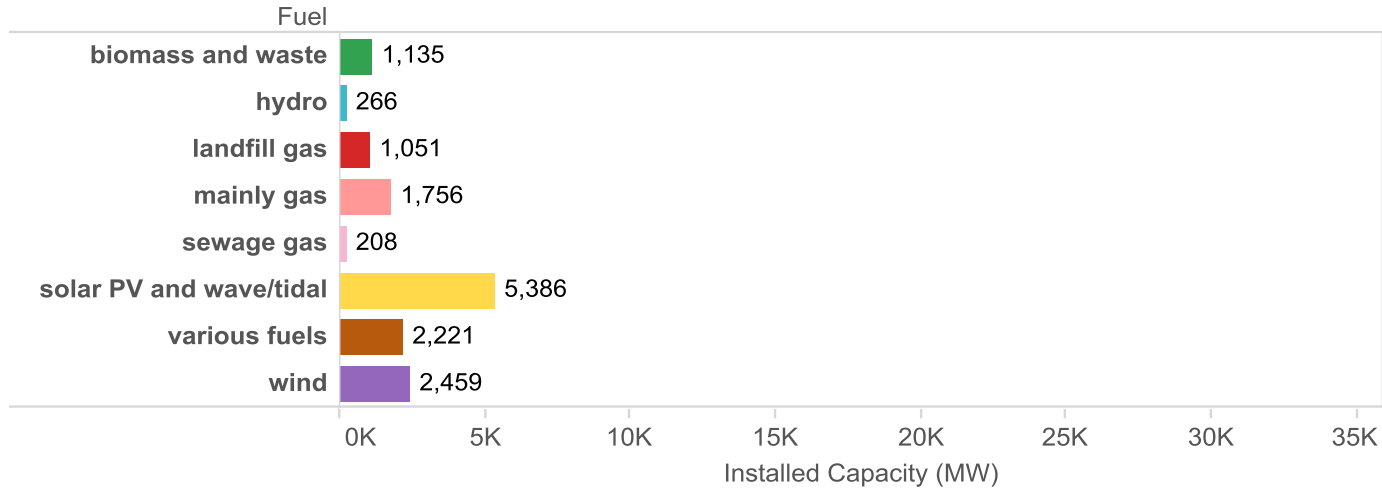

Source: Own analysis based on DECC data

Figure 33: .Major power producer Installed capacity of power generator by fuel type in the UK

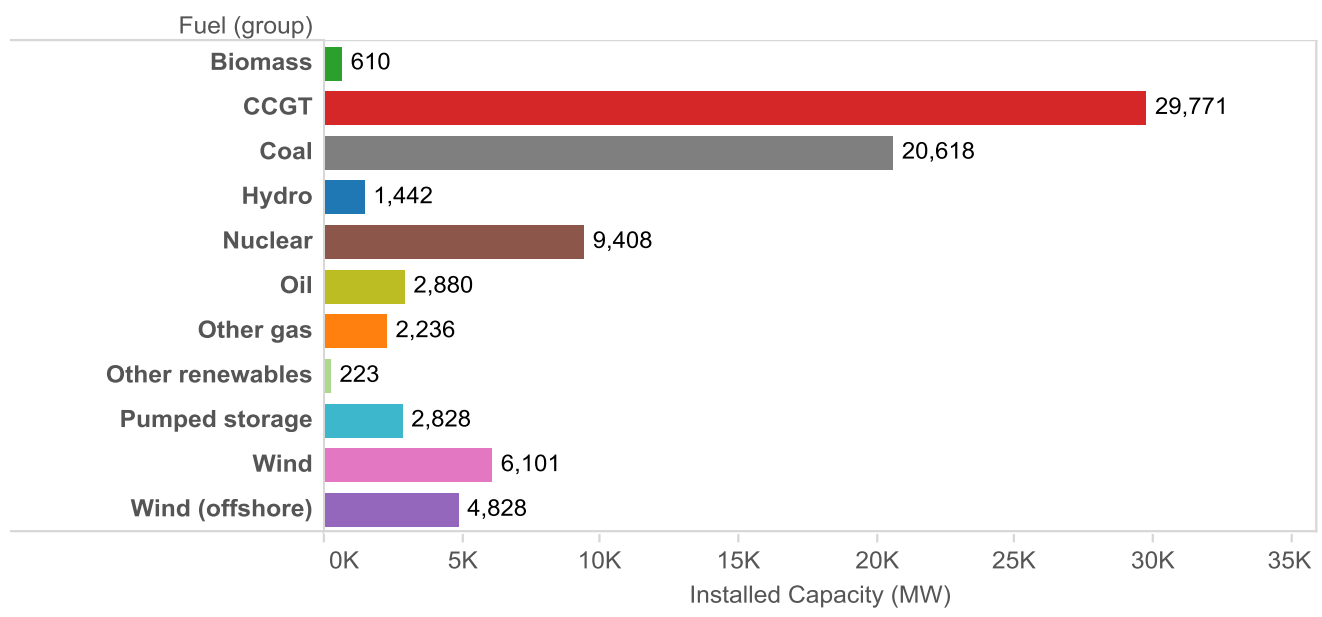

Source: Own analysis based on DECC data

A holistic framework for the study of interdependence between electricity and gas sectors 

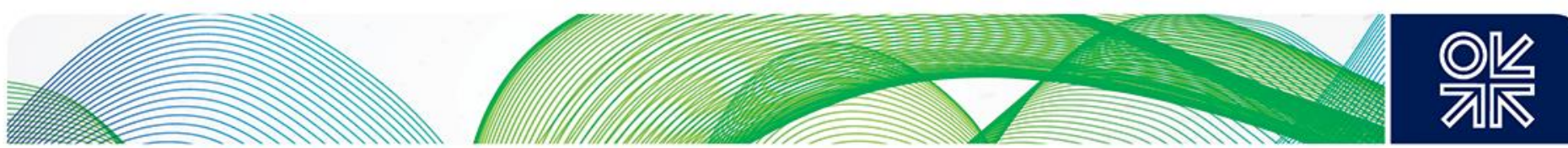

Figure 34: CCGT plants locations and the National Transmission System

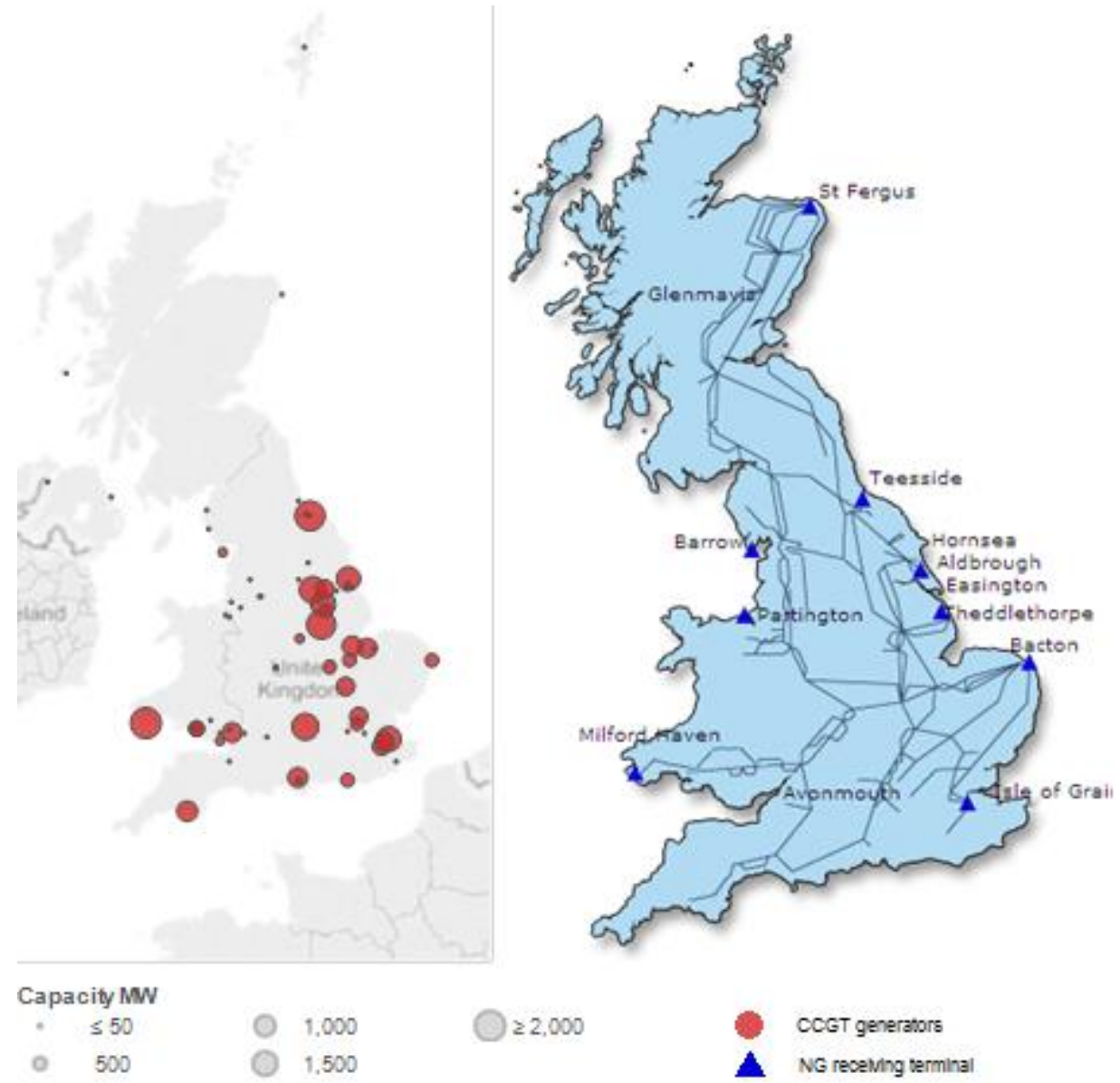

Source: Own analysis based on Enipedia data, National Grid

One crucial link of the gas-to-power supply chain infrastructure that needs to be examined is the supply of gas to CCGT plants via the gas transmission network. Figure 34 shows that the gas-fired generators in the UK are mainly located along two corridors: north to south, between Teesside and the Isle of Grain; east-to-west, between Milford Haven and the Isle of Grain. These are the locations of the four LNG gasification terminals built since 2005, of which two are located in Milford Haven. There is also a cluster of power plants close to the Easington terminal, which is the landing point of the Langeled pipeline, commissioned in 2007 to land imported natural gas from Norway.

Natural gas demand outside of power generation, 78 per cent of total gas demand in 2013, is mainly used to provide space and water heating services via gas boilers. The technology is well-established and mature, with limited future growth capacity (Figure 35).

Consumption of electricity in the UK comes from diverse sources, the most important being lighting and appliance use in the residential sector. Electrification of heating and transport already occurs, representing 15 per cent and 1 per cent of electricity demand in 2013. Further development is possible, since electrification is seen as a key to decarbonization in these sectors (Figure 36). 

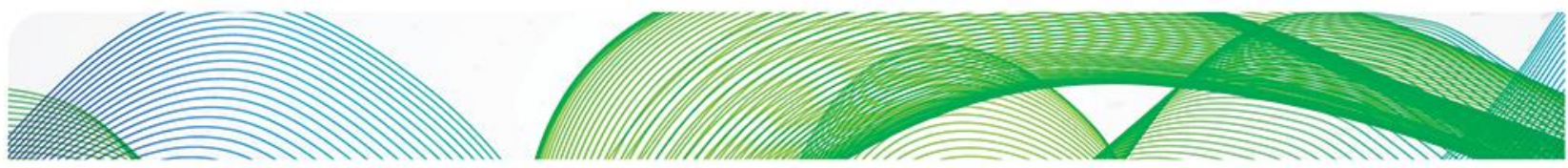

\section{O民n}

Figure 35: Breakdown of gas consumption in 2013

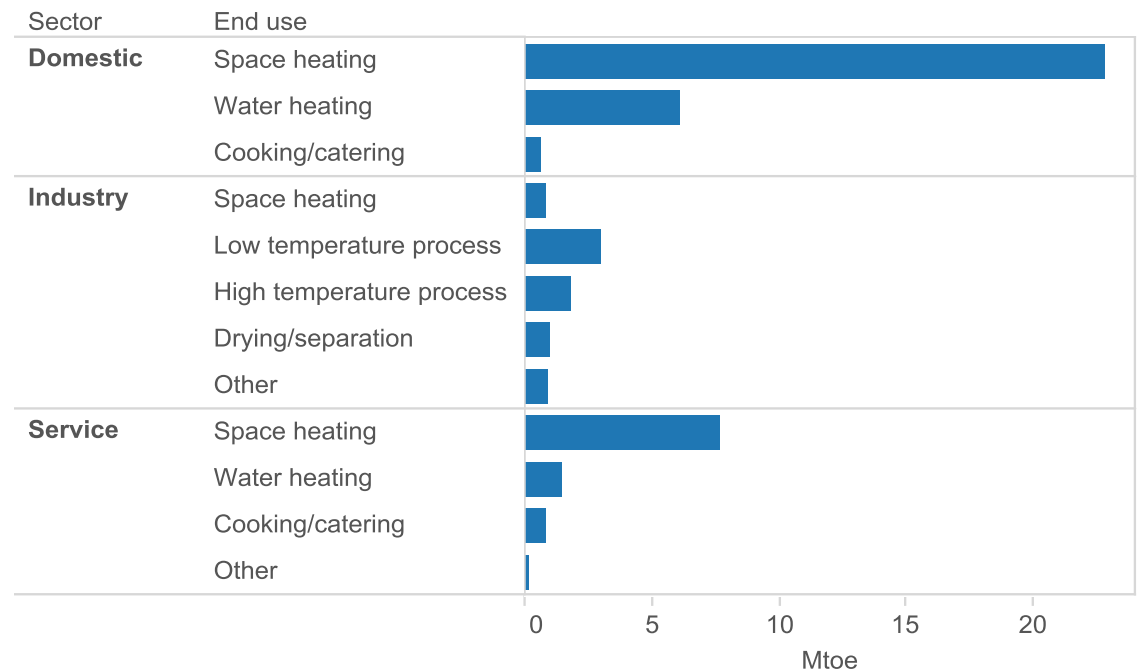

Source: Own analysis based on DECC data

Figure 36: Breakdown of electricity consumption in 2013

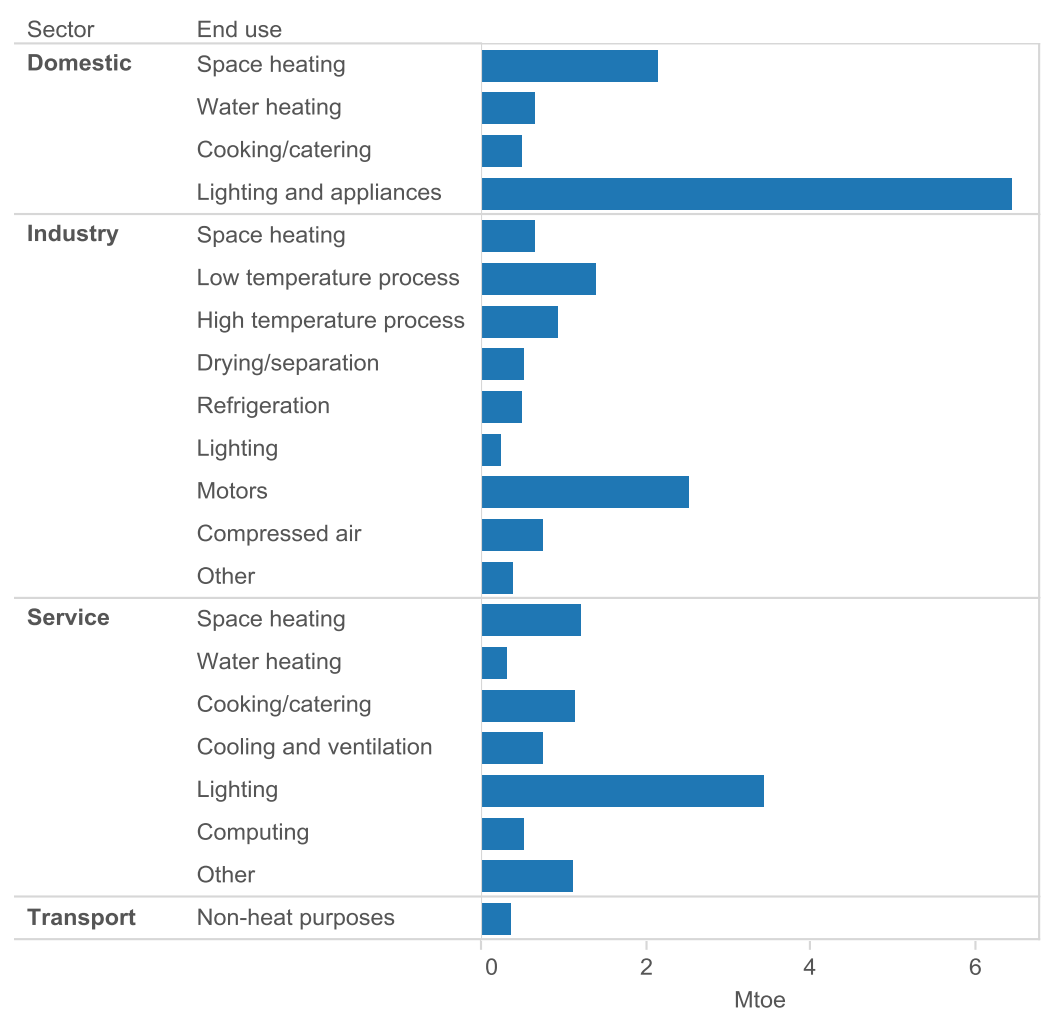

Source: Own analysis based on DECC data

A holistic framework for the study of interdependence between electricity and gas sectors 

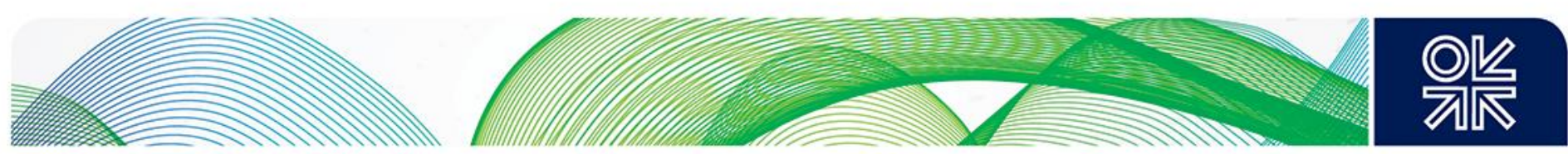

\subsubsection{Coordination mechanisms}

The power and gas industries rely on market mechanisms for both short-term and long-term coordination. The power and gas wholesale markets take place either via exchanges (ICE, APX UK, and UK N2EX), where energy commodities and derivatives can be traded anonymously and pricing information is published, or via the Over-the-Counter (OTC) market, where parties enter into bilateral contracts and may be brokered, and the price is revealed through price reporting agencies. Within both types of organized markets, spot, prompt, and forward markets can be differentiated, based on the differences in the lead time that delivery date has with respect to the delivery date: spot for delivery within the same day, prompt for delivery between a day and the next month (front month), and forward for delivery beyond the front month. In the UK, spot trading for both power and gas tends to be exchange-based, but this represents the trade of smaller volumes than is the case on the OTCdominated forward market.

Long-term structured contracts signed with gas producers or electricity generators can also be arranged bilaterally; this is typically considered as a subset of the OTC market. An important difference in the organization of power and gas wholesale markets in the UK is the importance of long-term contracts. Long-term sales agreements have supported large capital investments in the gas industry. The takeor-pay clauses which require the buyer to pay for a contractually determined minimum volume, even if delivery is not taken, have transferred price and volume risk to the buyer, to ensure project viability when facing financing institutions. The volumes and prices of such contracts are not as transparent as shorter-term trades, but, according to data on 426 natural gas long-term contracts, in 2015, companies based in the UK have signed long-term contracts which have an annual delivery volume of $35 \mathrm{bcm}$, of which 8 bcm comes from long-term LNG shipments (Neumann, Rüster, \& von Hirschhausen, 2015). This quantity is 40 per cent of the total gas consumption in the UK and 75 per cent of total imports. The parallel of long-term gas contracts in the UK power sector are not contracts between power suppliers and foreign gas exporters; instead, they are long-term contracts between the government and (typically) low-carbon generators. However, as a policy tool (feed-in tariffs and the contract for difference) they also exist to transfer risk and encourage upstream investment. The generation reported by the FiT scheme licensees in 2013-14 amounts to $3.3 \mathrm{GWh}$, or 1 per cent of total UK electricity consumption in 2013 (Ofgem, 2014).

The National Balancing Point (NBP) is the principal delivery point for gas traded in the UK through longterm contracts and short-term trades. It can be conceived as the entire National Transmission Network circumscribed by a number of entry points, a zone for which gas input and output needs to be balanced. Natural gas demand does not vary by much within the same day. Therefore, the gas spot market in the UK, OCM (On the Day Commodity Market) is effectively the balancing market, where shippers balance their own supply/demand portfolios while the gas system operator, National Grid, balances the system as one among many traders, based on information it receives concerning contracted flows. On the other hand, the power system operator (also National Grid) cannot rely on spot trade to balance the power grid, for power balancing needs vary second to second. The power system operator takes over the matching of supply and demand within the power grid an hour before real time consumption (gate closure), and dispatches generation, demand response, or other ancillary services procured through the balancing mechanism and other programmes. Balancing parties provide their likely actual generation/demand level for each half-hour settlement period ahead of gate closure (one hour before), and the charge/payment they are willing to make to deviate from that level.

The presence of gas pipelines, LNG terminals, and power interconnectors that connect the UK to other countries, open to short-term trading, means that the domestic market dynamics, integrated with continental Europe and the global LNG market, are no longer purely determined by fundamentals such as domestic supply and demand. Price integration (the correlation of price across markets) can be used as an indicator to assess the level of market integration. Evidence suggests that the European gas hubs - NBP, Title Transfer Facility (the Netherlands), Zeebrugge Hub (Belgium), Central European Gas Hub

A holistic framework for the study of interdependence between electricity and gas sectors 

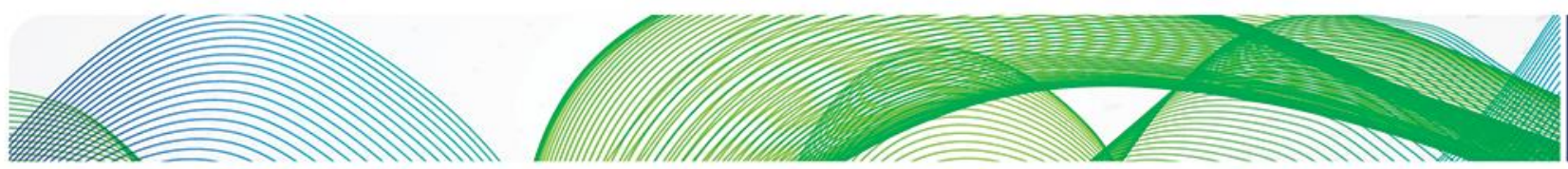

\section{此}

(Austria), Gaspool (Germany), Net Connect Germany, Points d'Echange de Gaz (France), Punto di Scambio Virtuale (Italy) - are already part of the same integrated market, showing strong price correlation that increases with time (Petrovich, 2013). As for wholesale power markets, the UK has also seen the correlation of its power price with the Dutch price increase by 25 per cent since the establishment of the BritNed interconnector (Castagneto-Gissey, 2014). 


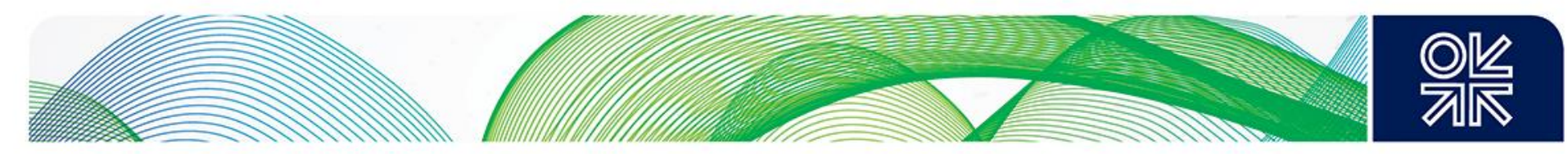

Table 16: Power and gas markets in the UK excluding retail

\begin{tabular}{|c|c|c|c|c|c|}
\hline Commodity & Mechanism & Market & Duration & Delivery date & 2013 volume (TWh) \\
\hline Gas & OTC & Long-term contract & typically 10 years & $\mathrm{N} / \mathrm{A}$ & $342^{12}$ \\
\hline Gas & OTC & Forward & month, quarter, season, year & front month to year 3 & 12131 \\
\hline Gas & OTC & Prompt & day, weekend, week, month & day-ahead to current month & \\
\hline Gas & Exchange $=\mathrm{ICE}$ & OCM (spot) & & within-day & 108 \\
\hline Gas & Exchange $=$ ICE & Futures & around 7 years & $\mathrm{N} / \mathrm{A}$ & Not available \\
\hline Electricity & FiT & Long-term contract & & $N / A$ & 3.3 \\
\hline Electricity & OTC & Forward & month, quarter, season & front month to season 7 & 558 \\
\hline Electricity & OTC & Prompt & month, quarter, season & day-ahead to current month & \\
\hline Electricity & Exchange $=\mathrm{APX}$ & Prompt & 8 to 48 hours & 7 days & 3.35 \\
\hline Electricity & Exchange $=\mathrm{APX}$ & Spot & 0.5 to 4 hours & 49.5 hours & 10.66 \\
\hline Electricity & Exchange $=\mathrm{APX}$ & Day-ahead auction (prompt) & hour & day-ahead & 8.57 \\
\hline Electricity & Exchange $=\mathrm{N} 2 \mathrm{EX}$ & Day-ahead auction (prompt) & hour & day-ahead & 139.4 \\
\hline Electricity & Exchange $=$ ICE & Futures & around 5 years & N/A & Not available \\
\hline
\end{tabular}

Source: National Grid, APX, ICE, Nord Pool Spot, Argus, Ofgem E-serve

\footnotetext{
${ }^{12}$ Estimated from
}

Table 17.

A holistic framework for the study of interdependence between electricity and gas sectors 


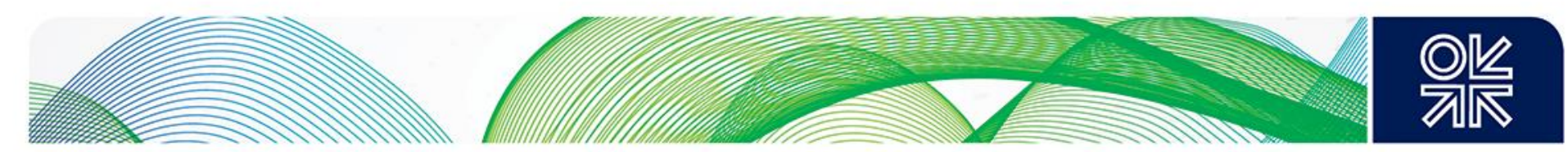

Table 17: Long-term contracts between the UK and natural gas producers

\begin{tabular}{|c|c|c|c|c|c|c|c|c|}
\hline $\begin{array}{l}\text { Participant } \\
\text { (company) }\end{array}$ & $\begin{array}{l}\text { Seller } \\
\text { (company) }\end{array}$ & Type & $\begin{array}{c}\text { Contract } \\
\text { conclusion }\end{array}$ & $\begin{array}{c}\text { Start of } \\
\text { deliveries }\end{array}$ & $\begin{array}{l}\text { Contract } \\
\text { duration }\end{array}$ & $\begin{array}{c}\text { End of } \\
\text { deliveries }\end{array}$ & $\begin{array}{l}\text { Yearly volume } \\
(\mathrm{bcm})\end{array}$ & $\begin{array}{c}\text { Total volume } \\
\text { (bcm) }\end{array}$ \\
\hline BP & Statoil & pipeline & 2001 & 2001 & 15 & 2,015 & 2 & 24 \\
\hline \multirow[t]{7}{*}{ Centrica } & Cheniere & LNG & 2013 & 2018 & 20 & 2,037 & 2 & 48 \\
\hline & Petronas & LNG & 2004 & 2007 & 15 & 2,021 & 3 & 45 \\
\hline & Qatargas & LNG & 2013 & 2014 & 5 & 2,018 & 2 & 8 \\
\hline & RasGas & LNG & 2006 & 2008 & 20 & 2,027 & 3 & 68 \\
\hline & Statoil & pipeline & 2002 & 2005 & 10 & 2,014 & 5 & 50 \\
\hline & Statoil & pipeline & 2011 & 2015 & 10 & 2,024 & 5 & 50 \\
\hline & Statoil & pipeline & 2011 & 2015 & 10 & 2,024 & 1 & 50 \\
\hline $\begin{array}{l}\text { Centrica/ British } \\
\text { Gas Trading }\end{array}$ & Gasunie & pipeline & 2002 & 2005 & 10 & 2,014 & 8 & 80 \\
\hline $\begin{array}{l}\text { Gazprom Market } \\
\text { and Trading }\end{array}$ & Dong & pipeline & 2006 & 2007 & 15 & 2,021 & 1 & 9 \\
\hline Scottish Power & Statoil & pipeline & 2005 & 2007 & 10 & 2,016 & 1 & 5 \\
\hline Shell UK & Statoil & pipeline & 2003 & 2007 & 10 & 2,016 & 4 & 40 \\
\hline
\end{tabular}

Source: Own analysis based on data from Neumann et al., 2015 

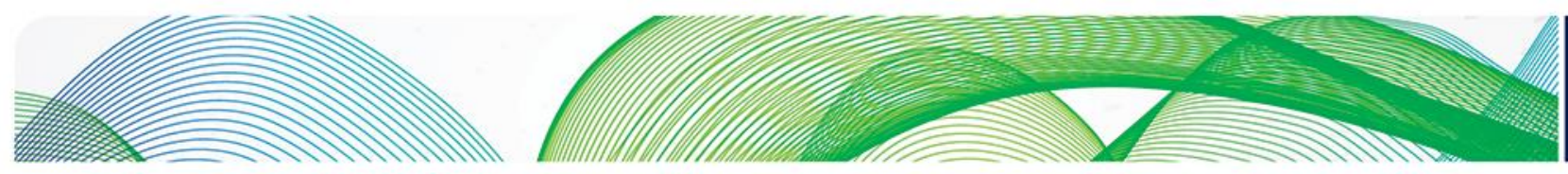

數

\subsubsection{Management of imbalances and flexibility}

The most important cause of imbalance in the gas supply chain has been seasonal temperature changes, as heating load is a major part of demand. Prior to the decline of production, much of the flexibility to meet seasonal variation in gas demand was provided by the beach swing. However, that flexibility has declined with the production level. Today, pipeline import from Norway and the Netherlands is playing a more important role in the management of seasonal supply/demand imbalance, via volume flexibility in long-term contracts rather than short-term trading (Figure 37). Shorter-term imbalances are resolved through short-term trade across the Interconnector, LNG spot cargoes, and storage.

\section{Figure 37: UK gas sources and destinations}

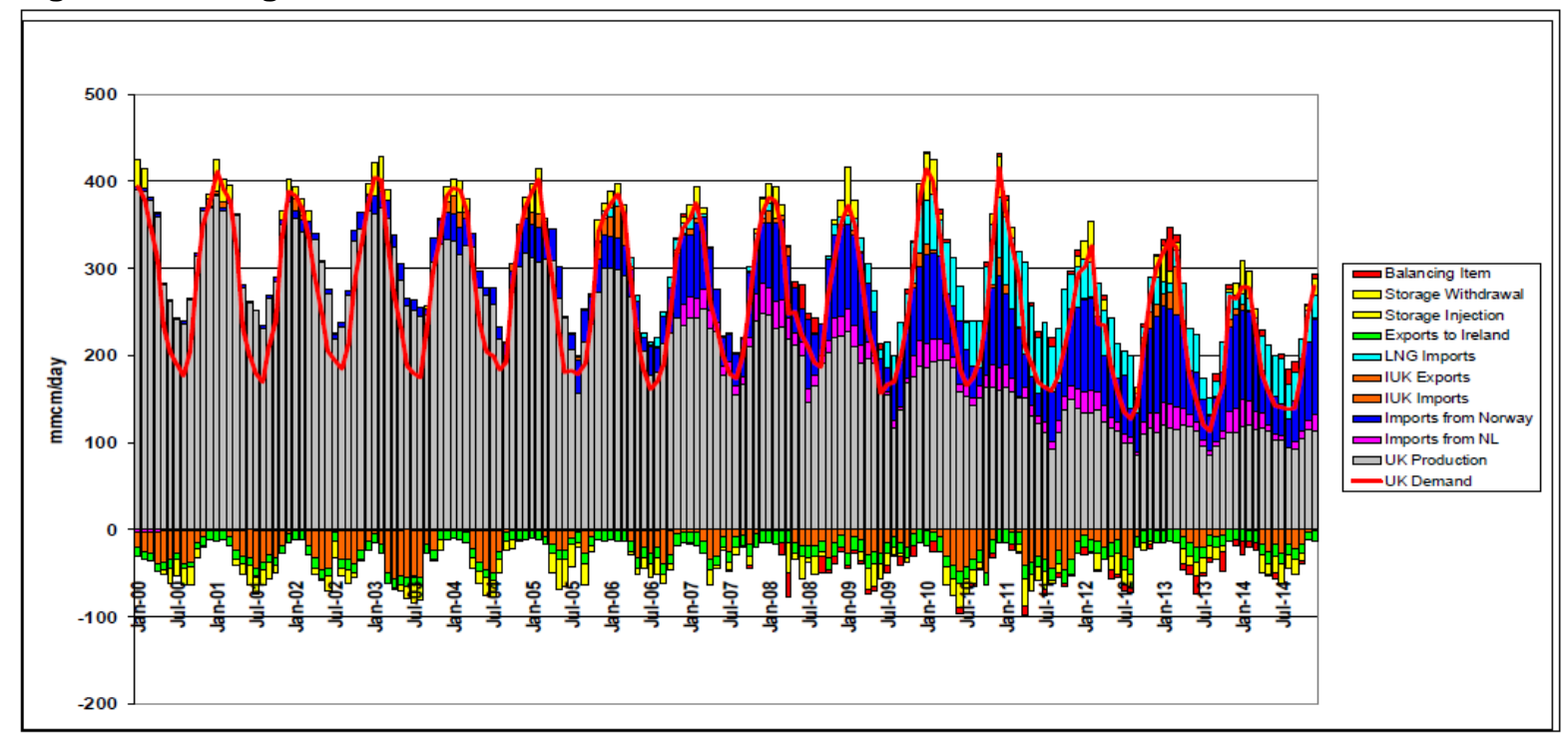

Source: Le Fevre, 2015

In the power supply chain, causes of imbalance occur across many timescales. Variation in demand experiences seasonal, weekly, and daily cycles that are driven by heating (and perhaps lighting) needs, work schedule, and daily schedule. Higher demand is experienced during October to March, midweek, and 5-6 p.m. respectively (Figure 38). Variation in renewable generators also introduces different scales of imbalance. Solar, hydro (run-of the river and reservoir but not pumped storage), and wind in the UK all exhibit seasonal cycles; more energy is supplied during summer (higher solar intensity) and winter (wet season and windy). On a daily scale, solar generation only occurs during daylight hours, and hydro reservoir can be dispatched to follow daily power demand (observe the pattern of hydro generation in Figure 39). The latter represents a source of flexibility rather than imbalance, demonstrating how the same generation resource can bring imbalance and flexibility. Wind, for the same timescale, does not exhibit any trend at all. 

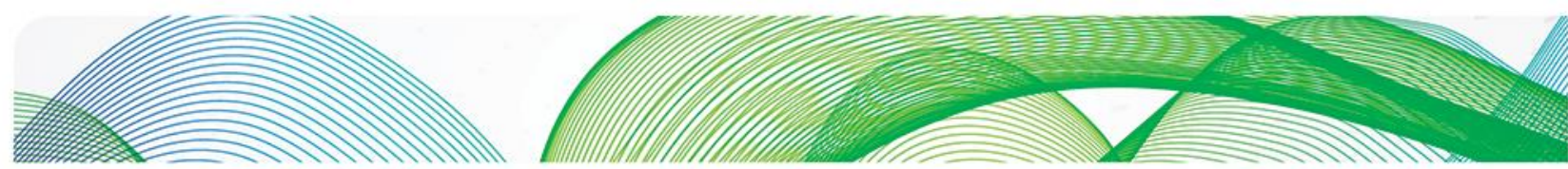

O는

Figure 38: Average UK electricity demand for various temporal resolutions

Seasonal demand pattern: monthly resolution

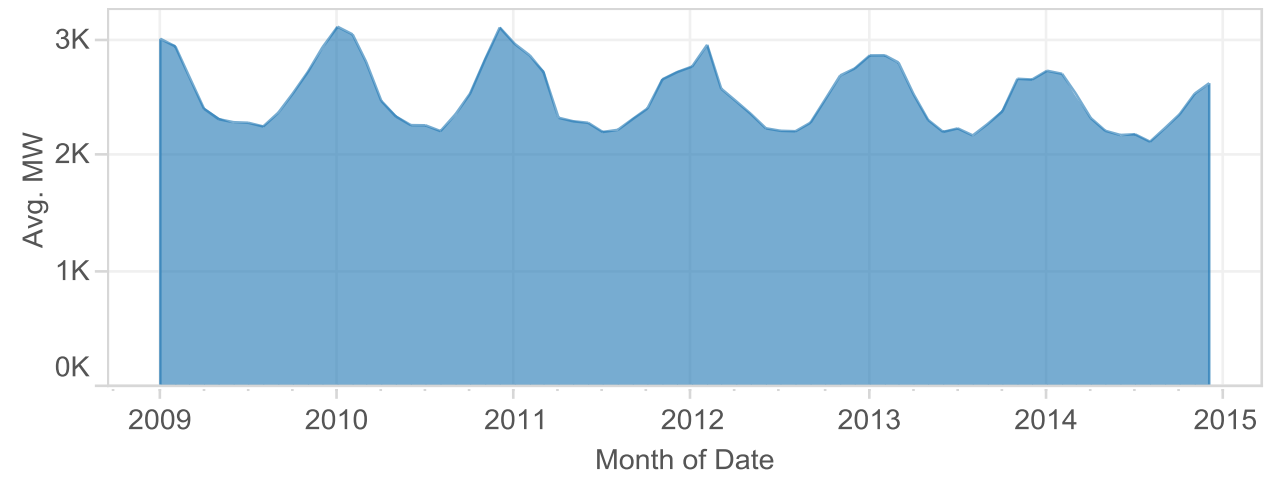

Weekly demand pattern: daily resolution

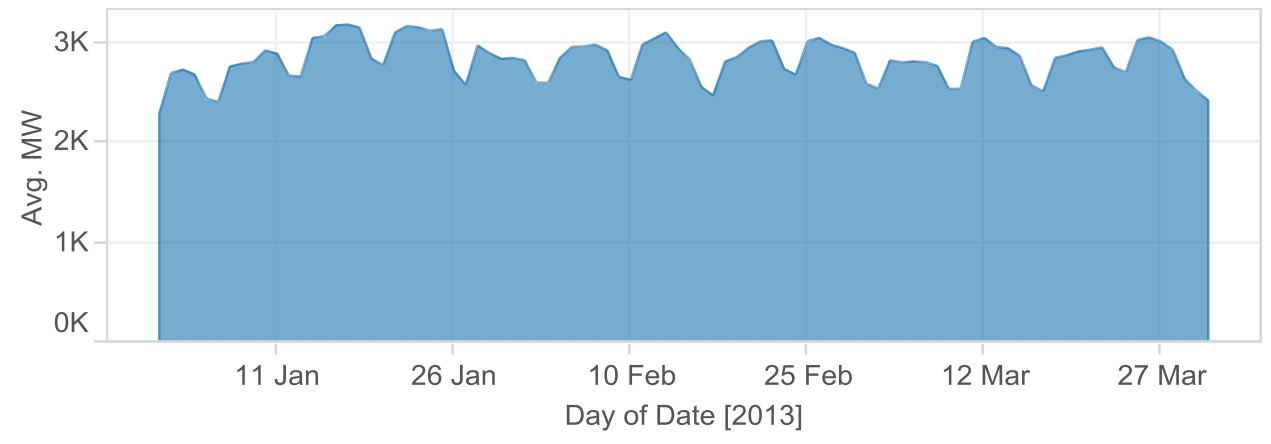

Daily demand pattern: hourly resolution

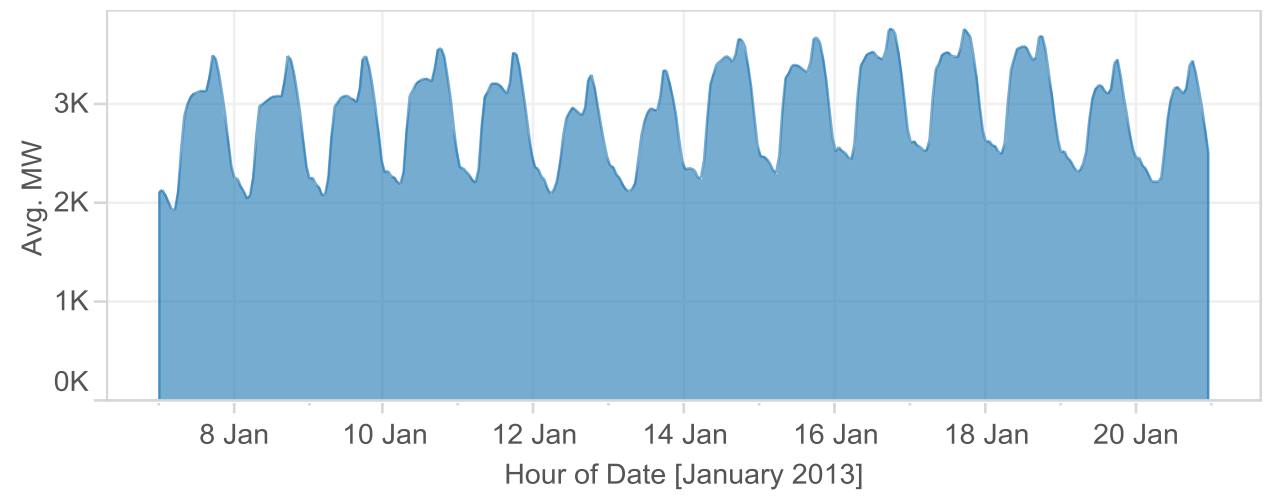

Source: Elexon portal, own calculations, demand served by embedded generation estimations have been included

A holistic framework for the study of interdependence between electricity and gas sectors 

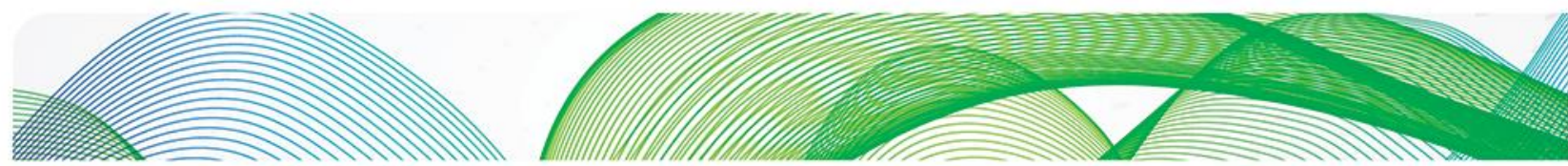

O는

Figure 39: Average UK renewable electricity supply for various temporal resolutions Seasonal RE supply pattern: monthly resolution

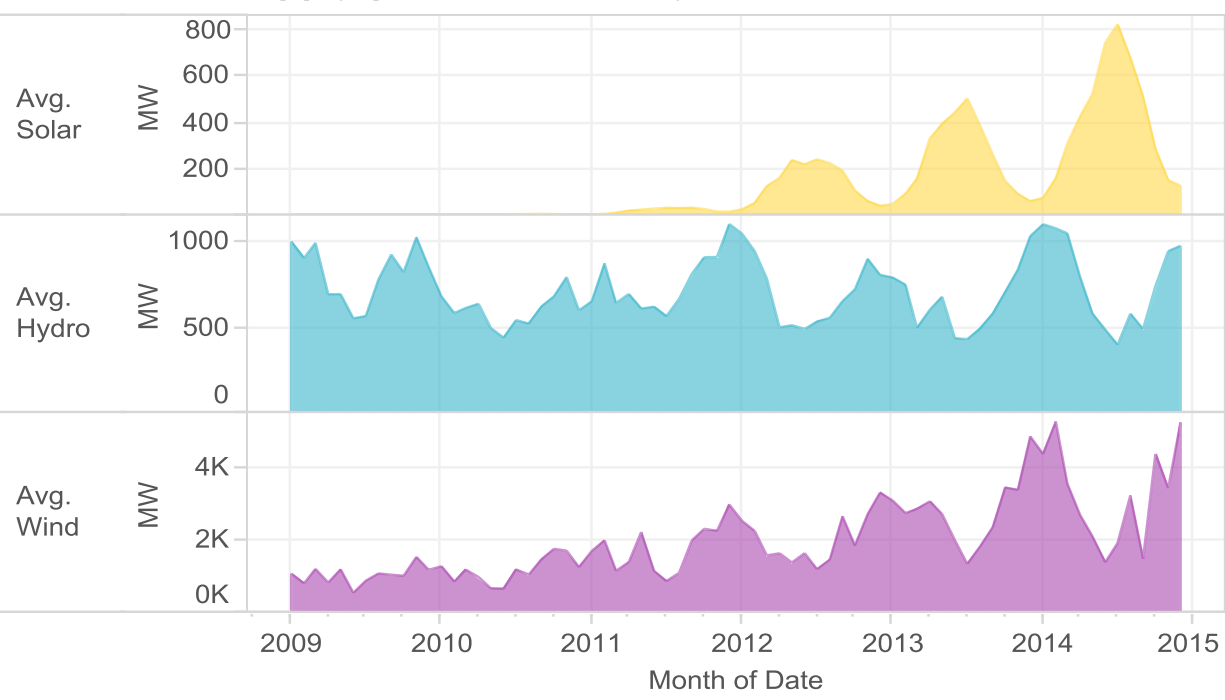

Daily RE supply pattern: hourly resolution

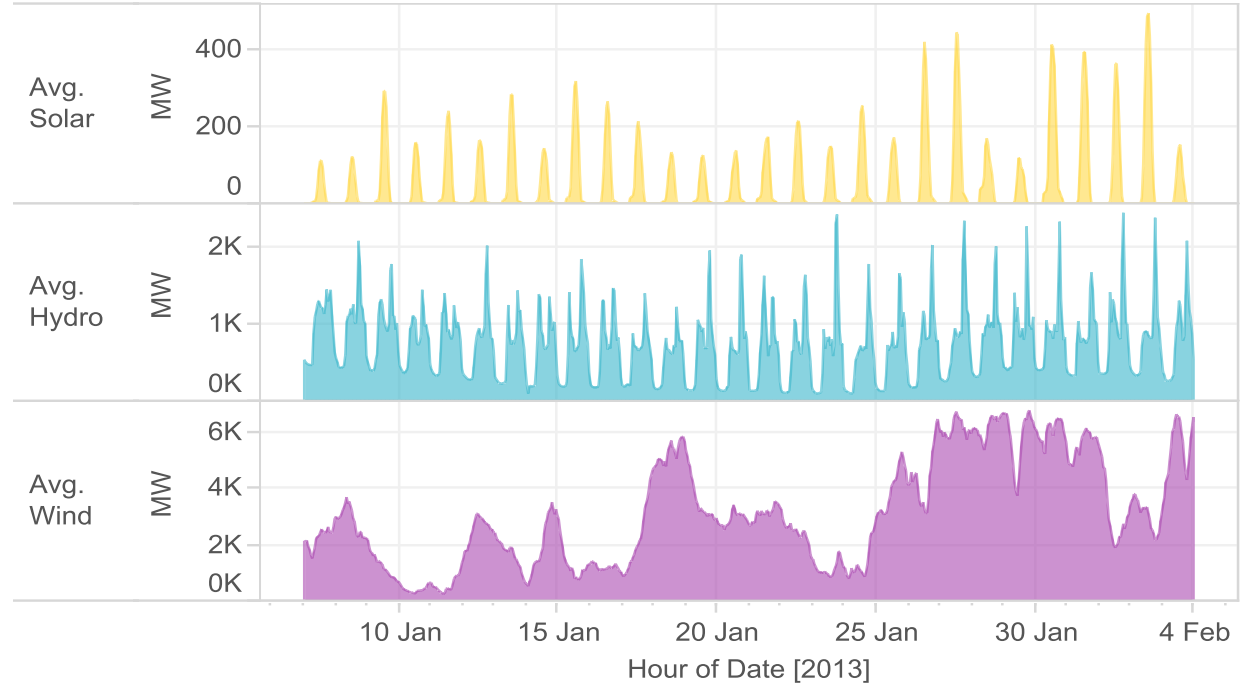

Source: Elexon portal, own calculations, embedded generation estimations have been included

The main sources of supply-end flexibility are now examined. In the long term, nuclear power generation does exhibit some variation, but in the short term (hourly resolution), it can be considered to be essentially flat and inflexible. Coal and CCGT are both capable of load following, but coal exhibits a seasonal cycle which gas-fired generators do not. On a daily basis, CCGT exhibits hourly variation that matches the variation in hourly demand, which coal generation does not (Figure 40). Thus, it can be concluded that coal is used to balance seasonal imbalance in electricity supply and demand in the UK, while natural gas is used to balance daily to hourly imbalances.

A holistic framework for the study of interdependence between electricity and gas sectors 

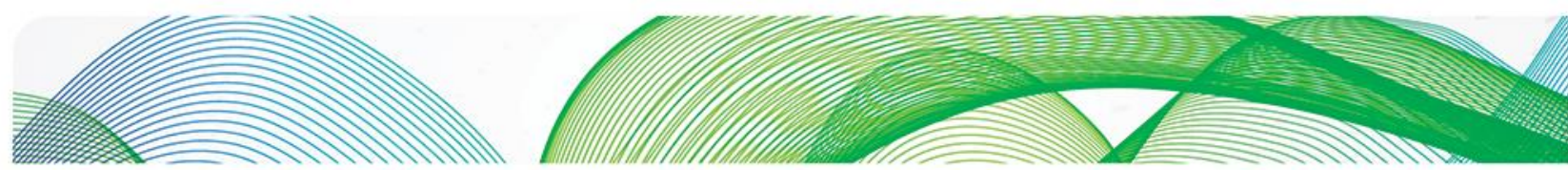

O지소

Figure 40: Average UK thermal electricity supply for various temporal resolutions) Seasonal thermal supply pattern: monthly resolution

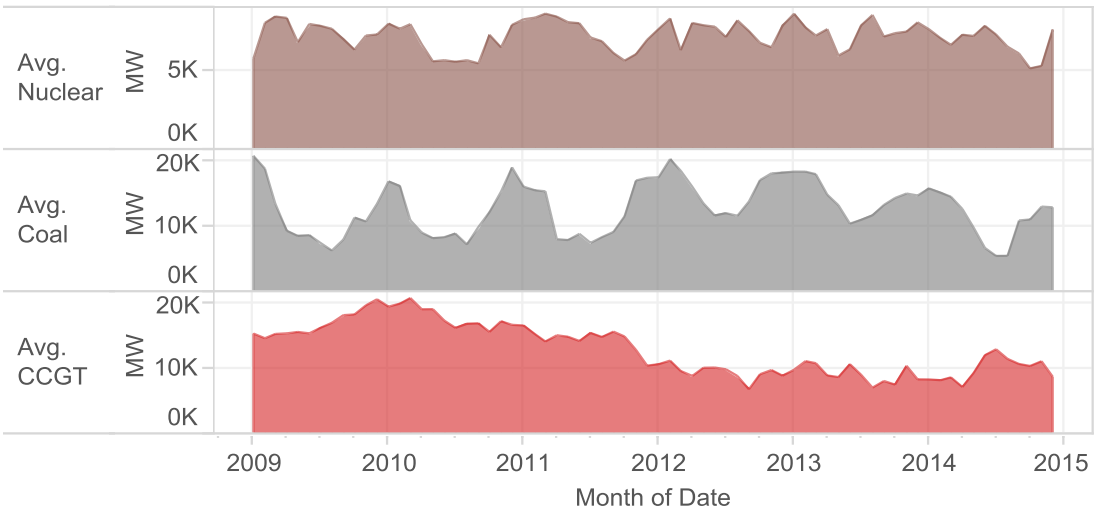

Weekly thermal supply pattern: daily resolution

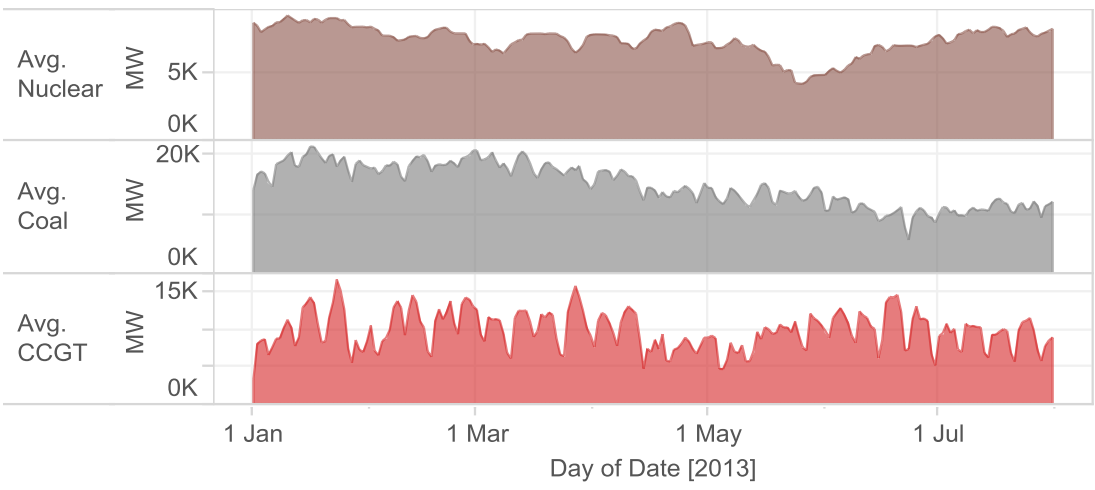

Daily thermal supply pattern: hourly resolution

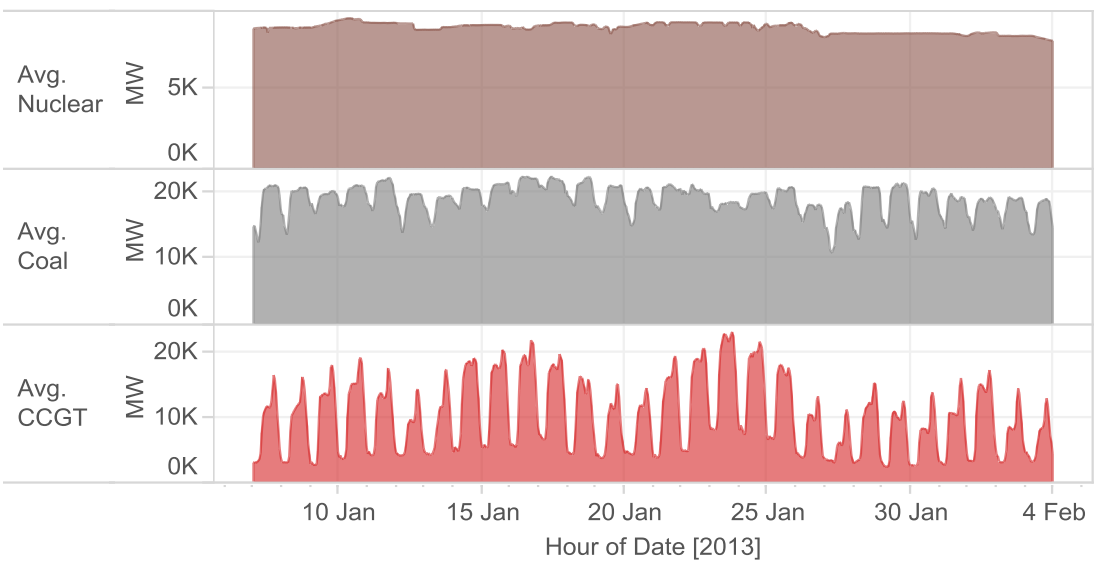

Source: Elexon portal, own calculations

A holistic framework for the study of interdependence between electricity and gas sectors 

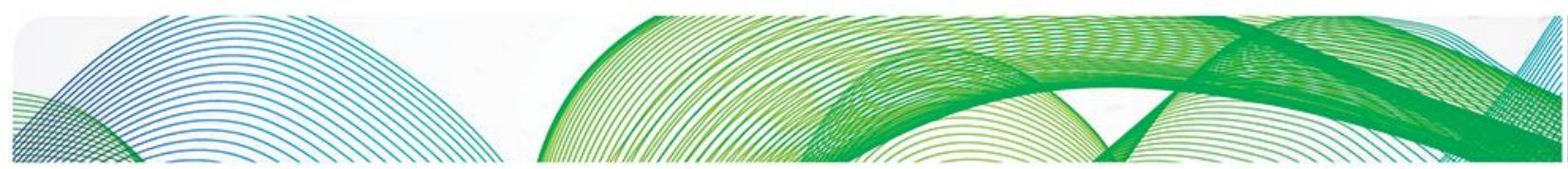

O는

While inspecting the generation pattern for 2009-2013, it can be seen that, of the remaining sources of flexibility (pumped hydro and interconnectors), pumped hydro is clearly dispatched during peak hours only to meet daily peak demand (Figure 41).

Figure 41: Average UK pumped hydro and interconnector supply for various temporal resolutions

Weekly other supply pattern: daily resolution

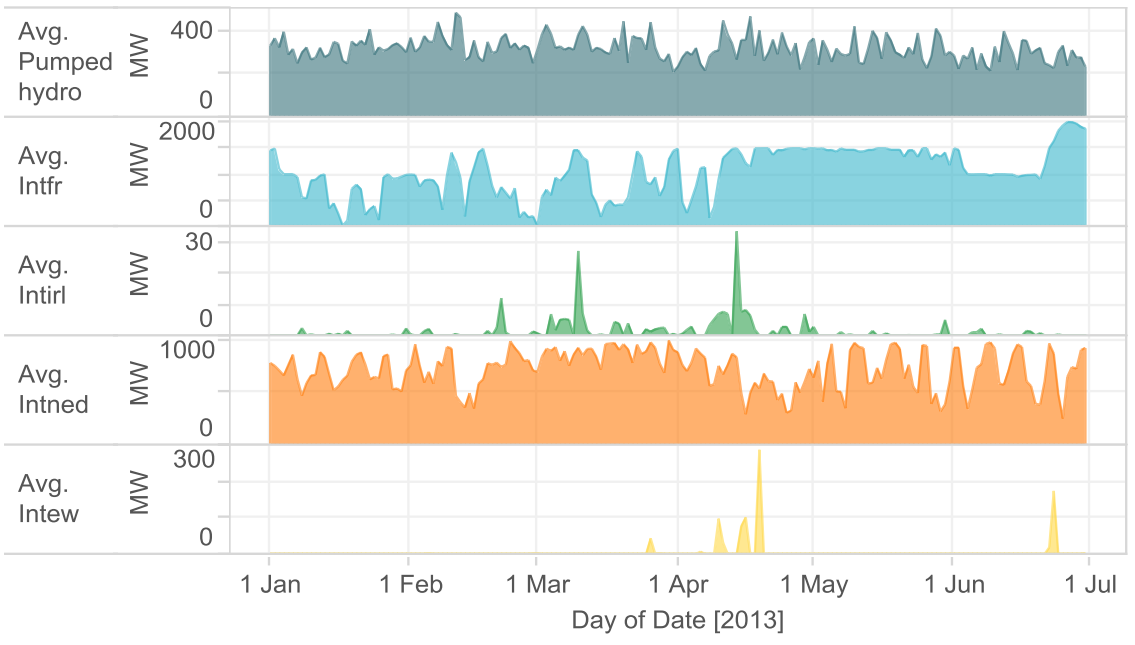

Daily other supply pattern: hourly resolution

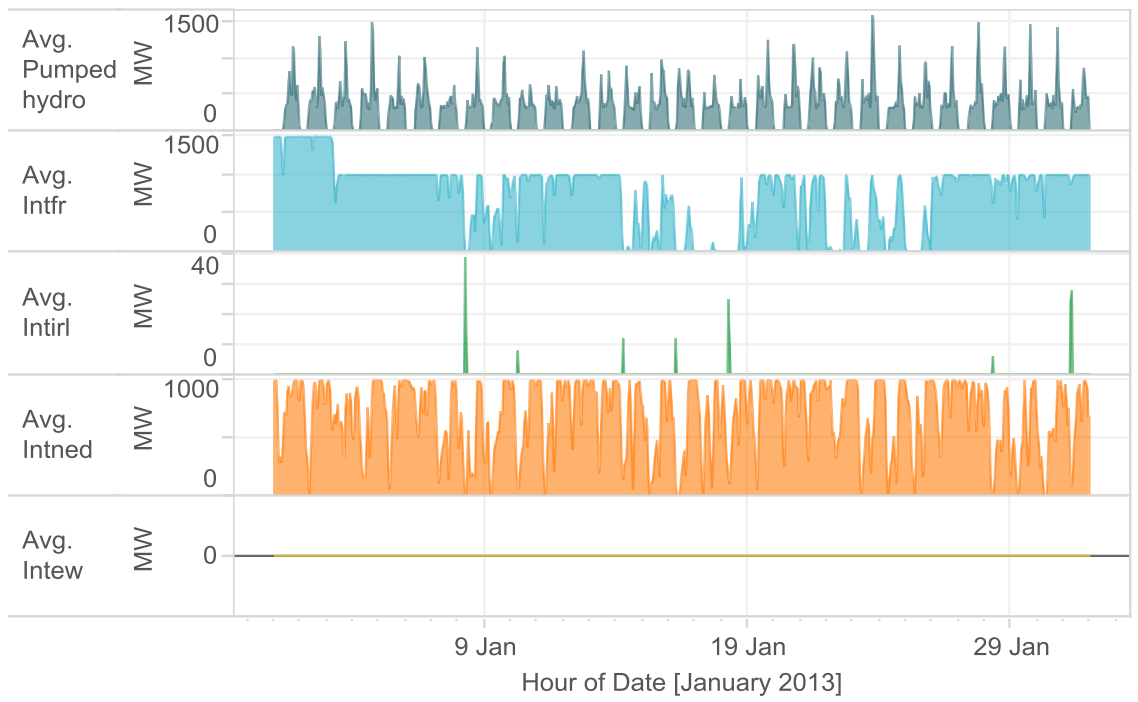

Source: Elexon portal, own calculations ${ }^{13}$

\footnotetext{
${ }^{13}$ The acronyms used for Intfr: Interconnexion France-Angleterre; Intirl: Moyle interconnector; Intned: BritNed interconnector; Intew, East-West interconnector.
}

A holistic framework for the study of interdependence between electricity and gas sectors 

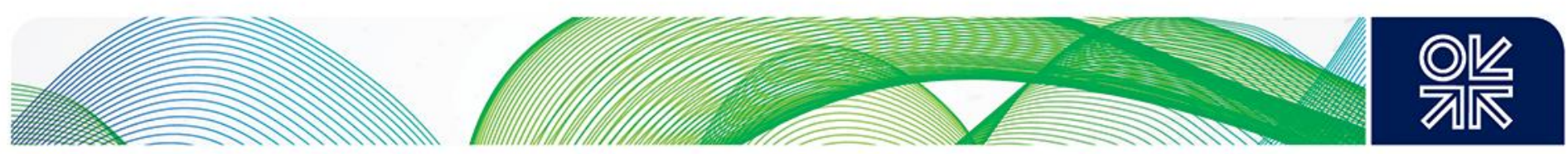

As for the four interconnectors, since only import data is available, it is only possible to comment partially on their function in the UK's power market. The interconnectors to Northern Ireland and the Republic of Ireland contribute relatively little to imports. According to other references, they were used solely for exports before 2008 (Bolton, 2013). Compared to the interconnector to France, the interconnector to the Netherlands appears to be much more active in responding to short-term demand variations. Possibly because French exports, coming from low-cost nuclear generation, are less responsive to short-term market signals. The planned addition of new interconnectors, especially ones connected to countries with important flexible generation (such as hydropower from Norway and Iceland), will provide additional sources of supply flexibility.

\subsection{Performance and regulation}

Now that the structure, infrastructure, and existing coordination mechanisms for the gas and power industries have been surveyed, the dynamic interaction between industry agents and the government regulating bodies can be analysed.

The current energy agenda of the UK government is articulated in three dimensions: energy security, sustainability, and affordability. This is also known as the energy trilemma - the challenge of 'keeping the lights on, at an affordable price, while decarbonizing the UK power system' (DECC, 2014a). This multi-layered approach evolved from an earlier focus on liberalization and market opening throughout the 1980s and 1990s, and the shift in focus is mirrored in the change of the key government institution that deals with energy. The Department of Energy, established in 1974 in the wake of the 1973 oil crisis and the increasing importance of UKCS oil and gas production, was abolished in 1992, following the privatization and liberalization of the industries. Its core activities, related to setting the energy policy agenda, were then transferred to the Department of Trade and Industry (DTI), while new regulatory authorities such as Ofgas and OFFER became responsible for the regulation of the liberalized power and gas industries, and energy efficiency functions were transferred to the Department of the Environment. After the turn of the twenty-first century, the energy policy-related functions were rehoused under the newly created Department of Energy and Climate Change (DECC) which, as its name indicates, puts important focus on tackling climate change. The government policies that are directly relevant to owners and operators of the gas-to-power supply chain have been summarized in Table 18.

Of the three energy trilemma objectives, only sustainability has clearly stated targets. Through the 2008 Climate Change Act, the UK has legislated that a carbon emission reduction of 80 per cent is to be achieved by 2050, with respect to a 1990 baseline level. The path to the emission reduction target is directed via a set of five-year carbon budget periods, starting in 2008. By 2020, greenhouse gas emissions are to have been reduced by 34 per cent below the base level. A key component of decarbonization is the adoption of renewable energy: the 2009 Renewable Energy Directive has set a target for the UK to achieve 15 per cent of its energy consumption from renewable sources by 2020 , pledged as part of the EU 2020 climate and energy package to meet the EU-level goal of 20 per cent renewable energy by 2020. So far, a large number of measures have been applied in the upstream power supply segment, encouraging renewable and low-carbon generation investments, with some additional measures targeting downstream gas consumption and encouraging investments in lowcarbon (high efficiency) and renewable heating technologies. 

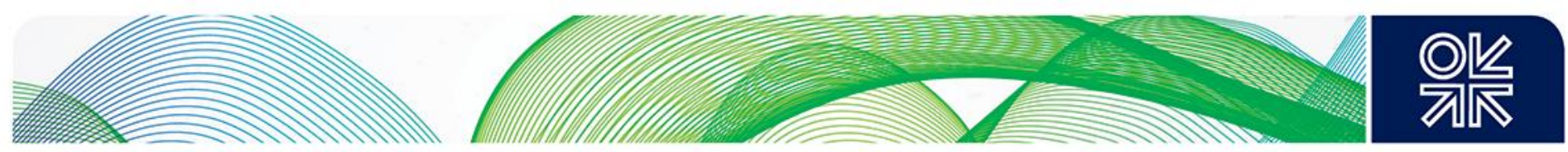

For energy security, the government mostly adopts ad hoc regulatory measures based on its evaluation of gas and electricity security of supply. The most recent evaluation of gas security of supply, conducted by Ofgem in 2012, was similar to the investigation triggered by the outage of Rough storage and the Russia-Ukraine crisis in 2006 (Kopp, 2015). It found that the gas wholesale market was effective in attracting significant investment in gas import infrastructure in response to declining indigenous supplies, and the diversity and quantity of supplies that can be delivered to Great Britain would protect consumers from supply disruptions in a broad range of events. Further measures could be taken to more fully reflect the value of gas security of supply to consumers, but 'a much fuller and a more rigorous assessment of the risks, costs and benefits of that measure would be needed'(Ofgem, 2012, p. 8). But, a 2013 review of UKCS oil and gas recovery has triggered the setting up of a new upstream regulator, the Oil and Gas Authority, with a mandate to maximize economic recovery of the UKCS reserves (DECC, 2014b). This could potentially enhance security of gas supply, provided uncoordinated decommissioning of important offshore infrastructure is avoided, preventing stranded reserves. Since the recent fall in global oil prices, the Oil and Gas Authority has identified significant reduction in exploration, infrastructure investment, and staffing levels. It proposed remediation measures such as: using fiscal levers to protect critical infrastructure and key production hubs, and supporting the development and implementation of a fiscal regime that instils confidence in the future potential of the UKCS (DECC, 2015).

As for electricity security of supply, assessments around 2010 pointed to a risk of generation capacity reduction, with little confidence that adequate new investment would come forth, due to concerns relating to commercial risks heightened by regulatory uncertainty. Ofgem did not consider that leaving the market arrangements unaltered was in the interests of consumers, and such concerns eventually led to the implementation of the Electricity Market Reform (EMR) in 2014. This is a policy package that includes long-term contracts for low-carbon generation - Contracts for Difference, which will eventually replace the renewable support mechanism (Renewables Obligation) in place - and a capacity market to reward reliable capacity contributions (Newbery \& Grubb, 2014). As an EU member, bound by the EU directives for regional power and gas market integration, the UK needs to achieve interconnection of at least 10 per cent of its installed electricity production capacity, as per the requirement of the European Council. The development of additional interconnector capacity, already in motion, is believed to contribute to electricity security of supply. This attitude is reflected through the inclusion of interconnectors in the second auction of the capacity market, to be held in December 2015 (DECC, 2014c).

Energy affordability has been addressed in two dimensions. It can interpreted as being the elimination of fuel poverty, ${ }^{14}$ on the grounds that access to energy is an essential public service. Or, it can be interpreted to be keeping energy bills at a reasonable level, by promoting efficient market operations. Under the first consideration, targets have been set to alleviate fuel poverty by raising home efficiency in England for as many fuel-poor homes 'as is reasonably practicable' to band $E$ by 2020 , and band D by 2025, through energy efficiency standards in rented accommodation (Secretary of State for Energy and Climate Change, 2015). Under the second consideration, Ofgem has asked the Competition and Markets Authority (CMA) to consider whether there are further barriers to effective competition across the wholesale and retail energy markets that make retail energy prices

\footnotetext{
${ }^{14}$ The term 'fuel poverty' itself is open for interpretation: much of the Hills report, mandated by the DECC to review the issues, is concerned with defining and measuring the phenomenon (See Hills, 2012).
}

A holistic framework for the study of interdependence between electricity and gas sectors 

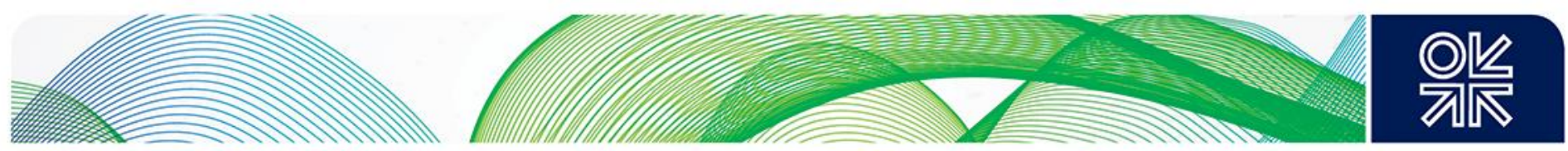

unnecessary high. The CMA has recently published its provisional findings and list of possible remedies, but no regulatory measures have been adopted as of writing (CMA, 2015).

The dynamics that can arise from the interaction of affected supply chain segments and governmental regulation are many. To understand their specifics requires a level of detail that is beyond this case study: a grounded knowledge of the objectives of the industry agents involved, the particular market in which they participate or enter (long-term contracts, short-term wholesale trade, balancing, retail), and the specific implementation details of the regulatory instruments (such as price level, quantity level, and restrictions on eligibility). For instance, take the example of electricity end-users, many of them can and do take the opportunity to participate in the feed-in tariff scheme. This is open to those considering the installation of small-scale Solar PV and Wind systems with a declared capacity of 50 $\mathrm{kW}$ or less, or micro combined heat and power generators with an installed capacity of $2 \mathrm{~kW}$ or less, because the capital investment required is within their reach. Under the FiT scheme, energy consumers-turned-distributed generation developers can receive payment at the approved tariff level for energy that they consume, and sell additional electricity generated to electricity suppliers at a fixed price. The FiT scheme is funded through out-of-market payments collected as a levy placed on all consumer energy bills. Therefore, an increased number of participants in the FiT scheme will result in a higher surcharge levied from all bills, increasing retail electricity prices, provided that the levy ceiling set through the Levy Control Framework has not yet been reached. Because the driver for investment and participation in the FiT scheme is the perceived saving, or even the profit, coming from self-generation of electricity (instead of purchasing it through a supplier), any consequent increase in retail price will drive more potential investors to participate in the FiT scheme, forming a positive feedback loop.

This dynamic is continued until a constraint is reached, either defined as part of the regulatory instrument (maximum quantity of capacity that is eligible for support) or coming from another part of the system, such as distribution network performance constraints that limit the export of power by self-generators. A more comprehensive study, hypothesizing dynamic interaction between EU member governments' renewable support policy to support the EU-wide decarbonization objective, and operational/investment decisions of major power producers, who own and operate a large fleet of conventional thermal generators, is available in Robinson (2015). The study argues that stagnant demand, growing intermittent renewable power generation, and changing end-user participation, (initiated or encouraged by the government via energy efficiency programmes, renewable energy, and distributed generation support mechanisms), exert downward pressure on the profit margins of major power producers such as the 'Big Six' in the UK, leading to generation asset impairment and decommissioning/mothballing of conventional thermal power plants. The capacity market recently implemented in the UK can be seen as the government's response to remediate the effects of its other policies on maintaining dispatchable thermal generation to meet peak demand and to accommodate the increasing adoption of intermittent renewable power generation. 


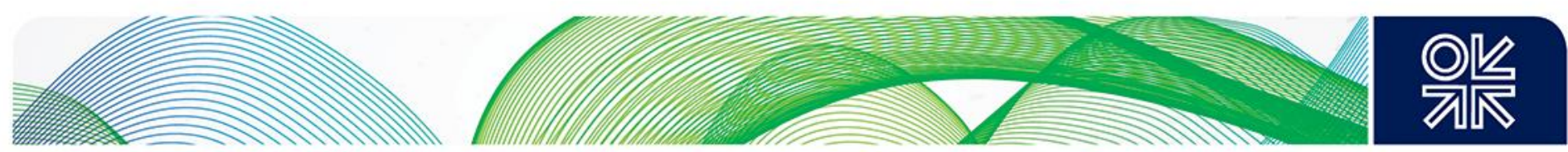

Table 18: A non-exhaustive UK energy policy inventory directly relevant to the gas-to-power supply chain

Sustainability

Security Affordability

\begin{tabular}{|c|c|c|c|c|}
\hline \multirow{3}{*}{$\begin{array}{l}\text { Gas } \\
\text { production }\end{array}$} & & \multirow{2}{*}{\multicolumn{2}{|c|}{$\begin{array}{l}\text { Creation of the Oil and Gas Authority } \\
\text { to maximize the economic recovery of } \\
\text { oil and gas and coordinate } \\
\text { decommissioning of key assets }\end{array}$}} \\
\hline & UKCS & & & \\
\hline & Unconventional & & $\begin{array}{l}\text { Establishment of the Office for } \\
\text { Unconventional Gas and Oil to } \\
\text { encourage recovery of } \\
\text { unconventional reserves }\end{array}$ & \\
\hline \multicolumn{5}{|l|}{ Gas import } \\
\hline \multicolumn{5}{|l|}{$\begin{array}{l}\text { Gas } \\
\text { transmission }\end{array}$} \\
\hline \multicolumn{5}{|l|}{$\begin{array}{l}\text { Gas } \\
\text { distribution }\end{array}$} \\
\hline \multicolumn{5}{|l|}{ Gas storage } \\
\hline Gas supplier & & $\begin{array}{l}\text { Required to promote energy } \\
\text { efficiency measures for consumers } \\
\text { through Energy Company } \\
\text { Obligation }\end{array}$ & & $\begin{array}{l}\text { Analysis of competitive environment by } \\
\text { the MCA }\end{array}$ \\
\hline \multirow[t]{2}{*}{$\begin{array}{l}\text { Power } \\
\text { generation }\end{array}$} & $\begin{array}{l}\text { Renewable/ } \\
\text { low carbon }\end{array}$ & $\begin{array}{l}\text { Incentivize investment in renewable } \\
\text { generation through renewables } \\
\text { obligation (RO), feed-in tariffs, and } \\
\text { Contracts for Difference (CfD); } \\
\text { incentivize use of low-carbon } \\
\text { generation via the carbon price } \\
\text { floor }\end{array}$ & $\begin{array}{l}\text { Incentivize investment in renewable } \\
\text { generation through renewables } \\
\text { obligation }(R O) \text {, feed-in tariffs, and } \\
\text { the Contracts for Difference (CfD) }\end{array}$ & $\begin{array}{l}\text { Analysis of competitive environment by } \\
\text { the MCA }\end{array}$ \\
\hline & Fossil fuels & $\begin{array}{l}\text { Emission performance standards } \\
\text { for generators; disincentivize use of } \\
\text { carbon intensive generation via the } \\
\text { carbon price floor }\end{array}$ & $\begin{array}{l}\text { Provide payment to reliable sources } \\
\text { of generation capacity via the } \\
\text { Capacity Market }\end{array}$ & $\begin{array}{l}\text { Analysis of competitive environment by } \\
\text { the MCA }\end{array}$ \\
\hline
\end{tabular}




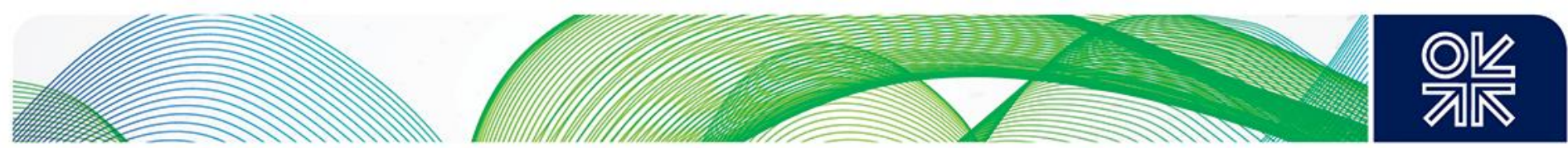

\begin{tabular}{lll}
\hline $\begin{array}{l}\text { Power } \\
\text { transmission }\end{array}$ & Sustainability & Security \\
\hline $\begin{array}{l}\text { Power } \\
\text { distribution }\end{array}$ & & \\
\hline $\begin{array}{l}\text { Power } \\
\text { interconnector }\end{array}$ & $\begin{array}{l}\text { Provide payment to reliable sources } \\
\text { of generation capacity via the } \\
\text { Capacity Market }\end{array}$ \\
\hline $\begin{array}{l}\text { Power } \\
\text { supplier }\end{array}$ & & Analysis of competitive environment by \\
\hline $\begin{array}{l}\text { Power } \\
\text { consumption }\end{array}$ & $\begin{array}{l}\text { Encourage adoption of electric } \\
\text { vehicles via match-funding to install } \\
\text { electric vehicle charging points }\end{array}$ & \\
\hline (OLEV programme) & & the \\
\hline
\end{tabular}

Source: Information concerning individual policy gathered from the DECC website 

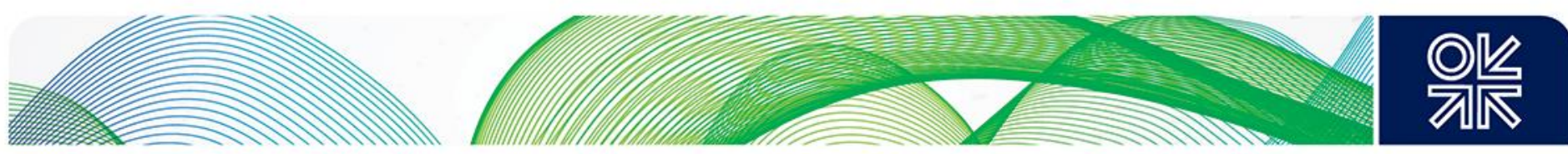

\subsection{Discussion}

The information presented above, gathered within the SCPR framework, is synthesized to answer the questions raised with respect to gas and power sector interdependencies in the first part of section 3.

Structural: To what extent does the ownership/operational control of the gas and power sectors experience overlap across different segments? And what could be the implications of any such overlap on the investment and operational decisions in the sector?

Table 15 confirms that mid and downstream integration of gas and power industries, across gas storage, gas supply, power generation, and power supply, through the 'Big Six' firms, is still the case. Except for Centrica, which retains gas production assets in the North Sea, the ownership overlap with the domestic gas production segment is tenuous and decreasing, following E.ON's and RWE's asset disposal. The six firms represent the most important demand in the UK wholesale gas markets, and their preferences for sourcing gas (long-term contracts from a number of gas producing countries/companies, OTC trading) will affect the liquidity in the shorter-term trading markets, and the composition of the set of countries supplying gas to the UK.

Infrastructure: What is the state of the gas-to-power supply chain infrastructure? What is the state of the gas and power demand infrastructure? What could be the potential implications for the absolute and relative use of gas and power, or on the substitution between gas and power?

The UK gas-to-power supply chain infrastructure is very mature, yet uncertainties plague two particular segments: domestic gas production and power generation. Without new investment, the UKCS production capacity is expected to continue its steep decline, but the quantity of investment that can be expected to enhance recovery from declining fields, or to develop increasingly difficult reserves, is uncertain. The generation capacity crunch, due to the implementation of the LCPD, expected retirement of nuclear power plants, and mothballing of non-profitable plants, has been noticed and is being addressed via the EMR, but the outcome of the new regulatory measures is also yet to be observed. New development is also expected in the power interconnectors segment, as the interconnector capacity is expected to double by 2020 .

Gas and electricity consumption devices have a wide established base in the UK. The overall level of energy consumption is unlikely to increase much. Rather, there is a possibility of overall demand reduction and inter-fuel substitution through the adoption of more efficient energy use practices, adoption of electric vehicles, and electricity or biomass-based heating systems.

Operational: In the case that gas-to-power flow is important, what is its consequence on gas balancing? Is the existing gas sector coordination mechanism adequate to handle it?

Currently, natural gas used for power generation represents 9 per cent of overall energy consumption, or 30 per cent of power generation fuels. It is being used to meet variations in power demand at the daily and hourly timescale. So far, the UK gas wholesale market has played an adequate role in supplying, within the timescales required, gas-fired power generation plants, which are conveniently located along major arteries of the gas transmission system. No major short-term coordination failure has been reported. A potential source of flexible power supply that may compete with natural gas in the wholesale power market is flexible hydropower from soon-to-be interconnected countries such as Norway (and potentially Iceland).

Regulatory: How does the government's energy policy relate to the gas and power sectors? Is it driven by power sector goals, by gas sector goals, or by a mix of the two? How are the government's regulatory measures in gas and power affecting the industry agents? What implications could they have on sector planning and short-term operations? 

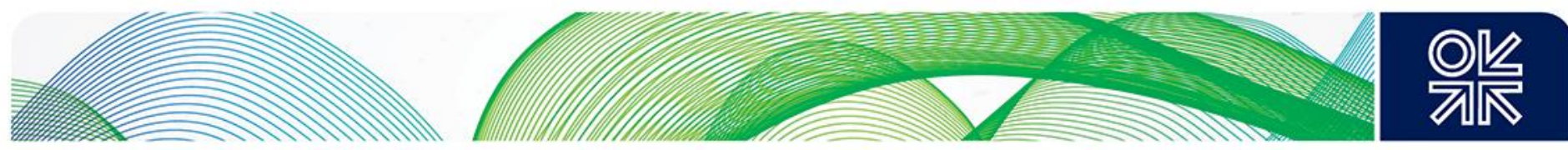

The energy policy of the UK government is mainly addressed at the power sector. Natural gas is expected to play the role of a balancing fuel, picking up when other forms of generation are not sufficient/flexible. As Table 18 shows, most policy targets and actions are applicable to the mid and downstream of the gas-to-power supply chain (the area of activity of the 'Big Six' firms), power generation being the segment most heavily influenced by policies. The power generation owners' reaction to the joint impact of all the regulatory action is a major source of uncertainty, and it influences gas sector planning by making the long-term downstream gas demand uncertain. The impact of the newly established Oil and Gas Authority (dedicated to the maximization of the economic recovery of UK oil and gas reserves) in directing investments toward the UKCS is yet to be observed.

\section{Concluding remarks}

Increasingly, the natural gas and power industries have been experiencing integration in the form of natural gas-fired power generation. The performance and future evolution of the extended gas-to-power supply chain is dependent on drivers and constraints in both industries. Therefore, a coherent understanding of both sectors is becoming important for agents active as: power and gas system operators, utilities, regulators, and government bodies responsible for overall energy policy. The Structure-Conduct-Performance-Regulation (SCPR) framework, proposed in this paper, provides a holistic ensemble view of the complex system that is the gas and power sectors. The key concepts covered include industry structure (which influences agents' participation and their motivation), the infrastructure in place and the mechanism employed to coordinate its use (which influences investment and operational decisions of industry agents), and the dynamic interaction of the above via governmental and industry self-regulation. Contextual information, important for the application of the SCPR framework to the specificities of the gas and power sectors, is also provided.

As an example, the SCPR framework is used to build a comprehensive joint profile of the power and gas industries in the United Kingdom. The structural, infrastructure, operational, and regulatory interdependencies of the UK gas and power sectors have been identified on the basis of information gathered using the SCPR framework. And, the potential evolution of the extended gas-to-power supply chain is synthesized below, from two perspectives: the likely development of gas-fired generation with respect to the overall energy system, and the likely development of self-sufficiency with respect to natural gas, two factors which have been used to develop the gas-to-power interdependence index.

Aside from structural changes in economic composition and fluctuations such as global economic recessions, the future demand of electricity in the UK is dependent upon the uptake of efficient energy practices and electric vehicles by end-users, which is incentivized by certain government programmes. The future demand for gas, other than the same consumer-driven change in the form of adoption of biomass heating systems via the Renewable Heat Incentive, will be significantly influenced by the interaction between major power producers' investment decisions and power generation-specific regulatory measures, which makes the power sector's demand for gas more uncertain. A wave of power interconnector projects, expected to come online by 2020, might also affect the use of flexible generation supply such as natural gas, depending on the prevailing market prices in the UK and in the interconnected country. Unless plentiful new reserves are discovered in the UKCS, which is unlikely as it is a mature basin, the UK's domestic production of natural gas is expected to decrease. The government's implementation of a recovery maximization strategy might slow the decline, but it is thwarted by the low oil price environment that has reduced global oil and gas investments. 

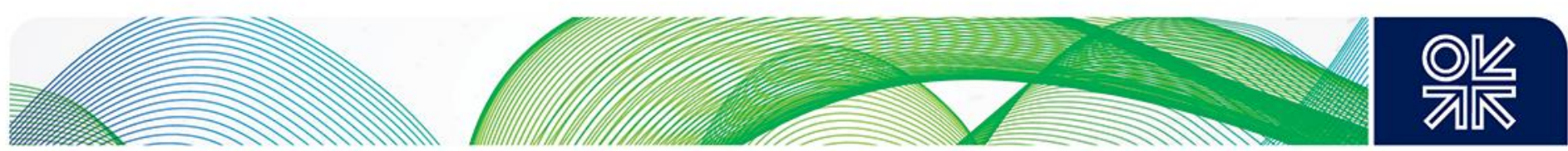

\section{References}

Adams, C. (2015a). 'UK blocks sale of North Sea gasfields to Fridman fund', Financial Times, 28 February.

Adams, C. (2015b). 'Centrica chief executive prepares to unveil turnround strategy', Financial Times, 23 June.

Adelman, M. A. (1993). 'Petroleum Production Costs in General', in The Economics of Petroleum Supply: Papers by M.A. Adelman, 1962-1993, MIT Press.

Baddeley, M. (2011). 'Energy, the Environment and Behaviour Change: A survey of insights from behavioural economics', Cambridge Working Papers in Economics. Retrieved from www.dspace.cam.ac.uk/handle/1810/242028.

Besant-Jones, J. (2006). 'Reforming Power Markets in Developing Countries: What Have We Learned?', World Bank Energy and Mining Sector Board Discussion Paper.

Blarke, M. B. \& Lund, H. (2008). 'The effectiveness of storage and relocation options in renewable energy systems', Renewable Energy, 33(7), 1499-1507. doi:10.1016/j.renene.2007.09.001.

Bolton, P. (2013). 'Energy imports and exports', House of Commons Briefing Paper.

Borrmann, J. \& Brunekreeft, G. (2011). 'The Effect of Monopoly Regulation on the Timing of Investment', Bremen Energy Working Paper.

Bradshaw, M., \& Watson, J. (2014). 'The UK's Global Gas Challenge - Research Report', UKERC Research Report.

Buchan, D. (2010). 'Eastern Europe's energy challenge: meeting its EU climate commitments', Oxford: Oxford Institute for Energy Studies Working Paper.

Burtraw, D.m\& Szambelan, S. J. (2009). 'U.S. Emissions Trading Markets for SO2 and NOx', Resources for the Future Discussion Paper.

Castagneto-Gissey, G. (2014). Electricity and Energy Price Interactions in Modern EU Markets, Imperial College London.

Charpentier, J. P., \& Schenk, K. (1995). 'International Power Interconnections', World Bank. Retrieved from http://siteresources.worldbank.org/EXTFINANCIALSECTOR/Resources/2828841303327122200/042charpe.pdf

Cludius, J., Hermann, H., Matthes, F. C., \& Graichen, V. (2014). 'The merit order effect of wind and photovoltaic electricity generation in Germany 2008-2016: Estimation and distributional implications', Energy Economics, 44, 302-313. doi:10.1016/j.eneco.2014.04.020.

CMA (2015, July 7). CMA sets out case for energy market reform, Competition and Markets Authority, 7 July. Retrieved from: https://www.gov.uk/government/news/cma-sets-out-case-for-energymarket-reform

Cornot-Gandolphe, S., Appert, O., Dickel, R., Chabrelie, M.-F., \& Rojey, A. (2003). 'The Challenges of Further Cost Reductions for New Supply Options', in 22nd World Gas Conference. Tokyo.

DECC (2014a). 'Delivering UK Energy Investment', Department of Energy \& Climate Change July. Retrieved from:

https://www.gov.uk/government/uploads/system/uploads/attachment_data/file/331071/DECC_E nergy_Investment_Report.pdf.

DECC (2014b). Government Response to Sir lan Wood's Review of the UK Continental Shelf (UKCS), Department of Energy \& Climate Change. Retrieved from:

https://www.gov.uk/government/publications/government-response-to-sir-ian-woods-review-ofthe-uk-continental-shelf-ukcs. 

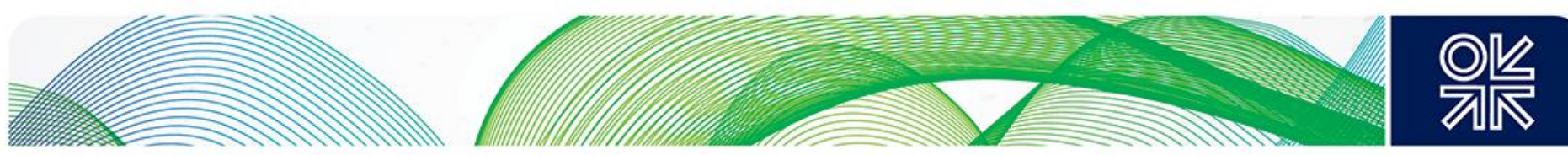

DECC (2014c). 'Interconnectors to participate in the Capacity Market from 2015', Department of

Energy \& Climate Change, 2 December. Retrieved from:

https://www.gov.uk/government/news/interconnectors-to-participate-in-the-capacity-market-from2015.

DECC. (2015a). Energy Consumption in the UK, Department of Energy \& Climate Change. Retrieved from https://www.gov.uk/government/statistics/energy-consumption-in-the-uk

DECC. (2015b). Power stations in the United Kingdom, Department of Energy \& Climate Change. Retrieved from https://www.gov.uk/government/statistics/electricity-chapter-5-digest-of-unitedkingdom-energy-statistics-dukes

DECC (2015c). 'New North Sea regulator issues urgent call to action', Department of Energy \& Climate Change, 25 February. Retrieved from: https://www.gov.uk/government/news/new-northsea-regulator-issues-urgent-call-to-action.

Del Río González, P. (2007). 'The interaction between emissions trading and renewable electricity support schemes. An overview of the literature', Mitigation and Adaptation Strategies for Global Change, 12(8), 1363-1390. doi:10.1007/s11027-006-9069-y.

EIA. (2014). International Energy Statistics, U.S. Energy Information Administration. Retrieved August 28, 2015, from http://www.eia.gov/beta/international/

EPRI (2010). Electricity Energy Storage Technology Options, Electric Power Research Institute. Retrieved from: www.epri.com/abstracts/Pages/ProductAbstract.aspx?Productld=000000000001020676.

Eurelectric (2011). 'Flexible generation: Backing up renewables'. Retrieved from http://www.eurelectric.org/media/61388/flexibility_report_final-2011-102-0003-01-e.pdf

Ferguson, P. R. \& Ferguson, G. (1994). Industrial Economics: Issues and Perspectives, New York: NYU Press.

Fischer, C. \& Preonas, L. (2010). 'Combining Policies for Renewable Energy: Is the Whole Less Than the Sum of Its Parts?', International Review of Environmental and Resource Economics, 4(1), 51-92. doi:10.1561/101.00000030.

Fouquet, R. (2008). 'Energy Demand, Technological Change and Economic Development', in Heat, power and light: Revolutions in Energy Services (p. 496), Edward Elgar Publishing.

Gilbert, R. J. \& Newbery, D. M. (1988). 'Regulation Games', UC Berkeley Department of Economics Working Paper.

Golove, W. H. \& Eto, J. H. (1996). 'Market Barriers to Energy Efficiency : A Critical Reappraisal of the Rationale for Public Policies to Promote Energy Efficiency', Energy Environment, 26(March), 66. doi:10.1177/0042098011427189.

Gómez, T. (2013). 'Electricity Distribution', in I. J. Pérez-Arriaga (Ed.), Regulation of the Power Industry, Springer.

Haase, N. (2008). 'European gas market liberalisation: Are regulatory regimes moving towards convergence ?', Oxford Institute for Energy Studies Working Paper.

Hagoort, J. (1988). Fundamentals of Gas Reservoir Engineering, Elsevier.

Haugland, T., Bergesen, H. O., \& Roland, K. (1998). Energy Structures and Environmental Futures, Oxford University Press.

Hedegaard, K. \& Meibom, P. (2012). 'Wind power impacts and electricity storage - A time scale perspective', Renewable Energy, 37(1), 318-324. doi:10.1016/j.renene.2011.06.034.

Helm, D. (2002). 'Energy policy: security of supply, sustainability and competition', Energy Policy, 30(3), 173-184, doi:10.1016/S0301-4215(01)00141-0. 

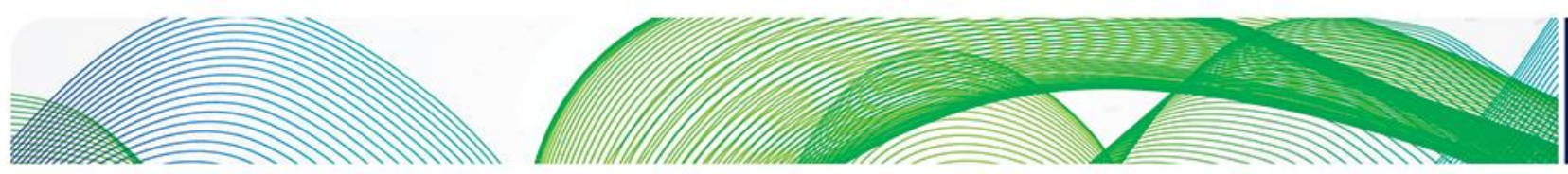

Henderson, M. \& Shahidehpour, M. (2014). 'Continuing to Grow: Natural Gas Usage Rising in Electricity Generation', [Guest Editorial], Power and Energy Magazine, IEEE, doi:10.1109/MPE.2014.2347696.

Hills, J. (2012). 'Getting the measure of fuel poverty: final report of the Fuel Poverty Review', CASE report 72. Retrieved from: http://sticerd.Ise.ac.uk/case/.

IEA (2002). Flexibility in Natural Gas Supply and Demand, Paris: International Energy Agency. doi:10.1016/B978-0-12-417013-1.00008-X.

IEA (2012). 'World Balance (2012)', International Energy Agency. Retrieved 16 March 2015, from www.iea.org/sankey/\#?c=World\&s=Balance.

IEA (2013a). 'Germany Balance (2012)', International Energy Agency. Retrieved 9 October 2015, from www.iea.org/sankey/\#?c=Germany\&s=Balance.

IEA (2013b). 'United Kingdom Balance (2012)', International Energy Agency. Retrieved 5 March 2015, from www.iea.org/sankey/\#?c=United Kingdom\&s=Balance.

IEA (2014). Combined Heat and Power Country Scorecards, International Energy Agency. Retrieved 7 October 2015, from https://www.iea.org/chp/countryscorecards/.

IEA (2015a). Energy Technology Perspectives 2015 - Mobilising Innovative Action, International Energy Agency.

IEA (2015b). Natural Gas Information: Database documentation, International Energy Agency. Retrieved from http://wds.iea.org/wds/pdf/Gas_Documentation.pdf.

Inniss, H. (2004). 'Operational Vertical Integration in the Gas Industry with emphasis on LNG necessary to ensure viability?', Centre for Energy, Petroleum and Mineral Law and Policy, Annual Review volume 8, University of Dundee.

Keay, M. (2006). The Dynamics of Power: Power Generation Investment in Liberalised Electricity Markets, Oxford: Oxford Institute for Energy Studies.

Kirschen, D. S. (2003). 'Demand-side view of electricity markets', Power Systems, IEEE Transactions on. doi:10.1109/TPWRS.2003.810692.

Kopp, S.-D. (2015). 'The UK Gas Market', in Politics, Markets and EU Gas Supply Security: Case Studies of the UK and Germany, Springer.

Laughton, M. (2012). 'Variable Renewables and the Grid: an Overview', in Renewable Electricity and the Grid: The Challenge of Variability, Earthscan.

Le Fevre, C. (2013). 'Gas storage in Great Britain', Oxford Institute for Energy Studies Working Paper.

Le Fevre, C. (2015). 'The Role of Gas in UK Energy Policy', Oxford Institute for Energy Studies Working Paper.

Leepa, C. \& Unfried, M. (2013). 'Effects of a cut-off in feed-in tariffs on photovoltaic capacity: Evidence from Germany', Energy Policy, 56, 536-542. doi:10.1016/j.enpol.2013.01.018.

Loisel, R. (2012). 'Power system flexibility with electricity storage technologies: A technical-economic assessment of a large-scale storage facility', International Journal of Electrical Power \& Energy Systems, 42(1), 542-552. doi:10.1016/j.jjepes.2012.04.058.

Mazer, A. (2007). Electric Power Planning for Regulated Markets and Deregulated Markets, John Wiley \& Sons.

Momoh, J. A., Meliopoulos, S., \& Saint, R. (2012). 'Centralized and Distributed Generated Power Systems - A Comparison Approach', Future Grid Initiative White Paper, Power Systems Engineering Research Center.

National Grid (2015). 'Interconnectors', European business development, National Grid. Retrieved 15 July 2015 from: http://www2.nationalgrid.com/About-us/European-businessdevelopment/Interconnectors/.

A holistic framework for the study of interdependence between electricity and gas sectors 

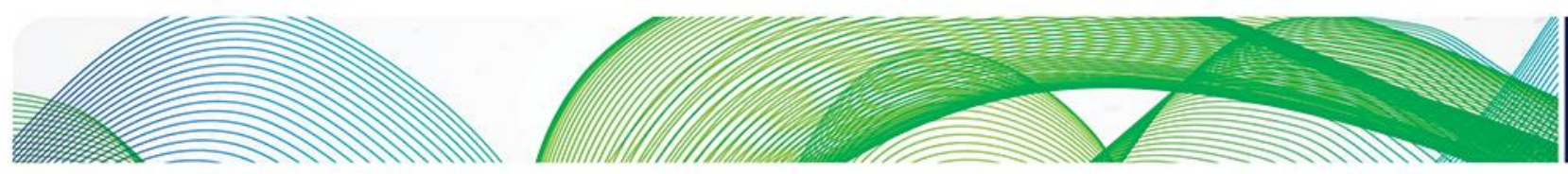

Neuhoff, K., Barquin, J., Bialek, J. W., Boyd, R., Dent, C. J., Echavarren, F., Grau, T., von Hirschhausen, C., Hobbs, B.F., Kunz, F., Nabe, C., Papaefthymiou, G., Weber, C., \& Weigt, H. (2013). 'Renewable electric energy integration: Quantifying the value of design of markets for international transmission capacity', Energy Economics, 40, 760-772.

doi:10.1016/j.eneco.2013.09.004.

Neuhoff, K., Sasso, L., \& Winzer, C. (2013). 'Policies for International Transmission Investment', Berlin: DIW Berlin: Politikberatung kompakt.

Neumann, A., Rüster, S., \& von Hirschhausen, C. (2015). 'Long-Term Contracts in the Natural Gas Industry - Literature Survey and Data on 426 Contracts (1965-2014)', DIW Berlin Data Documentation.

Newbery, D. \& Grubb, M. (2014). 'The Final Hurdle ?: Security of supply, the Capacity Mechanism and the role of interconnectors', Cambridge Energy Policy Research Group Working Paper.

Ofgem (2012). 'Gas Security of Supply Report', Ofgem report to Government. Retrieved from https://www.ofgem.gov.uk/ofgem-publications/40204/gas-sos-report.pdf.

Ofgem (2014). 'Feed-in Tariff: Annual Report 2013-14', Ofgem. Retrieved from https://www.ofgem.gov.uk/sites/default/files/docs/2014/12/feedin_tariff_fit_annual_report_2013_2014.pdf.

Oil and Gas Authority. (2015). 'UK Gas Reserves and Estimated Ultimate Recovery 2015', Oil and Gas Authority. Retrieved from https://www.gov.uk/government/uploads/system/uploads/attachment_data/file/441392/UK_Gas_ Reserves_and_EUR_2015.pdf

Petrovich, B. (2013). 'European gas hubs: how strong is the price correlation', Oxford Institute for Energy Studies Working Paper.

Plaat, H. (2009). 'Underground gas storage: Why and how', in D. J. Evans \& R. A. Chadwick (Eds.), Underground Gas Storage: Worldwide Experiences and Future Development in the UK and Europe, London: Geological Society of London.

Rangoni, B. (2012). 'A contribution on electricity storage: The case of hydro-pumped storage appraisal and commissioning in Italy and Spain', Utilities Policy, 23, 31-39. doi:10.1016/j.jup.2012.07.007.

Rathmann, M. (2007). 'Do support systems for RES-E reduce EU-ETS-driven electricity prices?', Energy Policy, 35(1), 342-349. doi:10.1016/j.enpol.2005.11.029.

Reuters (2015). 'Tanzania to finalise land acquisition for LNG project', Dar es Salaam, 9 May. Retrieved from http://www.reuters.com/article/2015/05/09/tanzania-gasidUSL1N0Y009220150509

Rivier, M., Pérez-Arriaga, I. J., \& Olmos, L. (2013). 'Electricity Transmission', in I. J. Pérez-Arriaga (Ed.) Regulation of the power sector. [In the series Power Systems (Vol. 61)]. Springer. doi:10.1007/978-1-4471-5034-3.

Robinson, D. (2015). 'The Scissors Effect: How structural trends and government intervention are damaging the major European electricity companies and affecting consumers', Oxford: Oxford Institute for Energy Studies Working Paper.

Rogner, H.-H. (1997). 'An Assessment of World Hydrocarbon Resources', Annual Review of Energy and the Environment, 22(1), 217-262. doi:10.1146/annurev.energy.22.1.217.

Rosso, A., Ma, J., Kirschen, D. S., \& Ochoa, L. F. (2011). 'Assessing the contribution of demand side management to power system flexibility', Decision and Control and European Control Conference (CDC-ECC), 2011 50th IEEE Conference on. doi:10.1109/CDC.2011.6161236. 

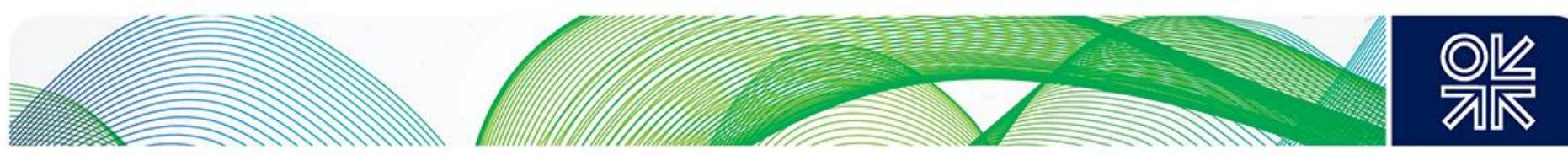

Sánchez Dominguez, D. J. J. (2008). Strategic Analysis of the Long-Term Planning of Electric Generation Capacity in Liberalised Electricity Markets, Universidad Pontificia Comillas de Madrid IIT.

Sauma, E. E. \& Oren, S. S. (2009). 'Alternative Economic Criteria and Proactive Planning for Transmission Investment in Deregulated Power Systems', in J. Momoh \& L. Mili (Eds.), Economic Market Design and Planning for Electric Power Systems, John Wiley \& Sons. Retrieved from http://www.amazon.com/Economic-Planning-Electric-SystemsEngineering/dp/0470472081.

Schmalensee, R. \& Stavins, R. N. (2013). 'The $\mathrm{SO}_{2}$ Allowance Trading System: The Ironic History of a Grand Policy Experiment', The Journal of Economic Perspectives, 27(1), 103-121 CR Copyright \&\#169; 2013 American Econom. doi:10.2307/41825464.

Secretary of State for Energy and Climate Change (2015). Cutting the cost of keeping warm: A fuel poverty strategy for England. Retrieved from https://www.gov.uk/government/uploads/system/uploads/attachment_data/file/408644/cutting_th e_cost_of_keeping_warm.pdf.

Sen, A. (2014). 'Divergent Paths to a Common Goal: An Overview of Challenges to Electricity Sector Reform in Developing versus Developed Countries', Oxford Institute for Energy Studies Working Paper.

Sensfuß, F., Ragwitz, M., \& Genoese, M. (2008). 'The merit-order effect: a detailed analysis of the price effect of renewable electricity generation on spot market prices in Germany', Energy Policy, 36(8), 3086-94. doi:10.1016/j.enpol.2008.03.035.

Shaton, K. (2014). 'Incentive Problem in Gas Transport Infrastructure Development on the Norwegian Continental Shelf', Procedia Computer Science, 31, 413-22. doi:10.1016/j.procs.2014.05.285.

Simmonds, G. (2002). Regulation of the UK Electricity Industry, 2002 edition, Industry Brief, Centre for the Study of Regulated Industries.

Spiecker, S., Vogel, P., \& Weber, C. (2013). 'Evaluating interconnector investments in the north European electricity system considering fluctuating wind power penetration', Energy Economics, 37, 114-127. doi:10.1016/j.eneco.2013.01.012.

Staffell, I. \& Green, R. (2015). 'Is There Still Merit in the Merit Order Stack? The Impact of Dynamic Constraints on Optimal Plant Mix', Power Systems, IEEE Transactions on. doi:10.1109/TPWRS.2015.2407613.

Sterman, J. D. (2001). 'System dynamics modeling: Tools for learning in a complex world', California Management Review, 43(4), 8+. doi:10.2307/41166098.

Stern, J. (1998). Competition and Liberalization in European Gas Markets: A Diversity of Models, The Royal Institute of Internal Affairs: Energy and Environmental Programme.

Stern, P. C. (1992). 'What psychology knows about energy conservation', American Psychologist, 47(10), 1224-1232. doi:10.1037/0003-066X.47.10.1224.

The Economist (2014). 'Power under the sea', The Economist, January. Retrieved from www.economist.com/blogs/schumpeter/2014/01/icelandic-electricity.

Thomas, S. (2003). 'Gas as a Commodity. The UK Gas Market: From Nationalism to the Embrace of the Free Market', in M. Arentsen \& R. Kunneke (Eds.), National reforms in European gas (p. xiii, 387 p.), Gulf Professional Publishing.

Timera Energy (2013). 'A framework for understanding European gas hub pricing'. Retrieved 10 June 2015, from www.timera-energy.com/a-framework-for-understanding-european-gas-hub-pricing/.

Tveten, A. G., Bolkesjø, T. F., Martinsen, T., \& Hvarnes, H. (2013). 'Solar feed-in tariffs and the merit order effect: A study of the German electricity market', Energy Policy, 61, 761-70.

doi:10.1016/j.enpol.2013.05.060.

A holistic framework for the study of interdependence between electricity and gas sectors 

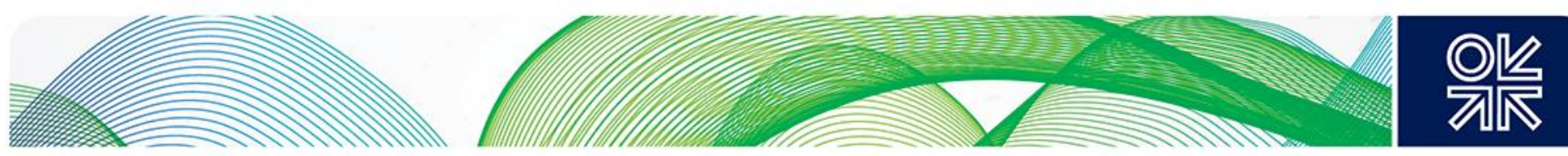

UNDP/ESMAP (2003). Cross-Border Oil and Gas Pipelines : Problems and Prospects, Joint UNDP/World Bank Energy Sector Management Assistance Programme.

United Nations. (2006). Multi Dimensional Issues in International Electric Power Grid Interconnections. New York.

Warshaw, C. (2011). 'The political economy of expropriation and privatization in the oil sector', in Oil and Governance: State-Owned Enterprises and the World Energy Supply, Cambridge University Press.

Weron, R. (2014). 'Electricity price forecasting: A review of the state-of-the-art with a look into the future', International Journal of Forecasting, 30(4), 1030-81. doi:10.1016/j.ijforecast.2014.08.008.

Wilson, C. \& Dowlatabadi, H. (2007). 'Models of Decision Making and Residential Energy Use', Annual Review of Environment and Resources, 32(1), 169-203. doi:10.1146/annurev.energy.32.053006.141137.

Wolak, F. A. (2014). 'Regulation Competition in Wholesale Electricity Supply', in N. L. Rose (Ed.), Economic Regulation and Its Reform: What have we learned?, Chicago: University of Chicago Press.

Wright, P. (2006). Gas Prices in the UK: Markets and Insecurity of Supply, Oxford: Oxford Institute for Energy Studies. 